University of Rhode Island

DigitalCommons@URI

Open Access Master's Theses

2017

\title{
Toxicant Isomers Characteized Using Fluorescence Emission of Coumarin Attached to Beta-Cyclodextrin
}

Benjamin R. Smith

University of Rhode Island, bsmith@chm.uri.edu

Follow this and additional works at: https://digitalcommons.uri.edu/theses

\section{Recommended Citation}

Smith, Benjamin R., "Toxicant Isomers Characteized Using Fluorescence Emission of Coumarin Attached to Beta-Cyclodextrin" (2017). Open Access Master's Theses. Paper 1006.

https://digitalcommons.uri.edu/theses/1006

This Thesis is brought to you for free and open access by DigitalCommons@URI. It has been accepted for inclusion in Open Access Master's Theses by an authorized administrator of DigitalCommons@URI. For more information, please contact digitalcommons-group@uri.edu. 
TOXICANT ISOMERS CHARACTERIZED USING

FLUORESCENCE EMISSION OF COUMARIN ATTACHED

TO BETA-CYCLODEXTRIN

BY

BENJAMIN R. SMITH

A THESIS SUBMITTED IN PARTIAL FULFILLMENT OF THE

REQUIREMENTS FOR THE DEGREE OF

MASTER OF SCIENCE

IN

CHEMISTRY

UNIVERSITY OF RHODE ISLAND

2017 


\section{MASTER OF SCIENCE THESIS}

$\mathrm{OF}$

BENJAMIN R. SMITH

\section{APPROVED:}

Thesis Committee:

$\begin{array}{ll}\text { Major Professor } & \text { Mindy Levine } \\ \text { Brenton DeBoef } \\ \text { Geoffrey Bothun }\end{array}$

Nasser H. Zawia

DEAN OF THE GRADUATE SCHOOL

UNIVERSITY OF RHODE ISLAND

2017 


\begin{abstract}
Chapter 1 reports a highly sensitive and selective array-based sensing strategy for classifying isomeric and analogous analytes based on their differential interactions with three supramolecular cyclodextrin-fluorophore sensors. Each analyte-sensor interaction results in a distinct fluorescence modulation response, and these variable responses are then statistically classified via linear discriminant analyses (LDA) into clusters of maximum separation. Three classes of isomeric analytes (aromatic alcohols, aliphatic alcohols, and hexanes) and two classes of analogous analytes (analogues of dichlorodiphenyltrichloroethane (DDT) and congeners of polychlorinated biphenyls (PCBs)) have been successfully classified with $100 \%$ accuracy. High sensitivity of this sensor is demonstrated as well, with limits of detection approaching or surpassing known levels of concern, and preliminary efforts at successfully classifying binary analyte mixtures using this sensor system are also reported.
\end{abstract}

Chapter 2 discusses the extensive literature reported on the properties of pyrene in $\beta$-cyclodextrin and $\gamma$-cyclodextrin. Despite this literature, little has been published on the interactions of pyrene with $\beta$-cyclodextrin derivatives (methyl- $\beta$ cyclodextrin and 2-hydroxypropyl- $\beta$-cyclodextrin) or mixtures of different cyclodextrins. These experiments focused on characterizing pyrene's interactions, as well as those of perdeuterated pyrene-d10 and benzo[a]pyrene, within different cyclodextrin solutions using fluorescence spectroscopy. The vibronic bands within the fluorescence emission spectrum of pyrene reflected the polarity of the 
microenvironment around pyrene (characterized by Py values). Little change in the Py values was observed when pyrene was introduced to different concentrations of methyl- $\beta$-cyclodextrin and 2-hydroxypropyl- $\beta$-cyclodextrin. Benzo $[a]$ pyrene had a large excimer peak when doped into $\gamma$ - or $\beta: \gamma$ solutions, which suggested that benzo $[a]$ pyrene may be forming 2:1 complexes with the cyclodextrins. Deuterated pyrene (pyrene-d10) had a lower binding constant in $\beta$-cyclodextrin (compared to pyrene-h10), but a higher binding constant in $\gamma$-cyclodextrin (compared to pyreneh10). Further studies should be conducted to determine why deuterium incorporation would produce a higher binding constant in the $\gamma$-cyclodextrin solutions. 


\section{ACKNOWLEDGMENTS}

This thesis could not have been completed if it weren't for the help of all the people in my life.

I want to first thank my advisor, Mindy Levine, for her support throughout my time in graduate school. Without her guidance and knowledge, I would not be where I am today. I have learned a lot since I've been in graduate school and I can attribute most of that to the time that I've spent in your lab.

I also want to thank my family for their love and support that they have given me. I can say that your investment in me throughout the years has not been in vain.

I also want to thank my wonderful fiancée, Abigail Johnson, for helping me through these stressful times. I know that moving up to Rhode Island was tough on both of us and I would not have made it without you.

Finally, I want to thank all of the friends that I have made up here at URI. Whether it was studying for an exam or trying to relax after a hard day, I will always cherish the time that we've spent together. 


\section{PREFACE}

This dissertation is presented in manuscript format according to the guidelines of the graduate school of the University of Rhode Island. Two manuscripts will be presented in this thesis. Chapter 1 is submitted for publication to Sensors and Actuators B: Chemical with the authors Sauradip Chaudhuri, Dana J. DiScenza, Benjamin Smith, Reid Yocum, and Mindy Levine. Chapter 2 is being prepared for submission to Supramolecular Chemistry with the authors Benjamin Smith and Mindy Levine. 


\section{TABLE OF CONTENTS}

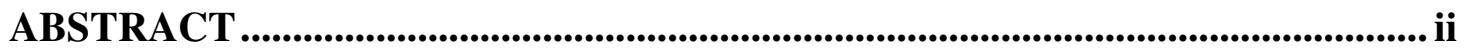

ACKNOWLEDGMENTS ................................................................................ iv

PREFACE ......................................................................................................................... V

TABLE OF CONTENTS................................................................................... vi

LIST OF TABLES ..................................................................................................................... vii

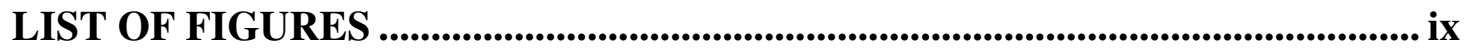

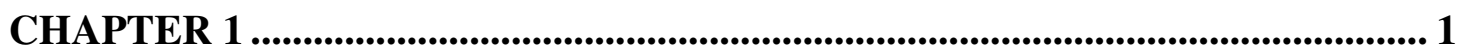

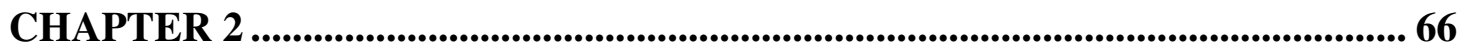




\section{LIST OF TABLES}

TABLE

PAGE

\section{Chapter 1}

Table 1. Association constants of analyte 5 in $\beta$-cyclodextrin ${ }^{\mathrm{a}}$ and in perbenzylated $\beta$ -

cyclodextrin, $\mathbf{S 2} \& \mathbf{S 3}$

Table 2. Fluorescence modulation of supramolecular sensors in the presence of aromatic alcohol analytes $\mathbf{5}-\mathbf{8}$

Table 3. Fluorescence modulation of sensors $\mathbf{S 1}-\mathbf{S 3}$ in the presence of analytes $\mathbf{9}-$

26.

Table 4. Calculated limits of detection and comparisons to known levels of concern 18

Fluorescence Modulation Summary Table 32

Limit of Detection Summary Table 34

Summary Table for Arrays 34

\section{Chapter 2}

Table 1. Pyrene (1 mg/mL in THF) doped into different solvents. Band I/ Band III ratios calculated from each fluorescence spectrum

Table 2. Benzo[ $[a]$ pyrene fluorescence $(\mathrm{Fl})$ Ratio (integration of benzo $[a]$ pyrene in cyclodextrin solution/integration of benzo[a]pyrene in water) and Excimer ratio (integration of excimer peak of benzo[a]pyrene/integration of the monomer peak of benzo $[a]$ pyrene).

Table S1 Py values for mixed cyclodextrins containing $1 \mathrm{mM} \beta$-cyclodextrin and 9 $\mathrm{mM}$ of 2-hydroxypropyl- $\beta$-cyclodextrin, methyl- $\beta$-cyclodextrin, or $\gamma$-cyclodextrin.. 77 Table S2. Excimer/monomer ratio calculations based on the integrated values found 
for the monomer and the excimer peaks

Table S3. Py values calculated for $\gamma-, \beta-$, and $\beta: \gamma$ cyclodextrin concentrations used during the course of these experiments.

Table S4. Integration ratios between the integration of the fluorescence emissions with the host $\left(\mathrm{I}_{\mathrm{w} / \text { Host }}\right) /$ the integration of the fluorescence emissions of pyrene in water $\left(\mathrm{I}_{\mathrm{water}}\right), \mathrm{I}_{\mathrm{w} / \mathrm{Hos}} / \mathrm{I}_{\mathrm{water}}$ 79 


\section{LIST OF FIGURES}

FIGURE

PAGE

\section{Chapter 1}

Figure 1. Schematic illustration of the advances in this work compared to previously

published work 5

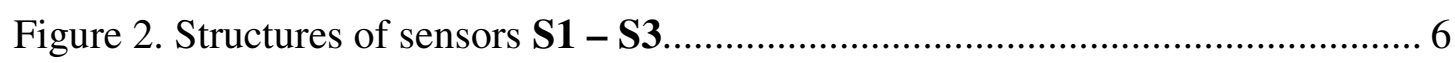

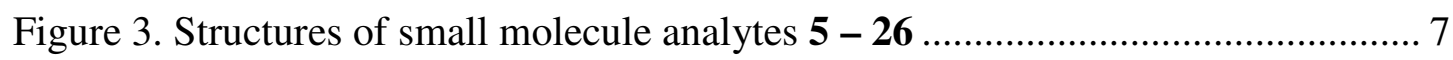

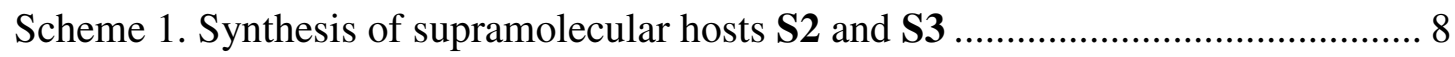

Figure 4. Fluorescence emission spectra of supramolecular hosts $\mathbf{S 1}$ - S3 (1 $\mu \mathrm{M})$ (inset shows the fluorescence of $\mathbf{S 2}$ and $\mathbf{S 3}$ in more detail) in 80:20 water-DMSO solution.

$\left(\lambda_{\mathrm{ex}}=320 \mathrm{~nm} ; 3 \mathrm{~nm}\right.$ excitation slit width; $3 \mathrm{~nm}$ emission slit width) 9

Figure 5. Fluorescence emission of (A) sensor S1; (B) sensor S2; and (C) sensor S3 in the presence of analyte 8 . $\left(\lambda_{\mathrm{ex}}=320 \mathrm{~nm} ; 3 \mathrm{~nm}\right.$ excitation slit width; $3 \mathrm{~nm}$ emission slit width)

Figure 6. Linear discriminant analysis showing $100 \%$ differentiation between analytes 5 - 8 based on their interactions with supramolecular hosts $\mathbf{S 1 ~ - ~ S 3 . . . . . ~}$

Figure 7. (A) Fluorescence response of host $\mathbf{S 1}$ in the presence of analytes $\mathbf{9 - 1 2}$; (B) Linear discriminant analysis of the fluorescence responses, leading to $100 \%$ differentiation of the analyte signals. $\left(\lambda_{\mathrm{ex}}=320 \mathrm{~nm} ; 3 \mathrm{~nm}\right.$ excitation slit width; $3 \mathrm{~nm}$ emission slit width) 13

Figure 8. (A) Fluorescence response of host $\mathbf{S 2}$ in the presence of analytes 13 - 16; (B) Linear discriminant analysis of the fluorescence responses, leading to $100 \%$ 
differentiation of the analyte signals. $\left(\lambda_{\mathrm{ex}}=320 \mathrm{~nm} ; 3 \mathrm{~nm}\right.$ excitation slit width; $3 \mathrm{~nm}$

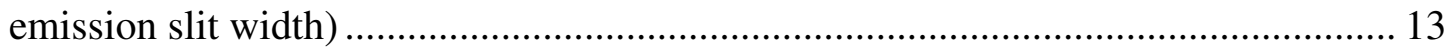

Figure 9. (A) Fluorescence response of host $\mathbf{S 3}$ in the presence of analytes $\mathbf{1 7}-\mathbf{2 1}$; (B) Linear discriminant analysis of the fluorescence responses, leading to $100 \%$ differentiation of the analyte signals. $\left(\lambda_{\mathrm{ex}}=320 \mathrm{~nm} ; 3 \mathrm{~nm}\right.$ excitation slit width; $3 \mathrm{~nm}$ emission slit width) 14

Figure 10. (A) Fluorescence response of host $\mathbf{S 2}$ in the presence of analytes $\mathbf{2 2}-\mathbf{2 6}$;

(B) Linear discriminant analysis of the fluorescence responses, leading to $100 \%$ differentiation of the analyte signals. $\left(\lambda_{\mathrm{ex}}=320 \mathrm{~nm} ; 3 \mathrm{~nm}\right.$ excitation slit width; $3 \mathrm{~nm}$ emission slit width) 14

Figure 11. Linear discriminant analysis results of binary mixtures of analytes $\mathbf{5}-\mathbf{8} 18$ Supplementary Information for Chapter 1

Reaction 1. Synthesis of Perbenzylated $\beta$-Cyclodextrin 24

Reaction 2. Synthesis of Mono-debenzylated $\beta$-cyclodextrin ................................ 25

Reaction 3. Synthesis of Di-debenzylated $\beta$-cyclodextrin ....................................... 26

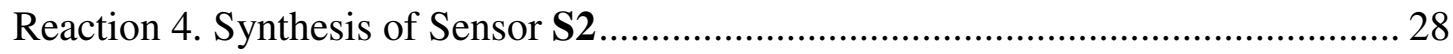

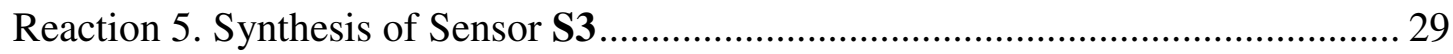

Summary Figures for Fluorescence Modulation............................................. 28

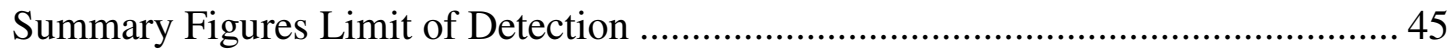

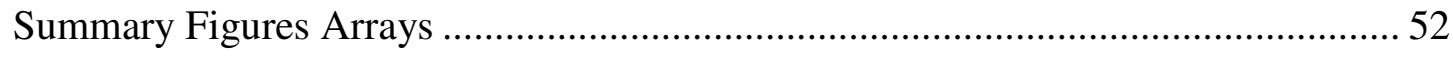

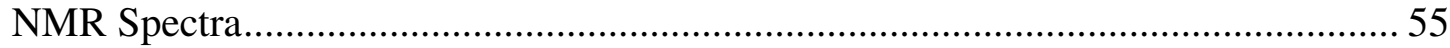

Spectroscopic Investigation of Sensors S1-S3 ............................................... 58

\section{Chapter 2}


Figure 1. Pyrene doped into $10 \mathrm{mM} \beta$-cyclodextrin in water. Band I and Band III represent fluorescence emissions from different relaxation pathways

Figure 2. A. Monomer emission (345 - $455 \mathrm{~nm})$ and B. Excimer emission (456 - 600

$\mathrm{nm})$ intensity with increasing concentration of $\gamma$-cyclodextrin. 68

Figure 3. Benesi-Hildebrand plot for the binding of pyrene-h10 to $\beta$-cyclodextrin. The best fit line $y=5 E-10 X+1 E-6$ with an $R^{2}$ value of 0.9605 and calculated binding constant: $\mathrm{Ka}=2000 \mathrm{M}^{-1}$ 68

Figure 4. Benesi-Hildebrand plot for the binding of pyrene-h10 to $\gamma$-cyclodextrin. The best fit line $y=2 E-9 x+4 E-6$ with an $R^{2}$ value of 0.9335 and calculated binding constant: $\mathrm{Ka}=2000 \mathrm{M}^{-1}$ 69

Figure 5. Benesi-Hildebrand plot for the binding of pyrene-d10 to $\beta$-cyclodextrin. The best fit line $y=(6 E-10) x+2 E-6$ with an $R^{2}$ value of 0.9784 and calculated binding constant: $\mathrm{Ka}=3333 \mathrm{M}^{-1}$.

Figure 6. B-H plot for the binding of pyrene-d10 to $\gamma$-cyclodextrin. The best fit line $y$ $=(2 \mathrm{E}-9) \mathrm{x}+(2 \mathrm{E}-6)$ with an $\mathrm{R}^{2}$ value of 0.9735 and calculated binding constant: $\mathrm{Ka}=$ $1000 \mathrm{M}^{-1}$ 70

Figure 7. Benzo[a]pyrene $(1 \mathrm{mg} / \mathrm{mL})$ solution doped in $2.5 \mathrm{~mL}$ of A. water, B. $10 \mathrm{mM}$ $\beta$-cyclodextrin, C. $10 \mathrm{mM} \gamma$-cyclodextrin, D. $5 \mathrm{mM}$ : $5 \mathrm{mM} \beta$-cyclodextrin: $\gamma$ cyclodextrin 70

Figure 8. One of pyrene's 6 Kekulé structures with the vertical axis defined as the zaxis and the horizontal axis defined as the y-axis. 72

Figure $9.1 \mu \mathrm{L}$ of pyrene $(1 \mathrm{mg} / \mathrm{mL})$ doped into $2.5 \mathrm{~mL}$ of $\mathrm{A}$. methyl- $\beta$-cyclodextrin and B. 2-hydroxypropyl- $\beta$-cyclodextrin 73 


\section{Supplementary Information for Chapter 2}

Figure S1. High concentrations of $2 \mathrm{HP} \beta \mathrm{CD} 1 \mathrm{mM}-10 \mathrm{mM}$. Equation: $\mathrm{y}=2 \mathrm{E}-8 \mathrm{x}+$

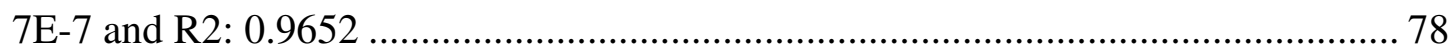

Figure S2. Py values for low concentrations of $\beta$-cyclodextrin and low concentrations of $\beta$-cyclodextrin in mixed cyclodextrin solution 


\section{CHAPTER 1}

Submitted for publication to Sensors and Actuators B: Chemical

Array-based detection of isomeric and analogous analytes employing synthetically modified fluorophore attached $\beta$-cyclodextrin derivatives

Sauradip Chaudhuri, Dana J. DiScenza, Benjamin Smith, Reid Yocum, and Mindy

Levine

Department of Chemistry, University of Rhode Island, Kingston, RI, USA

Corresponding Author:

Mindy Levine, Ph. D.

Department of Chemistry

University of Rhode Island

Kingston, Rhode Island 02881, USA

mlevine@chm.uri.edu 


\title{
Manuscript 1
}

\section{Array-based detection of isomeric and analogous analytes employing synthetically modified fluorophore attached $\beta$-cyclodextrin derivatives}

\begin{abstract}
Reported herein is a highly sensitive and selective array-based sensing strategy for classifying isomeric and analogous analytes based on their differential interactions with three supramolecular cyclodextrin-fluorophore sensors. Each analyte-sensor interaction results in a distinct fluorescence modulation response, and these variable responses are then statistically classified via linear discriminant analyses (LDA) into clusters of maximum separation. Three classes of isomeric analytes (aromatic alcohols, aliphatic alcohols, and hexanes) and two classes of analogous analytes (analogues of dichlorodiphenyltrichloroethane (DDT) and analogues of polychlorinated biphenyls (PCBs)) have been successfully classified with 100\% accuracy. High sensitivity of this sensor is demonstrated as well, with limits of detection approaching or surpassing known levels of concern, and preliminary efforts at successfully classifying binary analyte mixtures using this sensor system are also reported.
\end{abstract}

\section{INTRODUCTION}

The selective detection and accurate quantification of structurally similar analytes is a major environmental challenge for chemists and toxicologists, as structurally similar analytes often have widely disparate toxicities and environmental degradation pathways. ${ }^{1}$ The most common strategy to address 
this challenge is to use mass spectrometry based methods such as liquid chromatography-mass spectrometry $(\text { LC-MS })^{2}$ or gas chromatography-mass spectrometry (GC-MS). ${ }^{3}$ However, there are significant drawbacks associated with this approach, including the significant costs and time necessary to conduct such analyses, ${ }^{4}$ which limits the ability to conduct high throughput assays. ${ }^{5}$

An alternate strategy is to use array-based sensing systems, which have gained in popularity in recent years. ${ }^{6}$ This approach relies on the development of a chemical signature for each analyte based on analyte-specific interactions with a series of sensors. In a multi-component system, each individual analyte develops a unique response pattern, which is then compared against known samples to enable accurate identification.

Array-based sensing systems can be combined with supramolecular sensors, which rely on differential non-covalent interactions of isomeric analytes with supramolecular hosts, including cyclodextrins, ${ }^{7}$ fluorescent polymers, ${ }^{8}$ molecularly imprinted polymers, ${ }^{9}$ and metal-organic frameworks (MOFs). ${ }^{10}$ Cyclodextrin-based detection systems in particular have used either covalent $^{11}$ or non-covalent attachment ${ }^{12}$ of a spectroscopically active unit to achieve a read-out signal. However, often the detection specificity in this kind of sensing is limited due to structural similarities among related groups of analytes.

Although supramolecular array-based systems overcome many challenges associated with mass-spectrometry based detection methods, the analyte scope explored in most of these reports have been limited to aromatic 
small molecules such as xylenes $^{13}$ and nitrotoluenes. ${ }^{14}$ In a real-world contaminated environment, the nature of the various pollutants is highly complex, ${ }^{15}$ and includes complex mixtures of aromatic and non-aromatic compounds. ${ }^{16}$ This kind of situation requires the development of a sensing system which is rapid, simple and efficient in classifying a broad range of persistent organic pollutants (POPs). ${ }^{17}$ The proper identification of the contaminants using such a system would provide knowledge that would then inform the rational development of a decontamination strategy.

Our group has previously employed both $\beta$-cyclodextrin and $\gamma$-cyclodextrin in the development of array-based detection systems for the sensing and classification of a wide variety of environmental toxicants and POPs. ${ }^{18}$ The sensing strategy is based on cyclodextrin promoted analyte-to-fluorophore energy transfer as well as on analyteinduced fluorescence modulation. This fluorescence modulation relies on doping of the free fluorophore into the cyclodextrin solution prior to analyte addition, which often leads to binding of the fluorophore in the cyclodextrin and reduces the cyclodextrin's ability to bind the target analyte. As such, introduction of the analyte to the fluorophore-cyclodextrin solution requires the analyte-cyclodextrin association constants to be higher than the fluorophore-cyclodextrin constants in order to achieve binding (Figure 1A), or it requires the formation of higher order association complexes between the analyte, cyclodextrin and fluorophore (i.e. ternary complex formation) (Figure 1B). Such higher order association complexation is probable only for $\gamma$ cyclodextrin. ${ }^{19} \beta$-cyclodextrin, by contrast, has been extensively reported to participate 
in the formation of binary association complexes, ${ }^{20}$ and ternary inclusion complexes with $\beta$-cyclodextrin are less reported. ${ }^{21}$

(A)

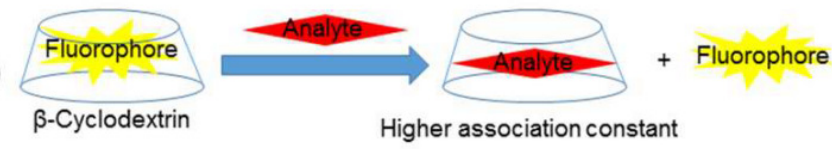

(B)

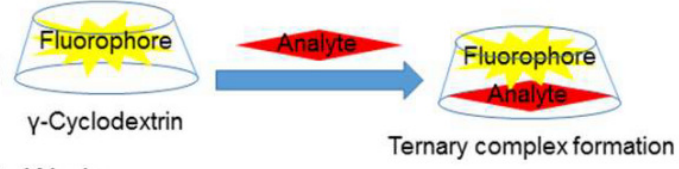

This Work:

Ternary complex formation

(C)

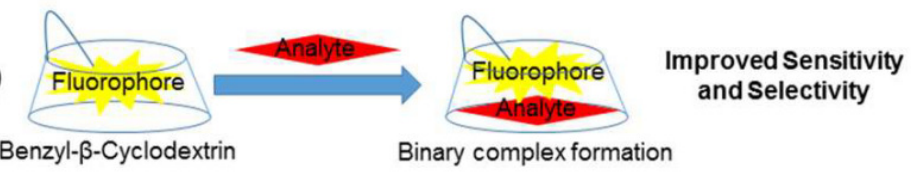

Figure 1. Schematic illustration of the advances in this work compared to previously published work.

Although in our previous work we have successfully distinguished between classes of analytes, the results tend to cluster structurally similar analytes and analyte derivatives near each other. Herein, we report the development of a highly selective array-based detection system using fluorophore-functionalized perbenzylated $\beta$ cyclodextrin sensors as the key components, which directly enables binary complex formation between the fluorophore-cyclodextrin and target analyte (Figure 1C). Each individual sensor is highly selective towards a specific isomer/analogue within a group of structurally similar analytes, which enables the array to distinguish isomers and structural analogues with high efficiency. Three classes of isomeric analytes and two classes of structurally similar analytes have been successfully classified based on this strategy, with a classification accuracy of $100 \%$ in every case. High sensitivity is demonstrated as well, with limits of detection approaching or surpassing literature- 
reported levels of concern. Finally, preliminary efforts at using this system for accurate identification of binary analyte mixtures are also reported.

\section{RESULTS AND DISCUSSION}

We employed a series of three cyclodextrin-based supramolecular sensors (Figure 2) for the detection of a broad variety of small molecule analytes (Figure 3). In these sensors, the perbenzylated $\beta$-cyclodextrin cavity acts as the receptor domain, and the attached fluorophore units act as the transducers, which are responsible for fluorescence-based responses to changes in their environment in the presence of the target analyte. The covalent attachment strategy used in sensors $\mathbf{S 2}$ and $\mathbf{S 3}$, with one and two degrees of functionalization on the primary rim, respectively, ensures the close proximity of the fluorophore units to the cyclodextrin receptor cavity, thereby facilitating productive fluorophore-analyte interactions. In contrast, sensor S1 is a noncovalent combination of the perbenzylated $\beta$-cyclodextrin and fluorophore $\mathbf{4}$, and is included to enable a direct determination of the benefits of covalent attachment in such sensor design.
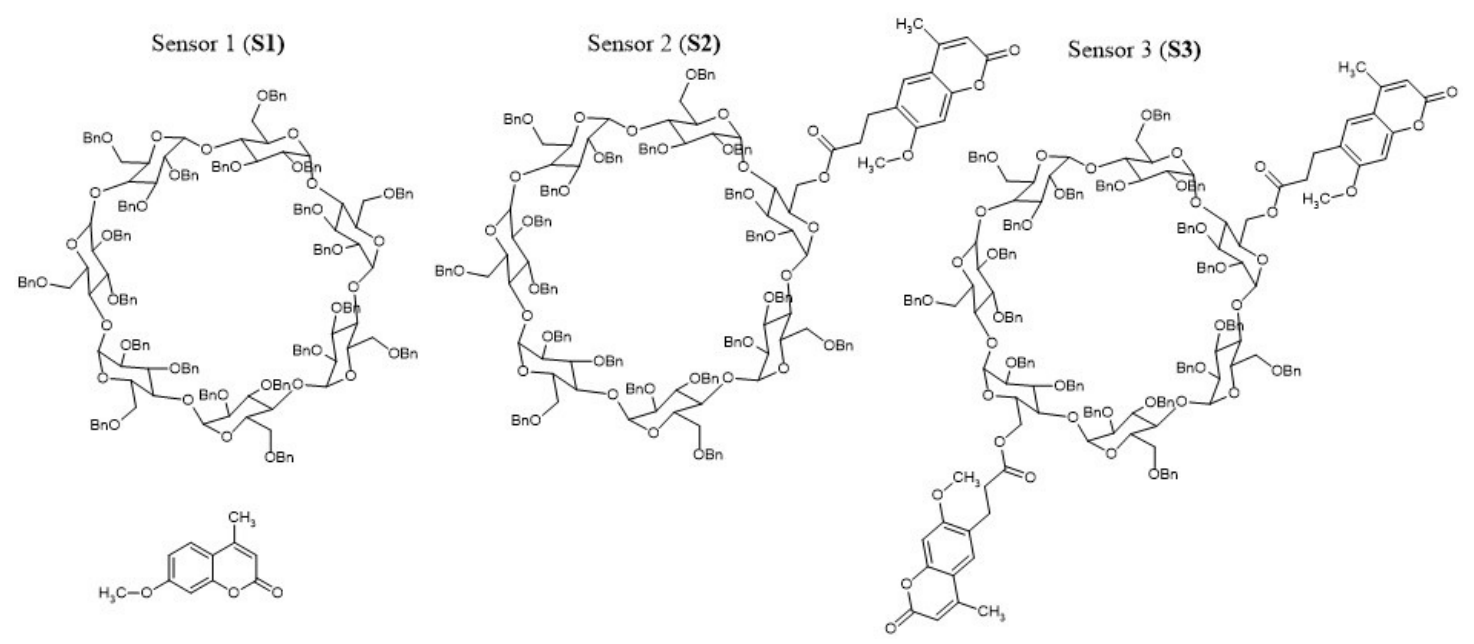
Figure 2. Structures of sensors S1 - S3.

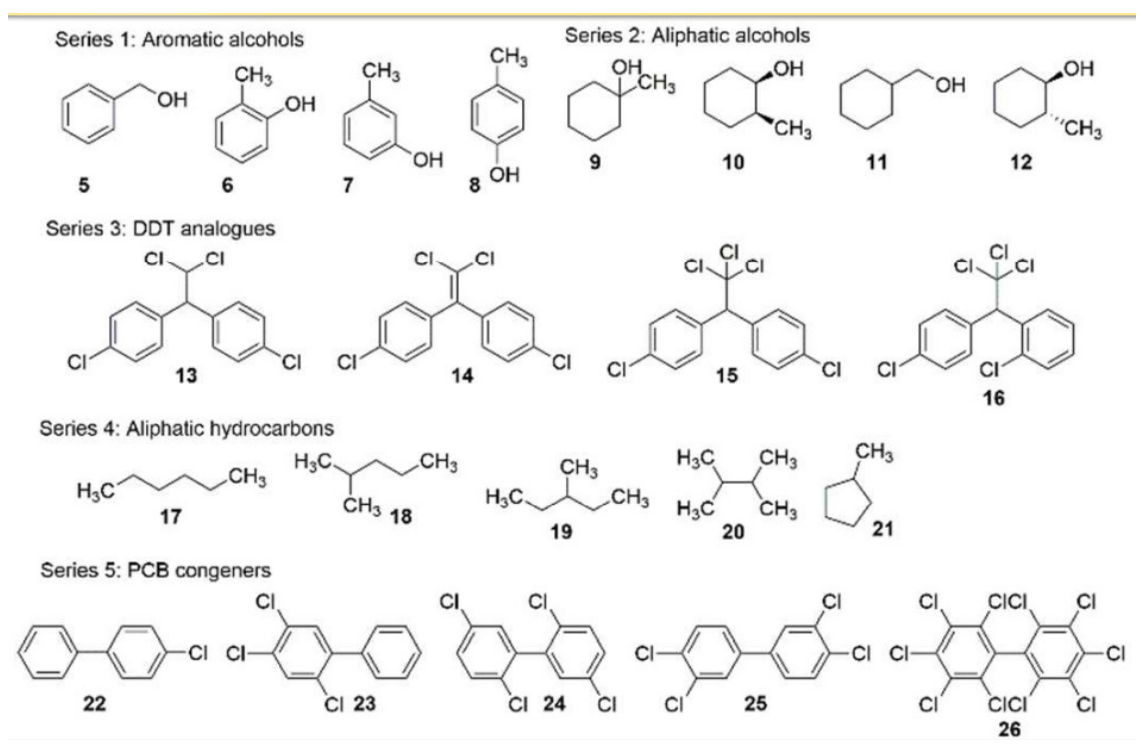

Figure 3. Structures of small molecule analytes $\mathbf{5} \mathbf{- 2 6}$.

The synthesis of supramolecular hosts $\mathbf{S 2}$ and $\mathbf{S 3}$ is shown in Scheme 1. Perbenzylated $\beta$-cyclodextrin is obtained from reacting $\beta$-cyclodextrin with excess benzyl chloride at room temperature in DMSO in the presence of excess sodium hydride. ${ }^{22}$ Regioselective debenzylation of the primary rim is effected by treating the perbenzylated $\beta$-cyclodextrin with DIBAL-H in toluene (ways to control the selectivity to achieve mono vs. di-debenzylation are discussed in the ESI). ${ }^{23}$ This is followed by Steglich esterification ${ }^{24}$ with the acid derivative of fluorophore 4, yielding mono- and di-functionalized sensors $\mathbf{S 2}$ and $\mathbf{S 3}$. New supramolecular compounds $\mathbf{S 2}$ and $\mathbf{S 3}$ were fully characterized by ${ }^{1} \mathrm{H}-\mathrm{NMR}$, ${ }^{13} \mathrm{C}-\mathrm{NMR}$, MALDI-TOF mass spectrometry, and UV-visible and fluorescence spectroscopy. 


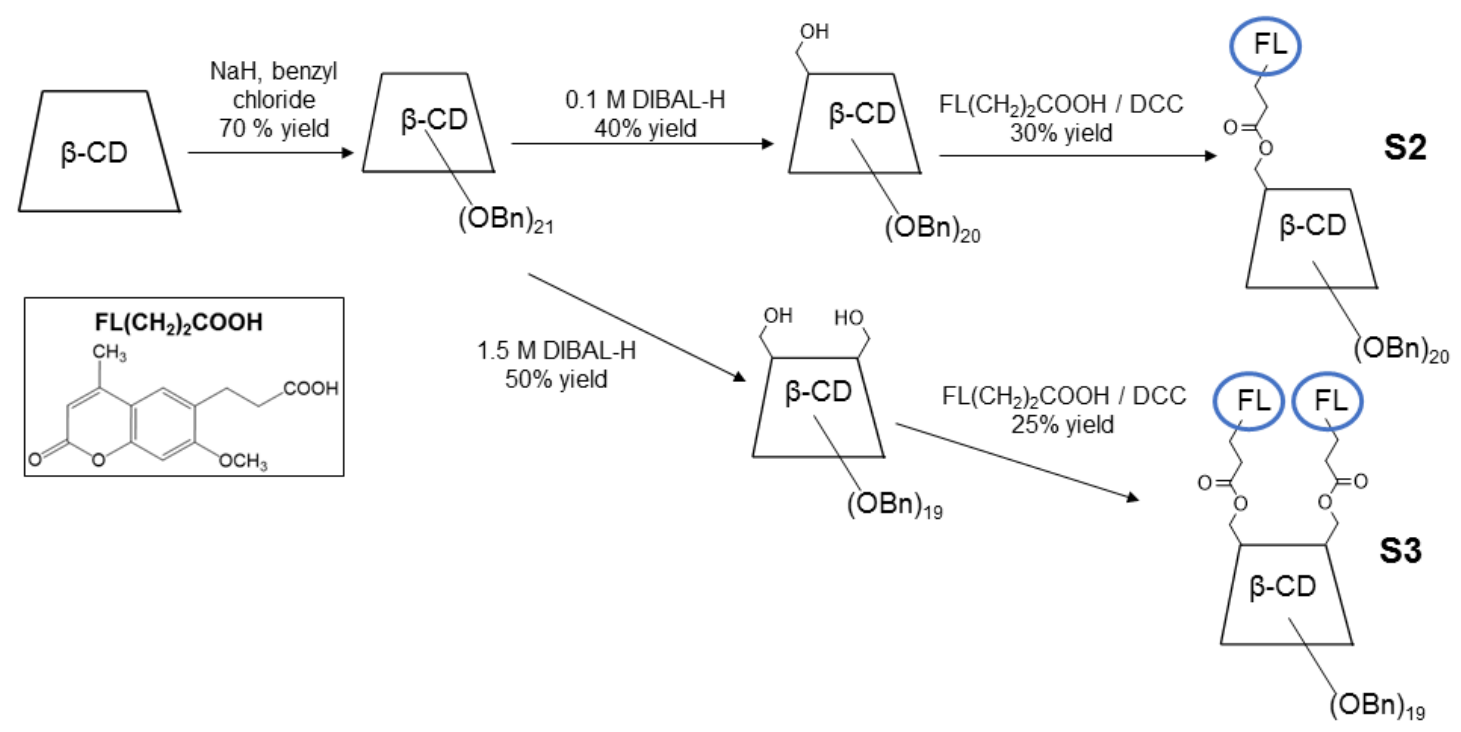

Scheme 1. Synthesis of supramolecular hosts $\mathbf{S 2}$ and $\mathbf{S 3 .}$

The fluorescence emission responses of sensors $\mathbf{S 1}, \mathbf{S 2}$ and $\mathbf{S 3}$ were investigated in varying solvent systems, with the goal of ensuring full dissolution of the sensor (requiring some DMSO) while enabling strong binding of analytes in the cyclodextrin host (optimal for aqueous environments). While sensor S1 showed a high fluorescence emission in predominantly aqueous solutions, sensors $\mathbf{S 2}$ and $\mathbf{S 3}$ displayed very little changes with changes in solvent composition. This led us to choose an 80:20 water-DMSO mixture as our sensing solvent. We note that the covalent strategy of the fluorophore used in sensors $\mathbf{S 2}$ and $\mathbf{S 3}$ led to a dramatic reduction of the fluorescence emission compared to the free fluorophore in S1 (Figure 4). This fluorescence decrease is in agreement with literature precedent in analogous systems, and is offset by the markedly improved fluorescence modulation results in the presence of various analytes (vide infra). ${ }^{25}$ 


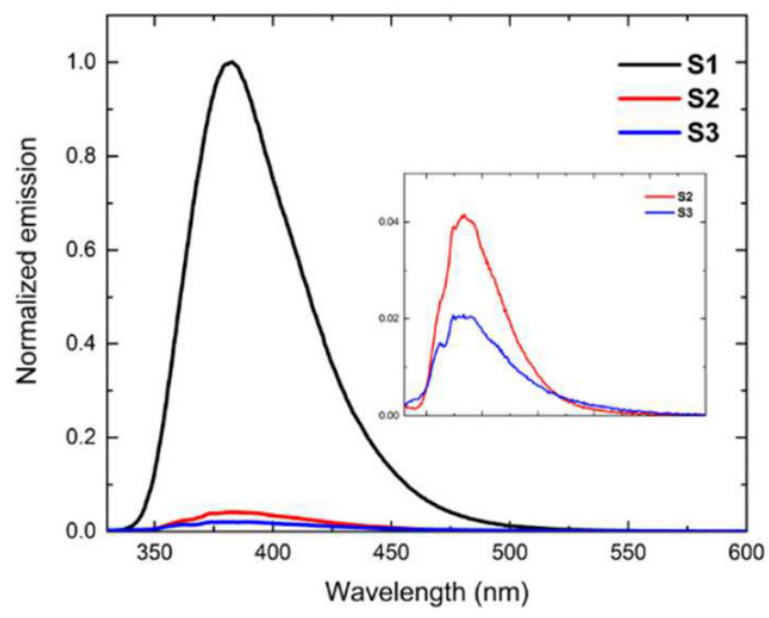

Figure 4. Fluorescence emission spectra of supramolecular hosts S1 - S3 (1 $\mu \mathrm{M}$ ) (inset shows the fluorescence of $\mathbf{S 2}$ and $\mathbf{S 3}$ in more detail) in 80:20 waterDMSO solution. $\left(\lambda_{\mathrm{ex}}=320 \mathrm{~nm} ; 3 \mathrm{~nm}\right.$ excitation slit width; $3 \mathrm{~nm}$ emission slit width).

The choice of perbenzylated $\beta$-cyclodextrin as a receptor over that of $\beta$ cyclodextrin is due to the stronger binding of organic guest molecules as a result of its extended hydrophobic cavity. ${ }^{25}$ In particular, a comparison of association constant values of analyte 5 revealed a 1000-fold increase in the binding constant with perbenzylated $\beta$-cyclodextrin over that of the naturally occurring $\beta$-cyclodextrin, and this binding constant is even higher in the fluorophorefunctionalized cyclodextrins S2 and S3 (Table 1). These binding constants are orders of magnitude higher than highest literature-reported binding constants for analyte 5 in $\beta$-cyclodextrin $\left(\mathrm{K}_{\mathrm{a}}=50-215 \mathrm{M}^{-1}\right){ }^{26}$ In general, higher association constants for the binding of an analyte in a sensor are known to lead to improved sensor performance. ${ }^{27}$ 
Table 1. Association constants of analyte 5 in $\beta$-cyclodextrin ${ }^{\mathrm{a}}$ and in perbenzylated $\beta$-cyclodextrin ${ }^{\mathrm{b}}, \mathbf{S 2}^{\mathrm{b}} \& \mathbf{S 3}^{\mathrm{b}}$.

\begin{tabular}{|c|c|}
\hline Host & Association Constant $\left(\mathbf{M}^{-\mathbf{1}}\right)$ \\
\hline $\boldsymbol{\beta}$-cyclodextrin & $0.2 \times 10^{2}$ \\
\hline Perbenzylated $\boldsymbol{\beta}$-cyclodextrin & $3.6(0.1) \times 10^{4}$ \\
\hline S2 & $4.8(0.5) \times 10^{4}$ \\
\hline S3 & $24.9(0.5) \times 10^{4}$ \\
\hline
\end{tabular}

${ }^{a}$ Association constant reported in the literature in aqueous solution.

${ }^{b}$ Association constants calculated using ${ }^{1} \mathrm{H}$ NMR titrations in 80:20 waterDMSO mixture.

Similarly, in this case, strong binding of analytes 5-8 in hosts S1- S3 induced marked changes in the resulting fluorescence emission due to proximity-induced interactions between the analyte and the fluorophore. These fluorescence modulation changes were quantified according to Equation 1, below:

Fluorescence modulation $=F l_{\text {analyte }} / F l_{\text {blank }}$

Where $F l_{\text {analyte }}$ is the integrated emission of the fluorophore in the presence of the analyte and $F l_{\text {blank }}$ is the integrated emission of the fluorophore in the absence of the analyte.

Although the fluorescence response was essentially unchanged with analyte addition in the case of S1 (leading to modulation values near 1.00 in every case), significant differences in the response patterns of sensors $\mathbf{S 2}$ and $\mathbf{S 3}$ with analyte addition were observed (Table 2). An example of analyte-induced fluorescence modulation for analyte $\mathbf{8}$ is shown in Figure 5 and highlights the small but distinct 
fluorescence changes observed for $\mathbf{S 2}$ and $\mathbf{S 3}$. The fluorescence signals of sensors S1S3 in the presence of analytes 5-8 were subjected to linear discriminant analysis, and enabled 100\% selectivity between the different aromatic alcohol isomers (Figure 6). This selectivity is particularly noteworthy as such isomers are challenging to separate using other chemical techniques. ${ }^{28}$

Table 2. Fluorescence modulation of supramolecular sensors in the presence of aromatic alcohol analytes $\mathbf{5} \mathbf{- 8}$.

\begin{tabular}{|c|c|c|c|}
\hline Analyte & S1 & S2 & S3 \\
\hline $\mathbf{5}$ & $1.00 \pm 0.00$ & $1.04 \pm 0.01$ & $0.98 \pm 0.01$ \\
\hline $\mathbf{6}$ & $1.01 \pm 0.00$ & $0.82 \pm 0.01$ & $0.88 \pm 0.01$ \\
\hline $\mathbf{7}$ & $0.99 \pm 0.00$ & $0.90 \pm 0.00$ & $1.05 \pm 0.02$ \\
\hline $\mathbf{8}$ & $1.01 \pm 0.01$ & $0.87 \pm 0.01$ & $0.75 \pm 0.01$ \\
\hline
\end{tabular}

a Results were calculated using Equation 1. All results represent an average of at least 3 trials.

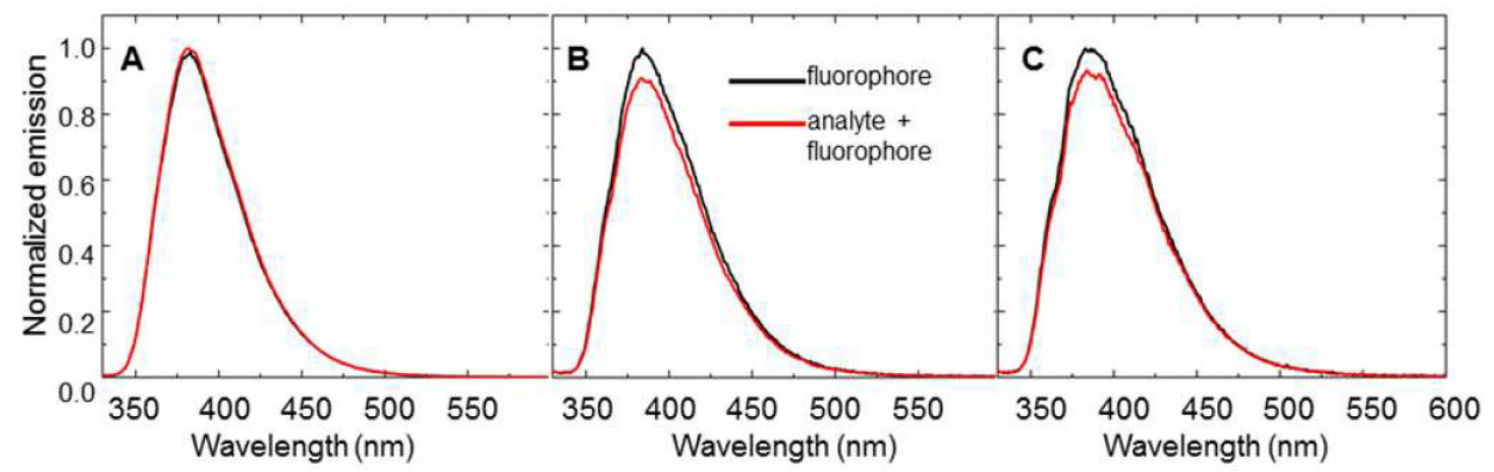

Figure 5. Fluorescence emission of (A) sensor S1; (B) sensor S2; and (C) sensor S3 in the presence of analyte 8 . $\left(\lambda_{\mathrm{ex}}=320 \mathrm{~nm} ; 3 \mathrm{~nm}\right.$ excitation slit width; $3 \mathrm{~nm}$ emission slit width). 


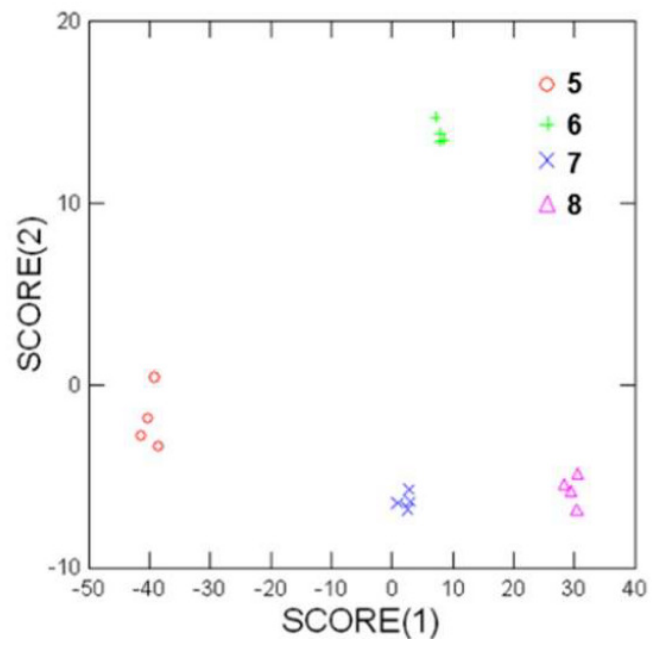

Figure 6. Linear discriminant analysis showing $100 \%$ differentiation between analytes 5 - 8 based on their interactions with supramolecular hosts $\mathbf{S 1 ~ - ~ S 3 . ~}$

The binding of other structural isomers and analogues in supramolecular hosts S1-S3 also led to noticeable, analyte-specific changes in the fluorescence emission (Table 3), with some key results highlighted in Figures 7-10.

Table 3. Fluorescence modulation of sensors $\mathbf{S 1}-\mathbf{S 3}$ in the presence of analytes $\mathbf{9}-$ 26.

\begin{tabular}{|c|c|c|c|}
\hline Analyte & S1 & S2 & S3 \\
\hline $\mathbf{9}$ & $1.01 \pm 0.00$ & $0.89 \pm 0.00$ & $1.07 \pm 0.05$ \\
\hline $\mathbf{1 0}$ & $1.01 \pm 0.00$ & $0.90 \pm 0.00$ & $0.97 \pm 0.01$ \\
\hline $\mathbf{1 1}$ & $1.01 \pm 0.00$ & $0.99 \pm 0.03$ & $0.77 \pm 0.06$ \\
\hline $\mathbf{1 2}$ & $0.99 \pm 0.00$ & $0.89 \pm 0.00$ & $1.14 \pm 0.01$ \\
\hline $\mathbf{1 3}$ & $1.00 \pm 0.00$ & $0.93 \pm 0.01$ & $1.33 \pm 0.03$ \\
\hline $\mathbf{1 4}$ & $1.01 \pm 0.00$ & $0.95 \pm 0.01$ & $1.07 \pm 0.04$ \\
\hline $\mathbf{1 5}$ & $0.98 \pm 0.01$ & $1.17 \pm 0.01$ & $1.35 \pm 0.05$ \\
\hline $\mathbf{1 6}$ & $0.99 \pm 0.01$ & $1.08 \pm 0.01$ & $1.04 \pm 0.05$ \\
\hline $\mathbf{1 7}$ & $1.00 \pm 0.00$ & $1.01 \pm 0.01$ & $0.94 \pm 0.02$ \\
\hline $\mathbf{1 8}$ & $1.05 \pm 0.00$ & $1.06 \pm 0.00$ & $0.93 \pm 0.02$ \\
\hline $\mathbf{1 9}$ & $0.98 \pm 0.00$ & $1.09 \pm 0.01$ & $0.95 \pm 0.02$ \\
\hline $\mathbf{2 0}$ & $1.00 \pm 0.00$ & $0.99 \pm 0.01$ & $1.01 \pm 0.01$ \\
\hline $\mathbf{2 1}$ & $1.03 \pm 0.01$ & $1.03 \pm 0.02$ & $0.89 \pm 0.01$ \\
\hline
\end{tabular}




\begin{tabular}{|l|l|l|l|}
$\mathbf{2 2}$ & $1.03 \pm 0.00$ & $1.06 \pm 0.06$ & $0.85 \pm 0.01$ \\
\hline $\mathbf{2 3}$ & $1.01 \pm 0.01$ & $1.02 \pm 0.04$ & $0.98 \pm 0.03$ \\
\hline $\mathbf{2 4}$ & $1.01 \pm 0.00$ & $1.07 \pm 0.04$ & $0.89 \pm 0.02$ \\
\hline $\mathbf{2 5}$ & $1.05 \pm 0.00$ & $0.56 \pm 0.01$ & $0.98 \pm 0.01$ \\
\hline $\mathbf{2 6}$ & $1.00 \pm 0.01$ & $0.92 \pm 0.03$ & $1.14 \pm 0.02$ \\
\hline
\end{tabular}

a Fluorescence modulation results were calculated using Equation 1. All results represent an average of at least 3 trials.
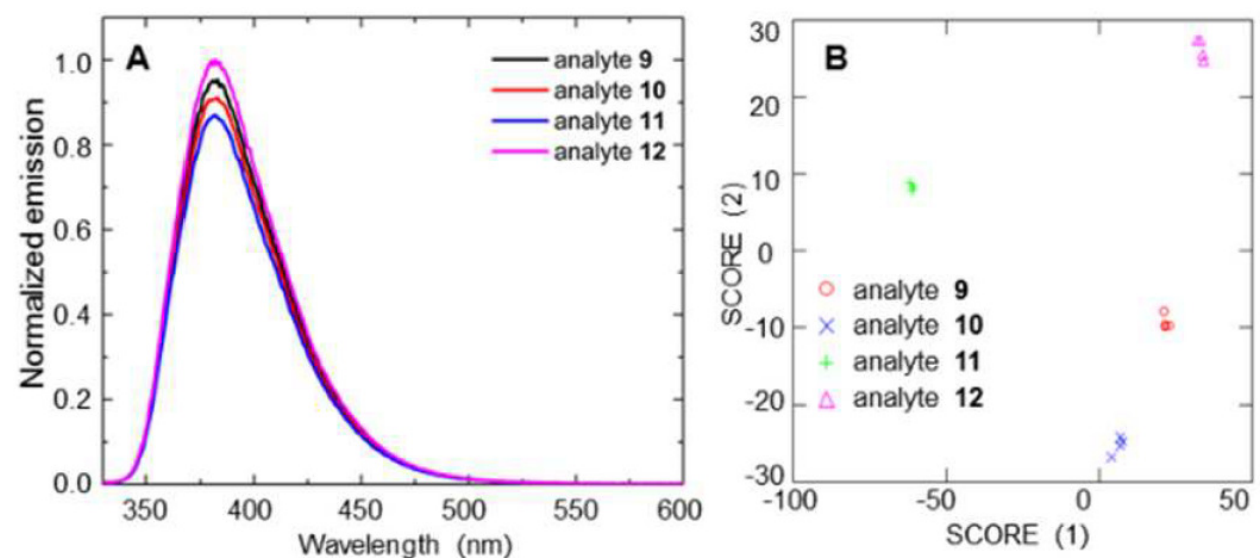

Figure 7. (A) Fluorescence response of host $\mathbf{S 1}$ in the presence of analytes $\mathbf{9}-\mathbf{1 2}$; (B) Linear discriminant analysis of the fluorescence responses, leading to $100 \%$ differentiation of the analyte signals. $\left(\lambda_{\mathrm{ex}}=320 \mathrm{~nm} ; 3 \mathrm{~nm}\right.$ excitation slit width; $3 \mathrm{~nm}$ emission slit width).
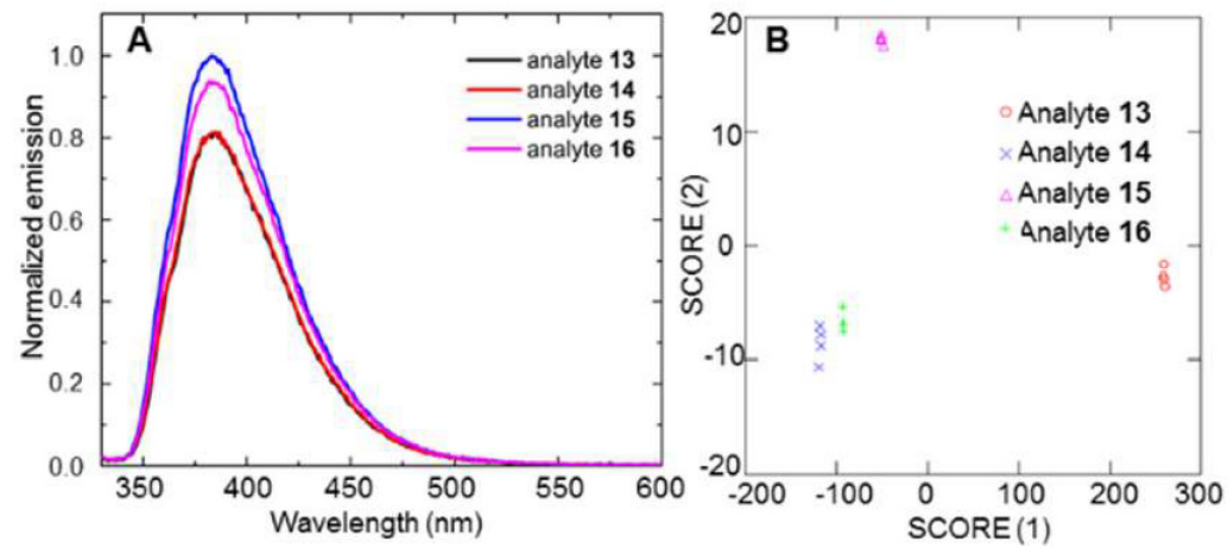
Figure 8. (A) Fluorescence response of host $\mathbf{S 2}$ in the presence of analytes 13-16;

(B) Linear discriminant analysis of the fluorescence responses, leading to $100 \%$ differentiation of the analyte signals. $\left(\lambda_{\mathrm{ex}}=320 \mathrm{~nm} ; 3 \mathrm{~nm}\right.$ excitation slit width; $3 \mathrm{~nm}$ emission slit width).
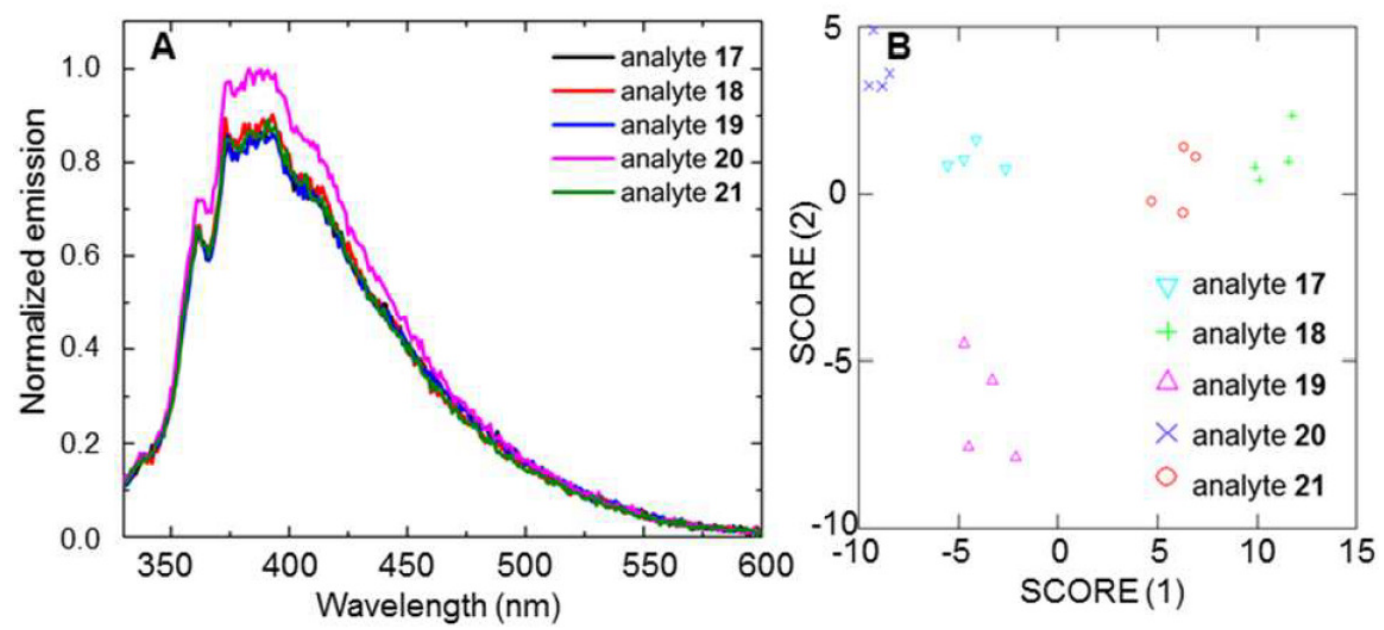

Figure 9. (A) Fluorescence response of host $\mathbf{S 3}$ in the presence of analytes 17-21;

(B) Linear discriminant analysis of the fluorescence responses, leading to $100 \%$ differentiation of the analyte signals. $\left(\lambda_{\mathrm{ex}}=320 \mathrm{~nm} ; 3 \mathrm{~nm}\right.$ excitation slit width; $3 \mathrm{~nm}$ emission slit width).
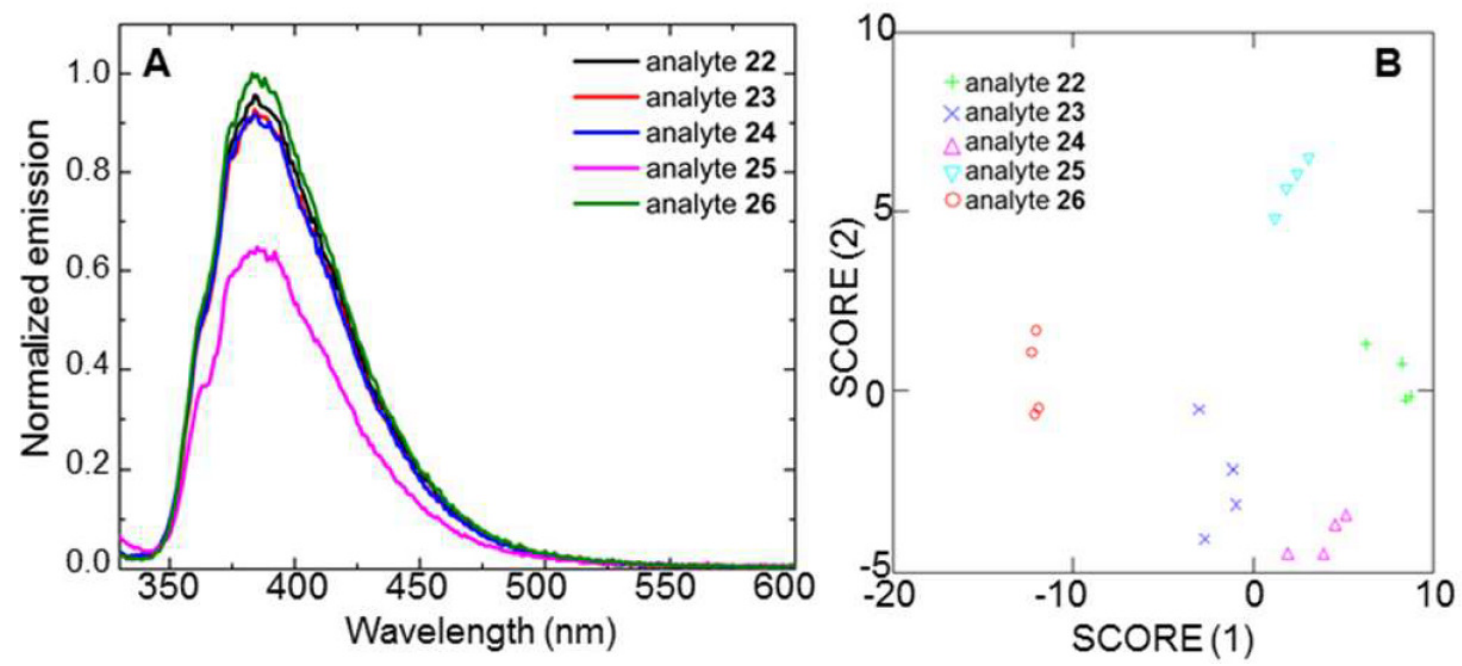
Figure 10. (A) Fluorescence response of host $\mathbf{S 2}$ in the presence of analytes $22-\mathbf{2 6}$;

(B) Linear discriminant analysis of the fluorescence responses, leading to $100 \%$ differentiation of the analyte signals. $\left(\lambda_{\mathrm{ex}}=320 \mathrm{~nm} ; 3 \mathrm{~nm}\right.$ excitation slit width; $3 \mathrm{~nm}$ emission slit width).

The sensor $\mathbf{S 1}$ shows a fluorescence modulation value close to 1.00 for all the tested analytes (see Figure 5A for an example), indicating minimal to no effect on the fluorescence emission of the fluorophore with the introduction of the analyte. In contrast to this, fluorescence modulation values measured for sensors $\mathbf{S 2}$ and $\mathbf{S 3}$ are significantly different from that of S1, and display widespread variability between different classes of analytes as well as within each analyte class. These results clearly demonstrate the effect of the sensor architecture, and in particular the effects of covalent fluorophore attachment and the number of fluorophore transducer units. The covalent attachment ensures close proximity between the cyclodextrin-bound analyte and the fluorophore moiety(ies), causing substantial modulation of the fluorescence emission signal.

Analytes 9-12 represent a class of aliphatic alcohols consisting of cyclohexylmethanol (11) and its isomers. These compounds are widely used as alkene precursors, ${ }^{29}$ and a structurally similar analogue was part of a recent chemical spill, ${ }^{30}$ making them important targets for detection. While all the analytes are structural isomers, analytes $\mathbf{1 0}$ and $\mathbf{1 2}$ are also stereoisomers. Distinct fluorescence modulation values are noted for sensor $\mathbf{S 3}$ in combination with stereoisomers $\mathbf{1 0}$ and 12, highlighting the power of the cyclodextrin-based supramolecular sensor in differentiating even small structural changes. Overall, the uses of sensors S1-S3 in 
combination with these analytes enabled $100 \%$ differentiation using linear discriminant analysis (Figure 6).

Analytes 13-16 represents aromatic pesticide $p, p$-DDT (compound 15), its known metabolites DDE (compound 13) and DDD (compound 14), ${ }^{31}$ and its often cooccurring structural isomer $o, p$-DDT (compound 16). ${ }^{32}$ These compounds are suspected carcinogens ${ }^{33}$ and toxicants, ${ }^{34}$ and are therefore important targets for detection. Although the analogues selected are extremely structurally similar, we nonetheless achieved $100 \%$ accurate classification for these analytes using supramolecular sensors S1-S3 and linear discriminant analysis (Figure 7). Interestingly, although sensor $\mathbf{S 3}$ demonstrated nearly identical fluorescence modulation values in response to analytes $\mathbf{1 3}$ and $\mathbf{1 5}$, sensor $\mathbf{S 2}$ was able to clearly differentiate between those two analytes. These results illustrate the fact that altering the degree of functionalization of the supramolecular sensor alters its response for a target analyte.

Analytes 17-21 represent aliphatic $n$-hexane (compound 17), its commonly occurring structural isomers (compounds 18-20, generated in 10-30\% yield from industrial production of hexane $)^{35}$ and its cyclopentane analogue (compound 21). The fact that hexanes co-occur as isomeric mixtures of compounds 17-20 complicates their accurate characterization as well as fuel applications that rely on such characterization. $^{36}$ Using this supramolecular sensing strategy, $100 \%$ accurate classification between these analytes has been achieved.

Analytes 22-26 represent a class of (POPs) called polychlorinated biphenyls (PCBs), which cause neurotoxicity ${ }^{37}$ and endocrine disruption. ${ }^{38}$ As a result, the use of 
PCBs has been banned in many countries; however, their extreme environmental persistence means that significant amounts of PCBs are still found in the environment today. ${ }^{39} 100 \%$ accurate classification has been achieved for these analytes via this strategy, which is particularly relevant because these analytes have widely disparate toxicities.

The ability of this detection method to generate well-separated signals was further investigated by generating an array with all analytes from all classes. In this case, the array exhibited well-separated clusters based on compound class, as well as excellent separation within each class. Overall, $100 \%$ accurate identification was obtained (see ESI for more details).

The limits of detection for each sensors S1, S2 and S3 for each class of analytes were calculated to determine their ability to sense analyte concentrations at or near environmental levels of concern and literature-reported levels of toxicity. In every case, the calculated limits of detection were at or lower than the literature reported limits of concern for these analytes (Table 4). These results illustrate the high sensitivity of this detection method.

Practical applications of this system require the capability to identify analyte mixtures, because environmental contamination scenarios almost never involve a single chemical contaminant. To that end, preliminary work focused on identification of 1:1 binary mixtures of aromatic alcohol analytes 5-8. Using the same supramolecular sensors and the same linear discriminant analytical techniques, $83 \%$ accurate identification of the 1:1 binary mixtures was obtained (Figure 11). Interestingly, the mixture of analytes $\mathbf{5}+\mathbf{7}$ is grouped near the mixtures of analytes $\mathbf{6}$ 
$+\mathbf{8}$ and $\mathbf{5}+\mathbf{8}$, which reduces the overall classification accuracy. This kind of coclustering of analyte groups has been observed in literature precedent reports of arraybased sensing ${ }^{40}$, and can possibly be attributed to similar sensor responses originating from competing interactions between each component of the mixture. Other than those combinations, the other mixtures demonstrated excellent signal separation and accurate identification. Current work in our group is focused on improving classification accuracy of analyte mixtures, expanding such techniques to multiple analyte classes, and moving from binary mixtures to ternary and even quaternary mixtures of analytes.

Table 4. Calculated limits of detection and comparisons to known levels of concern

\begin{tabular}{|c|c|c|c|}
\hline Analytes & Sensors & $\begin{array}{l}\text { LOD calculated } \\
(\mu \mathrm{M})\end{array}$ & $\begin{array}{l}\text { Limit of concern } \\
(\mu \mathrm{M})\end{array}$ \\
\hline 5 & $\mathbf{S 2}$ & 0.39 & $\mathrm{a}$ \\
\hline 6 & S1 & 0.51 & $21.27^{41}$ \\
\hline 6 & S3 & 2.20 & $21.27^{41}$ \\
\hline 9 & S3 & 4.97 & $437.87^{42}$ \\
\hline 11 & S1 & 8.34 & $\mathrm{a}$ \\
\hline 11 & $\mathbf{S 2}$ & 11.79 & $\mathrm{a}$ \\
\hline 15 & S1 & 1.17 & $2.82^{43}$ \\
\hline 15 & S2 & 1.85 & $2.82^{43}$ \\
\hline 15 & S3 & 26.30 & $2.82^{43}$ \\
\hline 18 & S1 & 2.20 & $5801.81^{44}$ \\
\hline 19 & S2 & 15.74 & $5801.81^{45}$ \\
\hline 21 & S3 & 19.82 & $\mathrm{a}$ \\
\hline 25 & S1 & 0.29 & $1.71^{46}$ \\
\hline 26 & S2 & 0.88 & $1.00^{44}$ \\
\hline 26 & S3 & 4.59 & $1.00^{44}$ \\
\hline
\end{tabular}

${ }^{a}$ Limits of concern have not been established for these compounds. 


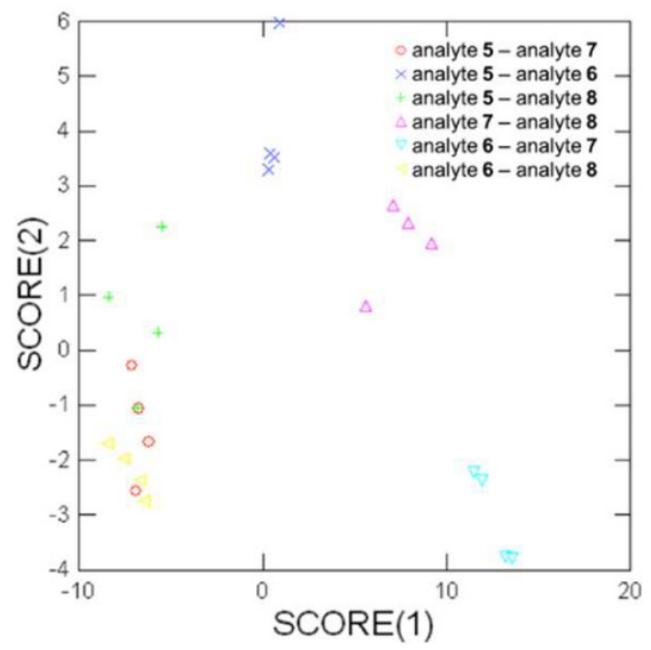

Figure 11. Linear discriminant analysis results of binary mixtures of analytes $\mathbf{5}-\mathbf{8}$. CONCLUSION

In conclusion, we have developed an efficient array-based detection strategy for isomeric and analogous analytes. The array employs three architecturally unique perbenzylated $\beta$-cyclodextrin-fluorophore sensors for identification of a particular isomer within a class of isomeric or structurally similar analytes. The binding of analytes to the cyclodextrin induces a distinct change in the fluorescence emission of the attached fluorophore units, which is then statistically translated into array clusters of maximum separation via linear discriminant analysis (LDA). We demonstrate a $100 \%$ successful classification of three isomeric (aromatic alcohols, aliphatic alcohols, aliphatic hexanes) and two analogous (DDT pesticides, PCB congeners) classes of analytes. Sensitivity measurements highlight that limits of detection are at or near literature-reported levels of concern. Finally, preliminary work on binary mixtures demonstrated promising levels of selectivity, with $83 \%$ accuracy obtained. Current work in our laboratory is focused on expanding the classes of analytes detectable via this system, improving analyte mixture identification, and developing a practical 
cyclodextrin-based detection device. The results of these and other investigations will be reported in due course.

\section{ACKNOWLEDEMENTS}

The authors gratefully acknowledge funding from the National Science Foundation (Award Number: 1453483) and from the National Cancer Institute (CA185435).

\section{REFERENCES}

1. K. L. Willett, E. M. Ulrich and R. A. Hites, Environ. Sci. Technol., 1998, 32, 2197; F.X. Prenafeta-Boldú, H. Ballerstedt, J. Gerritse and J. T. C. Grotenhuis, Biodegradation, 2004, 15, 59; M.A. Mehlman, Environ. Res., 1992, 59, 238;

G. Peng, U. Tisch, O. Adams, M. Hakim, N. Shehada, Y. Y. Broza, S. Billan, R. Abdah-Bortnyak, A. Kuten and H. Haick, Nat. Nanotechnol., 2009, 4, 669; M. Phillips, K. Gleeson and J. M. B. Hughes, J. Greenberg, R. N. Cataneo, L. Baker and W. P. McVay, Lancet, 1999, 353, 1930.

2. I. Rodriguez, M. Fraga, A. Alfonso, D. Guillebault, L. Medlin, J. Baudart, P. Jacob, K. Helmi, T. Meyer, U. Breitenbach, N. M. Holden, B. Boots, R. Spurio, L. Cimarelli, L. Mancini, S. Marcheggiani, M. Albay, R. Akcaalan,

L. Koeker and L. M. Botana, Environ. Toxicol. Chem., 2016, Ahead of Print; DOI: 10.1002/etc.3577.

3. M. Bergknut, A. Kucera, K. Frech, E. Andersson, M. Engwall, U. Rannug, V. Koci, P. L. Andersson, P. Haglund and M. Tysklind, Environ. Toxicol. Chem., 2007, 26, 208. 
4. U. Shafique, S. Schulze, C. Slawik, S. Kunz, A. Paschke and G. Schueuermann, Anal. Chim. Acta, 2017, 949, 8; A. Medvedovici, F. Albu and V. David, J. Liquid Chromatography Related Technol., 2010, 33, 1255.

5. J. E. Rager, M. J. Strynar, S. Liang, R. L. McMahen, A. M. Richard, C. M. Grulke, J. F. Wambaugh, K. K. Isaacs, R. Judson, A. J. Williams and J. R. Sobus, Environ. Int., 2016, 88, 269.

6. O. R. Miranda, B. Creran and V. M. Rotello, Curr. Opinion Chem. Biol., 2010, 14, 728; K. L. Diehl and E. V. Anslyn, Chem. Soc. Rev., 2013, 42, 8596.

7. X. Xu, Z. Liu, X. Zhang, S. Duan, S. Xu and C. Zhou, Electrochim. Acta, 2011, 58, 142; X. Chen, X. Chen and J. J. Gooding, Anal. Chem., 2012, 84, 8557.

8. S. Hussain, A. H. Malik and P. K. Iyer, J. Mater. Chem. B, 2016, 4, 4439.

9. B. B. Prasad and I. Pandey, Sensors Actuators B: Chem., 2013, 181, 596.

10. J. Zhang, X. Zhang, J. Chen, C. Deng, N. Xu, W. Shi and P. Cheng, Inorganic Chem. Commun., 2016, 69, 1.

11. A. Ueno, Supramolecular Science, 1996, 3, 31.

12. R. A. Agbaria, E. Roberts and I. M. Warner, J. Phys. Chem., 1995, 99, 10056; S. Hamai, J. Inclusion Phenom. Macrocyclic Chem., 2010, 67, 471.

13. S. Hatanaka, T. Ono and Y. Hisaeda, Chem. Eur. J., 2016, 22, 10346. 
14. S. Mukherjee, A. V. Desai, A. I. Inamdar, B. Manna and S. K. Ghosh, Crystal Growth \& Design, 2015, 15, 3493; B. Gole, W. Song, M. Lackinger and P. S. Mukherjee, Chem. Eur. J., 2014, 20, 13662.

15. E. A. Cohen Hubal, A. Richard, L. Aylward, S. Edwards, J. Gallagher, M.R. Goldsmith, S. Isukapalli, R. Tornero-Velez, E. Weber and R. Kavlock, J. Toxicol. Environ. Health B, 2010, 13, 299.

16. Z. Wang and M. F. Fingas, Marine Pollution Bull., 2003, 47, 423; L. J. Gensburg, C. Pantea, C. Kielb, E. Fitzgerald, A. Stark and N. Kim, Environ. Health Perspect., 2009, 117, 1265.

17. D. Megson, E. J. Reiner, K. J. Jobst, F. L. Dorman, M. Robson and J.-F. Focant, Anal. Chim. Acta, 2016, 941, 10.

18. D. J. DiScenza, L. Gareau, N. Serio, J. Roque, L. Prignano, M. Verderame and M. Levine, Anal. Chem. Lett., 2016, 6, 345; D. J. DiScenza and M. Levine, Supramol. Chem., 2016, 28, 881; D. J. DiScenza and M. Levine, New J. Chem., 2016, 40, 789; N. Serio, J. Roque, A. Badwal and M. Levine, Analyst, 2015, 140, 7503; N. Serio, D. F. Moyano, V. M. Rotello and M. Levine, Chem. Commun., 2015, 51, 11615; N. Serio, C. Chanthalyma, L. Prignano and M. Levine, Supramol. Chem., 2014, 26, 714; N. Serio, K. Miller and M. Levine, Chem. Commun., 2013, 49, 4821.

19. K. Higashi, S. Ideura, H. Waraya, W. Limwikrant, K. Moribe and K. Yamamoto, Chem. Pharm. Bull., 2010, 58, 769; C. Yang, T. Mori and Y. Inoue, J. Org. Chem., 2008, 73, 5786; C. Yang, A. Nakamura, T. Wada and Y. Inoue, Org. Lett., 2006, 8, 3005. 
20. M. Srivastava, P. Rai, J. Singh, S. Yadav, B. P. Tripathi and J. Singh, Current Organocatalysis, 2016, 3, 32.

21. N. K. Sangwan and H. J. Schneider, J. Chem. Soc. Perkin Trans., 1989, 1223; P. Jadhav, B. Petkar, Y. Pore, A. Kulkarni and K. Burade, Carbohydrate Polym., 2013, 98, 1317.

22. J. Bjerre, T. H. Fenger, L. G. Marinescu and M. Bols, Eur. J. Org. Chem., $2007,704$.

23. S. Volkov, L. Kumprecht, M. Budesinsky, M. Lepsik, M. Dusek and T. Kraus, Org. Biomol. Chem., 2015, 13, 2980; T. Lecourt, A. Herault, A. J. Pearce, M. Sollogoub and P. Sinay, Chem. Eur. J. 2004, 10, 2960.

24. B. S. Choi, J. Choi, S. Bak and S. Koo, Eur. J. Org. Chem., 2015, 2015, 514.

25. C. Huo, J.- C. Chambron and M. Meyer, New J. Chem., 2008, 32, 1536.

26. Y. Matsui and K. Mochida, Bull. Chem. Soc. Japan, 1979, 52, 2808; Q.-X. Guo, S.-H. Luo and Y.-C. Liu, J. Inclusion Phenom. Molecular Recognition Chem., 1998, 30, 173; G. W. Meindersma, T. van Schoonhoven, B. Kuzmanovic and A. B. de Haan, Chem. Engineer. Processing, 2006, 45, 175.

27. R. N. Dsouza, U. Pischel and W. M. Nau, Chem. Rev., 2011, 111, 7941; J. Falter, R. Medina and H.-L. Schmidt, Sensors Actuators B Chem., 1994, 19, 694.

28. J. Peng, Y. Zhang, X. Yang and M. Qi, J. Chromatography A, 2016, 1466, 148. 
29. J. J. Cawley and P. E. J. Lindner, J. Chem. Educ., 1997, 74, 102; M. M. Clennan and E. L. Clennan, J. Chem. Educ., 2011, 88, 646.

30. A. J. Whelton, L. McMillan, M. Connell, K. M. Kelley, J. P. Gill, K. D. White, R. Gupta, R. Dey and C. Novy, Environ. Sci. Technol., 2015, 49, 813; L. Stolze and F. Volpin, Environ. Sci. Pollution Res., 2015, 22, 7980; R. Bahadur and W. B. Samuels, J. Environ. Engineering, 2015, 141, 1.

31. M. Ricking and J. Schwarzbauer, Environ. Chem. Lett., 2012, 10, 317.

32. J. P. Arrebola, M. Cuellar, J. P. Bonde, B. Gonzalez-Alzaga and L. A. Mercado, Environ. Res., 2016, 151, 469.

33. J. F. Quensen III, S. A. Mueller, M. K. Jain and J. M. Tiedje, Science, 1998, 280, 722; A. M. Soto, K. L. Chung and C. Sonnenschein, Environ. Health Perspect., 1994, 102, 380.

34. A. Mansouri, M. Cregut, C. Abbes, M.-J. Durand, A. Landoulsi and G. Thouand, Appl. Biochem. Biotechnol., 2016, Ahead of Print; DOI: 10.1007/s12010-016-2214-5.

35. R. A. Myers, Handbook of Petroleum Refining Process, McGraw-Hill, New York, $4^{\text {th }}$ edn.,2004; R. Clavier, Wiley Critical Content: Petroleum Technology, Wiley-Interscience, Hoboken, New Jersey, 2007.

36. R. Hayati, S. Z. Abghari, S. Sadighi and M. Bayat, Korean J. Chem. Engineering, 2015, 32, 629; J. Hancsok, A. Hollo, J. Forstner, J. Gergely and J. Perger, Petroleum and Coal, 2000, 42, 166.

37. G. Winneke, J. Neurological Sci., 2011, 308, 9. 
38. T. Grzeskowiak, B. Czarczynska-Goslinska and A. Zgola-Grzeskowiak, TrAC, Trends Anal. Chem., 2016, 75, 209.

39. N. S. Shifrin and A. P. Toole, Environ. Engineering Sci., 1998, 15, 247; G. Fan, Y. Wang, G. Fang, X. Zhu and D. Zhou, Environ. Sci. Processes Impacts, 2016, 18, 1140.

40. N. Fahimi-Kashani and M. Reza Hormozi-Nezhad, Anal. Chem., 2016, 88, 8099.

41. Center for Disease Control and Prevention. The National Institute for Occupational Safety and Health (NIOSH): Cresols (o, m, p isomers) https://www.cdc.gov/niosh/idlh/cresol.html (accessed Dec 20, 2016).

42. Center for Disease Control and Prevention. The National Institute for Occupational Safety and Health (NIOSH): methylcyclohexanol https://www.cdc.gov/niosh/idlh/25639423.html (accessed Dec 20, 2016).

43. Center for Disease Control and Prevention. The National Institute for Occupational Safety and Health (NIOSH): DDT https://www.cdc.gov/niosh/idlh/50293.html (accessed Dec 20, 2016).

44. Center for Disease Control and Prevention. The National Institute for Occupational Safety and Health (NIOSH): 2-methylpentane. https://www.cdc.gov/niosh/ipcsneng/neng1262.html (accessed Dec 20, 2016).

45. Center for Disease Control and Prevention. The National Institute for Occupational Safety and Health (NIOSH): 3-methylpentane. 
https://www.cdc.gov/niosh/ipcsneng/neng1263.html (accessed Dec 20, 2016).

46. Center for Disease Control and Prevention. The National Institute for Occupational Safety and Health (NIOSH): Polychlorinated Biphenyls (PCB's). https://www.cdc.gov/niosh/docs/86-111/default.html (accessed Dec 20, 2016). 


\section{Supporting Information}

\section{Array-based detection of isomeric and analogous analytes employing synthetically modified fluorophore attached $\beta$-cyclodextrin derivatives}

METHODS AND MATERIALS

All of the reagents were obtained from Sigma Aldrich or Fisher Scientific and used without further purification, unless otherwise noted. $\beta$-cyclodextrin was dried in the oven prior to use. Reagent grade solvents (99.9\% purity) were used for the synthetic reactions. Column chromatography was performed in a Yamazen AKROSAutomatic TLC Smart Flash Chromatography System. ${ }^{1} \mathrm{H}$ and ${ }^{13} \mathrm{C}$ NMR spectra were recorded in a $400 \mathrm{MHz}$ Bruker AVANCE and $500 \mathrm{MHz}$ Varian NMR spectrometer, with assistance from Dr. Al Bach. Mass spectra were recorded in a Bruker Omniflex MALDI-TOF instrument with 2,5-dihydroxybenzoic acid as a matrix at the Department of Chemistry Instrumentation Facility (DCIF) at the Massachusetts Institute of Technology (MIT), with samples run by Dr. Li Li. All of the fluorescence measurements were performed using a Shimadzu RF 5301 spectrofluorophotometer. Both the excitation and emission slit widths were $3 \mathrm{~nm}$. All of the fluorescence spectra were integrated vs. wavenumber on the X-axis using Origin Pro Version 9.1

software. All arrays were generated using SYSTAT Version 13.

DETAILED PROCEDURES

DETAILED SYNTHETIC PROCEDURES

Overall Synthetic Scheme: 


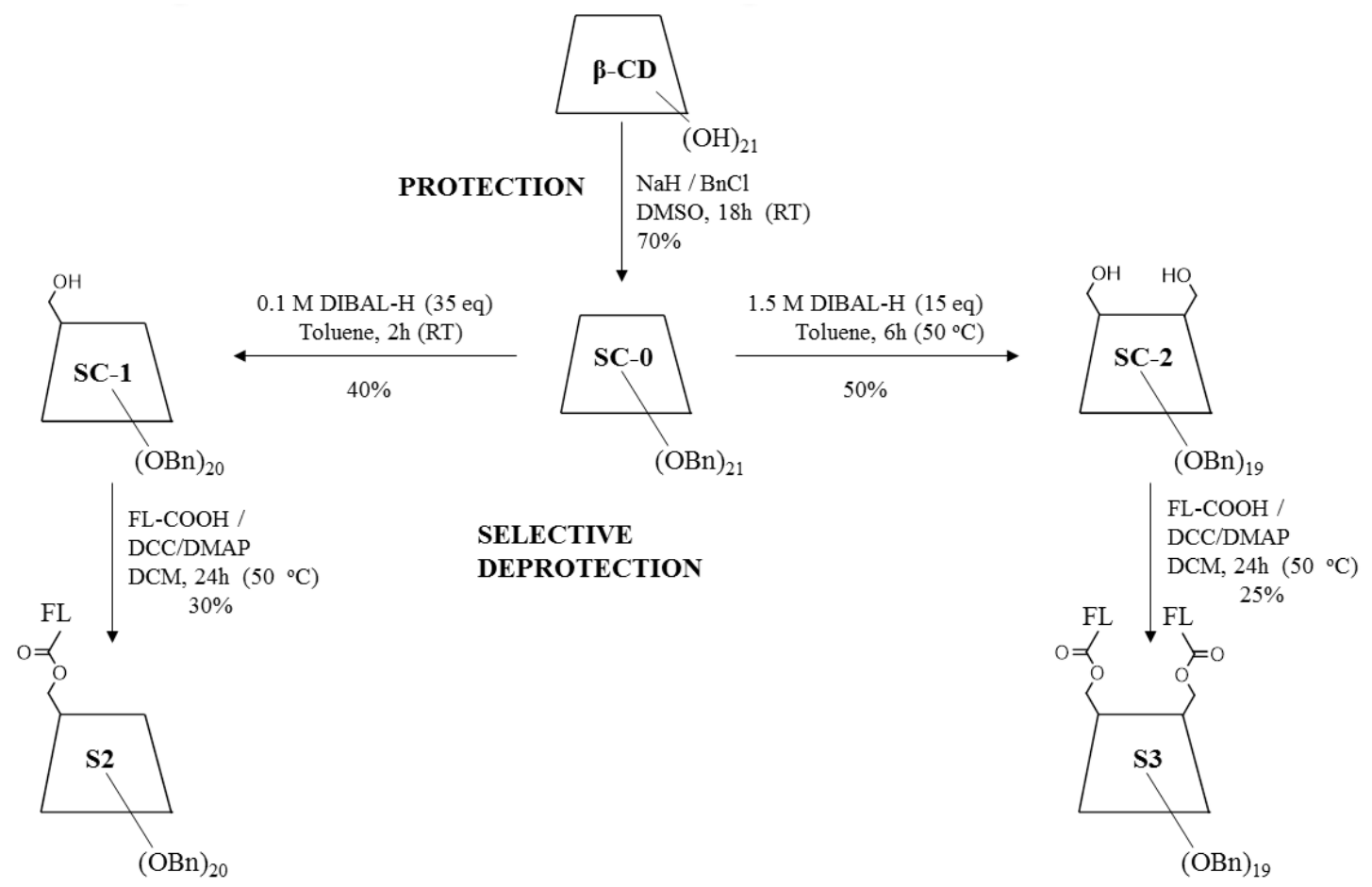

Reaction 1: Synthesis of Perbenzylated $\beta$-Cyclodextrin:
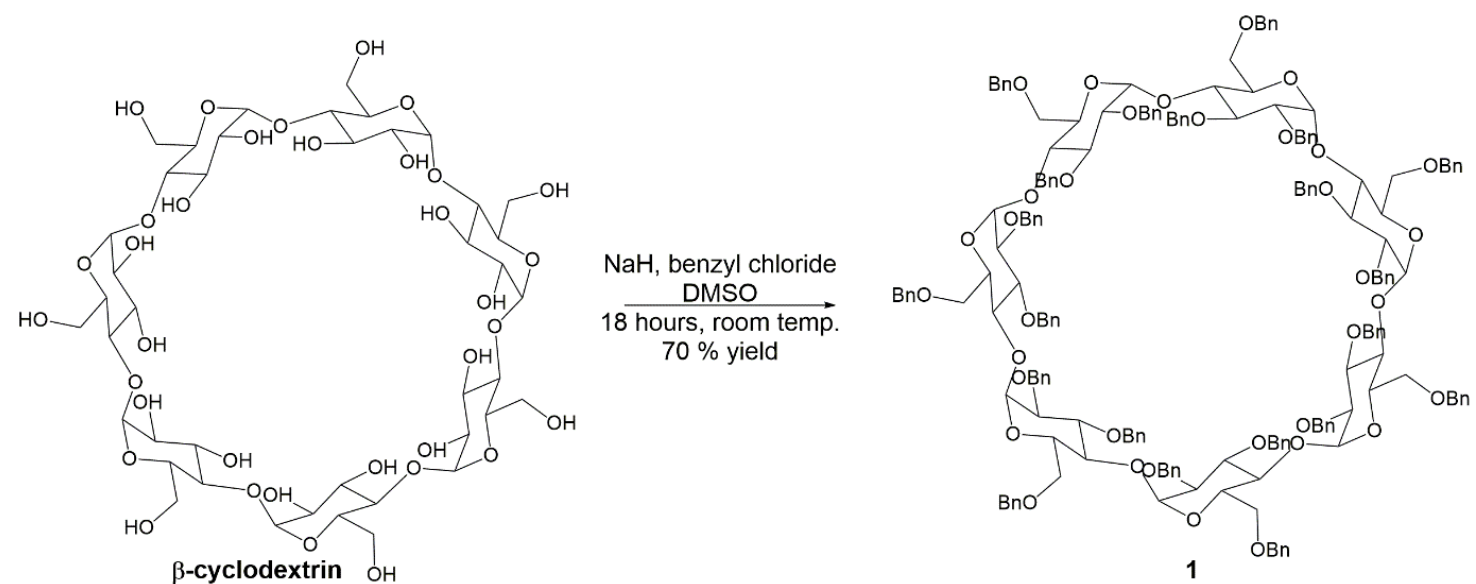

To a stirred solution of oven-dried $\beta$-cyclodextrin ( $2.00 \mathrm{~g}, 1.76 \mathrm{mmol}, 1.0 \mathrm{eq}$.) in DMSO (100 mL) under nitrogen, sodium hydride (2.60 g, $65 \mathrm{mmol}, 36$ eq.) was added carefully. The solution was allowed to stir for one hour at room temperature, after which time benzyl chloride ( $18.5 \mathrm{~mL}, 65 \mathrm{mmol}, 36$ eq.) was added over the course of one hour. The reaction mixture was stirred for 18 hours at room temperature, 
followed by the addition of methanol $(20 \mathrm{~mL})$. The reaction mixture was then diluted with water $(200 \mathrm{~mL})$ and extracted with diethyl ether $(3 \times 200 \mathrm{~mL})$. The combined organic layers were washed with brine $(200 \mathrm{~mL})$, dried with anhydrous $\mathrm{Na}_{2} \mathrm{SO}_{4}$ and concentrated under reduced pressure. The crude product was purified via column chromatography $(25-40 \% \mathrm{v} / \mathrm{v}$ gradient elution of ethyl acetate/hexanes) to obtain a white foamy compound $\mathbf{1}$ (3.6 g, $70 \%$ yield) after being dried under high vacuum. ${ }^{1} \mathrm{H}$ NMR (400 MHz, $\left.\mathrm{CDCl}_{3}\right): \delta=3.52\left(\mathrm{dd},{ }^{3} \mathrm{~J}_{2,3}=9.2 \mathrm{~Hz},{ }^{3} \mathrm{~J}_{2,1}=3.3 \mathrm{~Hz}, 7 \mathrm{H} ; 2-\mathrm{H}\right), 3.58$ $\left(\mathrm{d},{ }^{2} \mathrm{~J}=10.6 \mathrm{~Hz}, 7 \mathrm{H} ; 6-\mathrm{H}\right), 3.98-4.10$ (m, $\left.28 \mathrm{H} ; 3-\mathrm{H}, 4-\mathrm{H}, 5-\mathrm{H}, 6-\mathrm{H}\right), 4.39,4.43$ (AB, $\left.\mathrm{J}_{\mathrm{A}, \mathrm{B}}=12.2 \mathrm{~Hz}, 14 \mathrm{H} ; \mathrm{CH}_{2} \mathrm{Ph}\right), 4.50,4.54\left(\mathrm{AB}, \mathrm{J}_{\mathrm{A}, \mathrm{B}}=12.8 \mathrm{~Hz}, 14 \mathrm{H} ; \mathrm{CH}_{2} \mathrm{Ph}\right), 4.81$, $5.11\left(\mathrm{AB}, \mathrm{J}_{\mathrm{A}, \mathrm{B}}=11.0 \mathrm{~Hz}, 14 \mathrm{H} ; \mathrm{CH}_{2} \mathrm{Ph}\right), 5.22\left(\mathrm{~d},{ }^{3} \mathrm{~J}_{1,2}=3.3 \mathrm{~Hz}, 7 \mathrm{H} ; 1-\mathrm{H}\right), 7.15-7.30$ (m, $105 \mathrm{H}$; aromatic-H) ppm; ${ }^{13} \mathrm{C}$ NMR $(100 \mathrm{MHz}, \mathrm{CDCl} 3): \delta=69.2,71.4,72.6,73.2$, 75.4, 78.6, 78.7, 80.8, 98.4, 126.9-128.3, 138.1, 138.3, 139.2 ppm; MS (MALDITOF): $\mathrm{m} / \mathrm{z}=3050.49[\mathrm{M}+\mathrm{Na}]^{+}\left(\right.$Calculated for $\left.\mathrm{C}_{189} \mathrm{H}_{196} \mathrm{O}_{35}+\mathrm{Na}+=3050.55\right)$.

Reaction 2: Synthesis of Mono-debenzylated $\beta$-cyclodextrin:

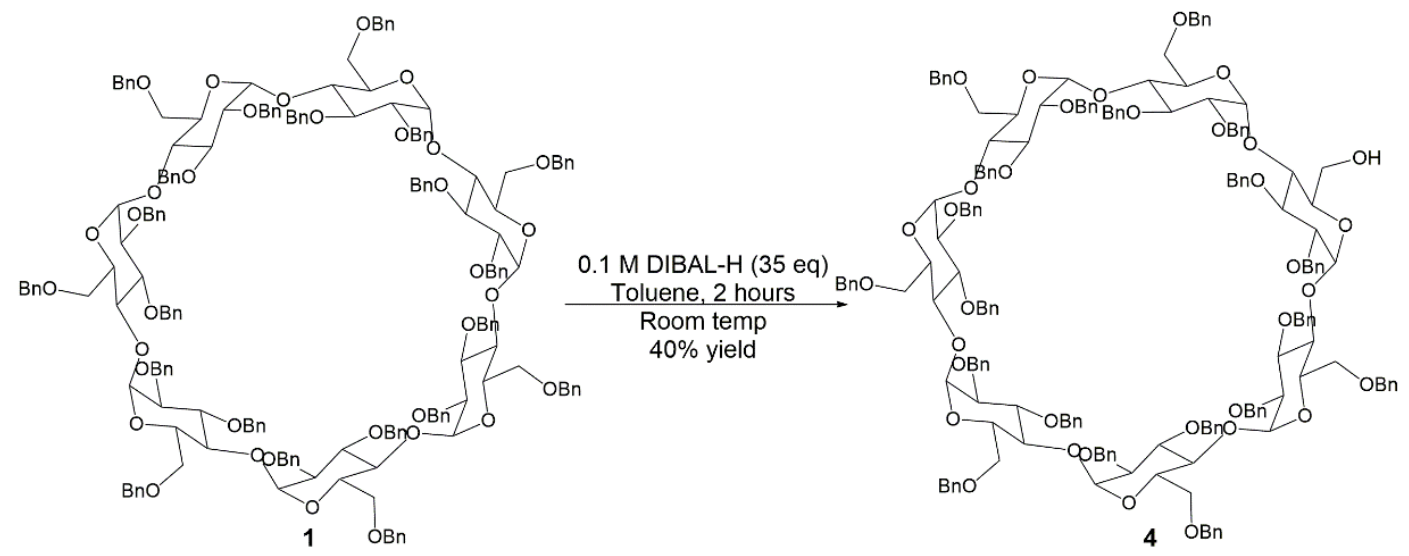

To a stirred solution of compound $\mathbf{1}(600 \mathrm{mg}, 0.2 \mathrm{mmol}, 1.0$ eq.) in anhydrous toluene $(65 \mathrm{~mL})$ under nitrogen, diisobutylaluminum hydride (DIBAL-H) $(4.7 \mathrm{~mL}, 7.0$ mmol, 35 eq.) was added dropwise to a final concentration of $0.1 \mathrm{M}$. The reaction 
mixture was allowed to stir for 2 hours at room temperature, after which the complete disappearance of starting material was observed via TLC analysis (25\% v/v ethyl acetate/hexane). The reaction mixture was cooled to $0{ }^{\circ} \mathrm{C}$ and hydrolyzed via the addition of $10 \%$ aqueous $\mathrm{HCl}(15 \mathrm{~mL})$ for 15 minutes. The crude product was extracted with ethyl acetate $(100 \mathrm{~mL})$, treated with anhydrous $\mathrm{Na}_{2} \mathrm{SO}_{4}$ and dried under reduced pressure. Purification via column chromatography (1:3 ethyl acetate/hexane gradient elution) led to a white compound 4 ( $250 \mathrm{mg}, 40 \%$ yield). ${ }^{1} \mathrm{H}$ NMR (400 MHz, CDCl3): $\delta=2.48$ (br s, $1 \mathrm{H} ; \mathrm{OH}), 3.34-4.07$ (m, $42 \mathrm{H} ; 7 \times 2-\mathrm{H}, 7 \times 3-\mathrm{H}, 7 \times 4-\mathrm{H}$, 7x5-H, 14x6-H), 4.27-4.51 (m, 24H; $\left.\mathrm{CH}_{2} \mathrm{Ph}\right), 4.60-4.75$ (m, 10H; $\left.\mathrm{CH}_{2} \mathrm{Ph}\right), 4.88-5.01$ (m, 6H; 6x1-H), 5.08-5.18 (m, $\left.4 \mathrm{H} ; \mathrm{CH}_{2} \mathrm{Ph}\right), 5.25\left(\mathrm{dd},{ }^{3} \mathrm{~J}_{1,2}=12.0,4.0 \mathrm{~Hz}, 2 \mathrm{H}\right.$; $\left.\mathrm{CH}_{2} \mathrm{Ph}\right), 5.36\left(\mathrm{~d},{ }^{3} \mathrm{~J}_{1,2}=4.0 \mathrm{~Hz}, 1 \mathrm{H} ; 1 \mathrm{x} 1-\mathrm{H}\right), 7.04-7.30$ (m, $100 \mathrm{H}$; aromatic-H) ppm; ${ }^{13} \mathrm{C}$ NMR $(100 \mathrm{MHz}, \mathrm{CDCl} 3): \delta=61.6,68.8,69.2,69.3,69.4,71.4,71.5,71.6,71.7$, 71.7, 71.8, 71.9, 72.5, 72.6, 72.7, 72.7, 72.9, 73.0, 73.3, 73.4, 73.4, 74.8, 75.0, 75.1, 75.3, 75.8, 75.9, 75.9, 76.0, 77.4, 77.7, 78.1, 78.8, 79.0, 79.1, 79.5, 79.6, 79.9, 80.1, 80.9, 81.0, 81.0, 81.1, 98.0, 98.3, 98.4, 98.4, 98.6, 98.8, 98.9, 127.0-128.4, 137.9, 138.1, 138.2, 138.2, 138.2, 138.3, 138.3, 138.4, 138.5, 138.5, 139.0, 139.1, 139.3, 139.3, 139.4, 139.4 ppm; MS (MALDI-TOF): $\mathrm{m} / \mathrm{z}=2960.29[\mathrm{M}+\mathrm{Na}]^{+}$(Calculated for $\left.\mathrm{C}_{182} \mathrm{H}_{190} \mathrm{O}_{35}+\mathrm{Na}=2960.43\right)$.

Reaction 3: Synthesis of Di-debenzylated $\beta$-cyclodextrin: 


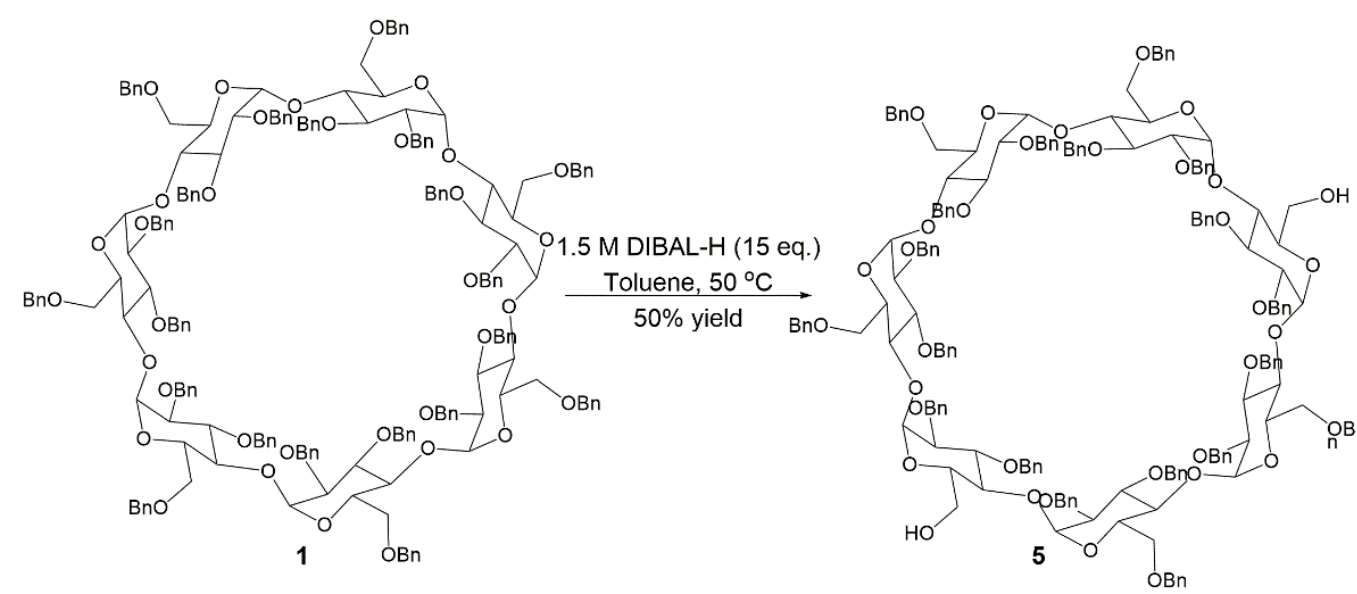

To a stirred solution of compound 1 (1.2 g, $0.4 \mathrm{mmol}, 1.0$ eq.) under nitrogen, DIBAL-H (4.0 mL, $6.0 \mathrm{mmol}, 15$ eq.) was added dropwise. The reaction mixture was stirred for 6 hours at $50{ }^{\circ} \mathrm{C}$ until a complete disappearance of starting material was observed via TLC analysis. After an additional 15 minutes of stirring, the reaction mixture was cooled to $0{ }^{\circ} \mathrm{C}$ and hydrolyzed by vigorously stirring with $10 \%$ aqueous $\mathrm{HCl}(15 \mathrm{~mL})$ for 20 minutes. The crude product was extracted with ethyl acetate (100 $\mathrm{mL}$ ), treated with anhydrous $\mathrm{Na}_{2} \mathrm{SO}_{4}$ and dried under reduced pressure. Purification via column chromatography (1:3 ethyl acetate/hexanes) led to a white compound $\mathbf{5}$ (566 mg, $50 \%$ yield). ${ }^{1} \mathrm{H}$ NMR (400 MHz, $\mathrm{CDCl}_{3}$ ): $\delta=2.69$ (br s, $\left.1 \mathrm{H} ; \mathrm{OH}\right), 2.78$ (br s, $1 \mathrm{H} ; \mathrm{OH}), 3.44-3.54$ (m, $5 \mathrm{H} ; 5 \times 2-\mathrm{H}), 3.60-4.15$ (m, $37 \mathrm{H} ; 2 \times 2-\mathrm{H}, 7 \times 3-\mathrm{H}, 7 \times 4-\mathrm{H}$, 7x5-H, 14x6-H), 4.44-4.88 (m, $\left.33 \mathrm{H} ; \mathrm{CH}_{2} \mathrm{Ph}\right), 4.89\left(\mathrm{~d},{ }^{3} \mathrm{~J}_{1,2}=3.3 \mathrm{~Hz}, 1 \mathrm{H} ; 1-\mathrm{H}\right), 4.98$ $\left(\mathrm{d},{ }^{3} \mathrm{~J}_{1,2}=3.7 \mathrm{~Hz}, 1 \mathrm{H} ; 1-\mathrm{H}\right), 5.00\left(\mathrm{~d},{ }^{3} \mathrm{~J}_{1,2}=4.0 \mathrm{~Hz}, 1 \mathrm{H} ; 1-\mathrm{H}\right), 5.02\left(\mathrm{~d},{ }^{3} \mathrm{~J}_{1,2}=3.4 \mathrm{~Hz}, 1\right.$ $\mathrm{H} ; 1-\mathrm{H}), 5.04\left(\mathrm{~d},{ }^{3} \mathrm{~J}_{1,2}=3.5 \mathrm{~Hz}, 1 \mathrm{H} ; 1-\mathrm{H}\right), 5.06\left(\mathrm{~d},{ }^{2} \mathrm{~J}=12.3 \mathrm{~Hz}, 1 \mathrm{H} ; \mathrm{CH}_{2} \mathrm{Ph}\right), 5.21-$ $5.25\left(\mathrm{~m}, 3 \mathrm{H} ; 3 \times \mathrm{CH}_{2} \mathrm{Ph}\right), 5.30\left(\mathrm{~d},{ }^{2} \mathrm{~J}=10.7 \mathrm{~Hz}, 1 \mathrm{H} ; \mathrm{CH}_{2} \mathrm{Ph}\right), 5.56\left(\mathrm{~d},{ }^{3} \mathrm{~J}_{1,2}=3.8 \mathrm{~Hz}, 1\right.$ $\mathrm{H} ; 1-\mathrm{H}), 5.67\left(\mathrm{~d},{ }^{3} \mathrm{~J}_{1,2}=3.7 \mathrm{~Hz}, 1 \mathrm{H} ; 1-\mathrm{H}\right), 7.12-7.33\left(\mathrm{~m}, 95 \mathrm{H}\right.$; aromatic-H) ppm; ${ }^{13} \mathrm{C}$ NMR $\left(100 \mathrm{MHz}, \mathrm{CDCl}_{3}\right): \delta=61.6,69.5,69.6,71.2,71.6,72.0,72.1,72.9,73.2$, 
73.25, 73.3, 73.9, 74.1, 76.1, 76.4, 77.6, 79.0, 79.7, 80.6, 80.9, 81.0, 81.6, 81.7, 97.6, 97.7, 98.2, 126.3-128.3, 137.7, 137.8, 137.9, 138.2, 138.6, 137.7, 139.2 ppm; MS (MALDI-TOF): $\mathrm{m} / \mathrm{z}=2870.1[\mathrm{M}+\mathrm{Na}]^{+}\left(\right.$Calculated for $\left.\mathrm{C}_{175} \mathrm{H}_{184} \mathrm{O}_{35}+\mathrm{Na}=2870.31\right)$.

Reaction 4: Synthesis of Sensor S2:

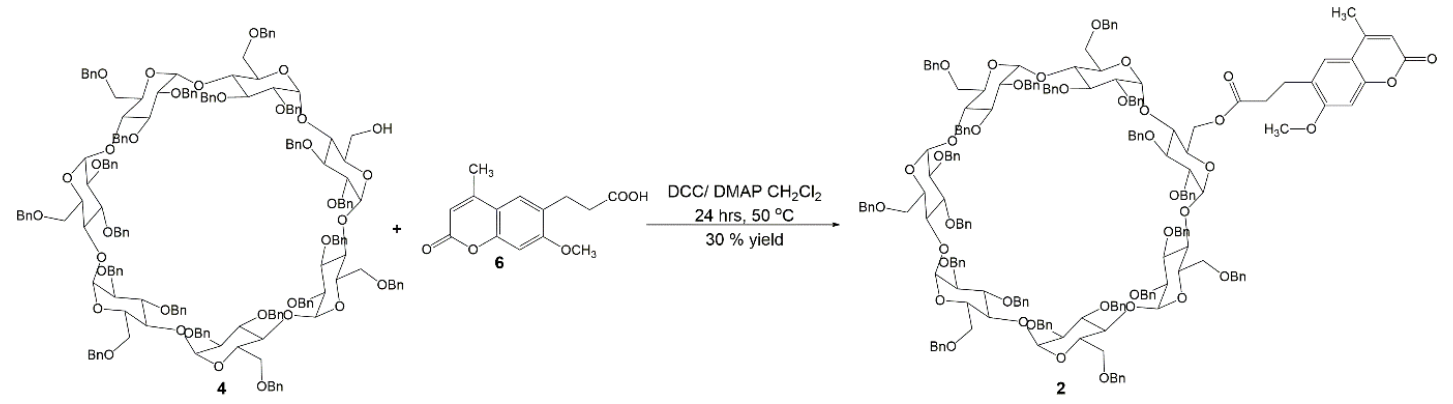

A mixture of compound 4 (100 mg, $0.034 \mathrm{mmol}, 1.0$ eq.), compound 6 (10.5 $\mathrm{mg}, 0.04 \mathrm{mmol}, 1.17$ eq.), $N, N^{\prime}$-dicyclohexylcarbodiimide (DCC) $(8.3 \mathrm{mg}, 0.04 \mathrm{mmol}$, 1.17 eq.) and 4-dimethylaminopyridine (DMAP) (0.5 mg, $0.004 \mathrm{mmol}, 0.1$ eq.) in dichloromethane $(1 \mathrm{~mL})$ was stirred at $50{ }^{\circ} \mathrm{C}$ for $24 \mathrm{hrs}$. The mixture was filtered, treated with 5\% aqueous acetic acid $(2 \times 3 \mathrm{~mL})$ and extracted with dichloromethane $(2$ x $4 \mathrm{~mL}$ ). The combined organic layer was dried under anhydrous $\mathrm{Na}_{2} \mathrm{SO}_{4}$ and subjected to solvent removal under reduced pressure. The crude product was purified via column chromatography (1:3 ethyl acetate/hexanes) to yield a white amorphous compound 2 (32 mg, 30\% yield). ${ }^{1} \mathrm{H}$ NMR (500 MHz, $\mathrm{d}_{6}$-acetone): $\delta=2.31$ (s, $3 \mathrm{H}$; $\left.\mathrm{ArCH}_{3}\right), 2.62\left(\mathrm{~m}, 2 \mathrm{H} ; \mathrm{CH}_{2} \mathrm{FL} 3\right), 2.93\left(\mathrm{t},{ }^{3} \mathrm{~J}_{1,2}={ }^{3} \mathrm{~J}_{1,2^{2}}=10.0 \mathrm{~Hz}, 2 \mathrm{H} ; \mathrm{CH}_{2} \mathrm{CHFL} 3\right)$, 3.43-3.50 (m, 7 H; 2-H), 3.62-3.74 (m, 7 H; 6-H), 3.84 (br t, 2 H; 6-H), 3.89 (s, 3 H; $\left.\mathrm{OCH}_{3}\right)$, 3.92-4.16 (m, $\left.26 \mathrm{H} ; 3-\mathrm{H}, 4-\mathrm{H}, 5-\mathrm{H}, 6-\mathrm{H}\right), 4.40-4.62$ (m, $\left.26 \mathrm{H} ; \mathrm{CH}_{2} \mathrm{Ph}\right), 4.75-$ 4.78 (m, $\left.7 \mathrm{H} ; \mathrm{CH}_{2} \mathrm{Ph}\right), 5.09-5.13\left(\mathrm{~m}, 7 \mathrm{H} ; \mathrm{CH}_{2} \mathrm{Ph}\right), 5.16\left(\mathrm{~d},{ }^{3} \mathrm{~J}_{1,2}=3.5 \mathrm{~Hz}, 1 \mathrm{H} ; 1-\mathrm{H}\right)$, $5.27\left(\mathrm{dd},{ }^{3} \mathrm{~J}_{1,2}=10,3.5 \mathrm{~Hz}, 2 \mathrm{H} ; 1-\mathrm{H}\right), 5.30(\mathrm{~m}, 3 \mathrm{H} ; 1-\mathrm{H}), 5.33\left(\mathrm{~d},{ }^{3} \mathrm{~J}_{1,2}=3.5 \mathrm{~Hz}, 1 \mathrm{H}\right.$; 
1-H), 6.02 (s, $\left.1 \mathrm{H} ; \mathrm{CH}=\mathrm{CCH}_{3}\right), 6.86(\mathrm{~s}, 1 \mathrm{H} ; \mathrm{ArH}), 7.12-7.33$ (m, $\left.80 \mathrm{H} ; \mathrm{PhH}\right), 7.48$ (s, $1 \mathrm{H}$; ArH) ppm; ${ }^{13} \mathrm{C}$ NMR (125 MHz, $\mathrm{d}_{6}$-acetone): $\delta=17.8,25.3,33.6,55.7,63.5$, $69.5,69.8,71.7,71.9,72.4,72.7,73.0,75.2,78.3-79.4,80.8-81.1,97.8-98.0,98.2$, 98.7, 98.7, 111.5, 112.8, 124.5, 125.6, 126.8, 127.29-128.25, 138.6, 138.7-138.8, 139.5-139.6, 152.8, 154.3, 160.1, 160.6, $172.0 \mathrm{ppm} ;$ MS (MALDI-TOF): $\mathrm{m} / \mathrm{z}=$ $3204.57[\mathrm{M}+\mathrm{Na}]^{+}$(Calculated for $\mathrm{C}_{196} \mathrm{H}_{202} \mathrm{O}_{39}+\mathrm{Na}=3204.67$ ).

Reaction 5: Synthesis of Sensor S3:

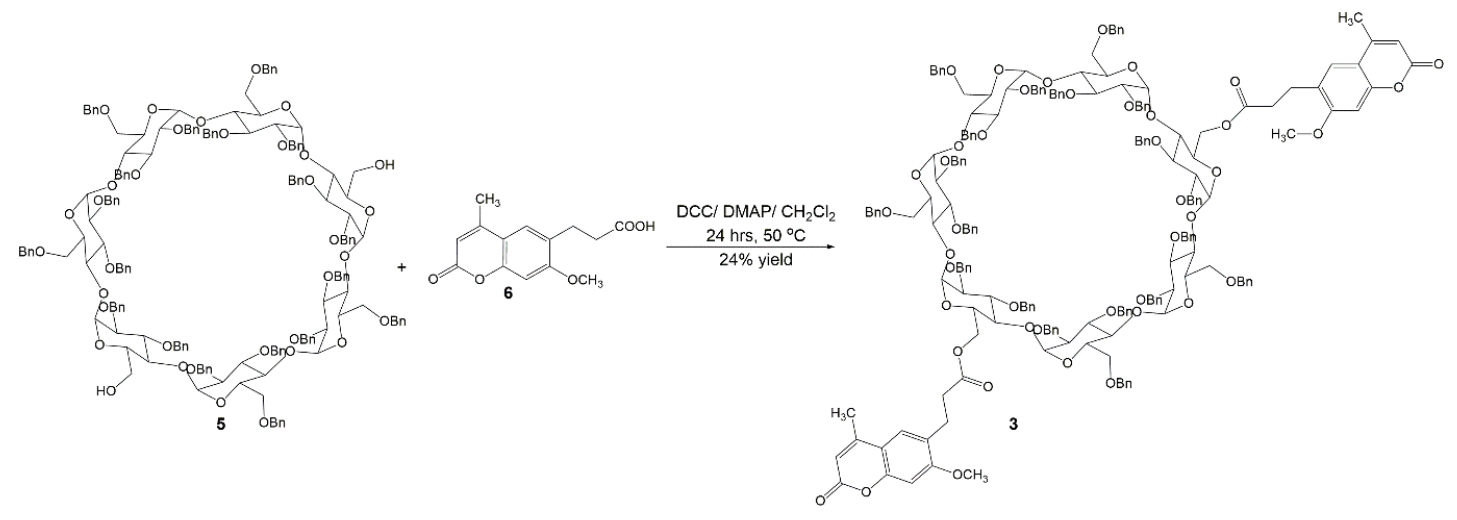

A mixture of compound 5 (100 mg, $0.035 \mathrm{mmol}, 1.0$ eq.), compound 6 (21.0 mg, 0.08 mmol, 2.34 eq.), $N, N$ '-dicyclohexylcarbodiimide (16.5 mg, $0.08 \mathrm{mmol}, 2.34$ eq.) and 4-dimethylaminopyridine $(1.1 \mathrm{mg}, 0.008 \mathrm{mmol}, 0.2 \mathrm{eq}$.$) in dichloromethane (1 \mathrm{~mL})$ was stirred at $50{ }^{\circ} \mathrm{C}$ for $24 \mathrm{hrs}$. The mixture was filtered, treated with $5 \%$ aqueous acetic acid $(2 \times 3 \mathrm{~mL})$ and extracted with dichloromethane $(2 \times 4 \mathrm{~mL})$. The combined organic layer was dried under anhydrous $\mathrm{Na}_{2} \mathrm{SO}_{4}$ and subjected to solvent removal under reduced pressure. The crude product was purified via column chromatography (1:3 ethyl acetate: hexanes) to lead to a white amorphous compound 3 (30 mg, $25 \%$ yield). ${ }^{1} \mathrm{H}$ NMR $\left(500 \mathrm{MHz}, \mathrm{d}_{6}\right.$-acetone): $\delta=2.31\left(\mathrm{~s}, 6 \mathrm{H}\right.$; $\left.\mathrm{ArCH}_{3}\right), 2.62(\mathrm{~m}, 4 \mathrm{H}$; CHFL3), 2.93 (m, 4 H; CHCHFL3), 3.44-3.51 (m, 7 H; 2-H), 3.62-3.74 (m, 7 H; 6-H), 3.82-3.89 (multiplet overlapped, $4 \mathrm{H}$; 6-H), 3.89 (singlet overlapped, $6 \mathrm{H}$; $\mathrm{OCH}_{3}$ ), 
3.94-4.16 (m, $24 \mathrm{H}$; 3-H, 4-H, 5-H, 6-H), 4.41-4.64 (m, 26H; $\left.\mathrm{CH}_{2} \mathrm{Ph}\right), 4.74-4.78$ (m, $\left.6 \mathrm{H} ; \mathrm{CH}_{2} \mathrm{Ph}\right), 5.08-5.12\left(\mathrm{~m}, 6 \mathrm{H} ; \mathrm{CH}_{2} \mathrm{Ph}\right), 5.22\left(\mathrm{dd},{ }^{3} \mathrm{~J}_{1,2}=8.5,3.5 \mathrm{~Hz}, 2 \mathrm{H} ; 1-\mathrm{H}\right), 5.26$ (m, $3 \mathrm{H} ; 1-\mathrm{H}), 5.29$ (m, $2 \mathrm{H} ; 1-\mathrm{H}), 6.01$ (s, $\left.2 \mathrm{H} ; \mathrm{CH}=\mathrm{CCH}_{3}\right), 6.86$ (s, $\left.2 \mathrm{H} ; \mathrm{ArH}\right), 7.06-$ 7.30 (m, $80 \mathrm{H} ; \mathrm{PhH}), 7.46\left(\mathrm{~d},{ }^{3} \mathrm{~J}_{1,2}=6.5 \mathrm{~Hz}, 2 \mathrm{H} ; \mathrm{ArH}\right) \mathrm{ppm} ;{ }^{13} \mathrm{C} \mathrm{NMR}\left(125 \mathrm{MHz}, \mathrm{d}_{6^{-}}\right.$ acetone): $\delta=17.8,24.6,25.2-25.4,25.6,25.8,30.6,32.1,33.5,34.1,55.7,63.5,69.3-$ 69.8, 71.6-73.1, 75.2, 78.3-79.4, 80.7-81.0, 97.9-98.7, 111.5, 112.7, 125.4-125.5, $126.8,127.3-128.3,138.6,138.7-138.8,139.4-139.6,152.7,154.3,160.0,160.6,172.1$ ppm; MS (MALDI-TOF): $\mathrm{m} / \mathrm{z}=3358.82[\mathrm{M}+\mathrm{Na}]^{+}\left(\right.$Calculated for $\mathrm{C}_{203} \mathrm{H}_{208} \mathrm{O}_{43}+\mathrm{Na}=$ 3358.40).

\section{DETAILED PROCEDURES FOR FLUORESCENCE MODULATION EXPERIMENTS}

Fluorescence emission spectra were obtained using a Shimadzu RF-5301PC spectrophotofluorimeter with $3 \mathrm{~nm}$ excitation and $3 \mathrm{~nm}$ emission slit widths. In a quartz cuvette, $0.5 \mathrm{~mL}$ of $\mathbf{S 1}, \mathbf{S 2}$, or $\mathbf{S 3}$ solutions ( $5 \mu \mathrm{M}$ in DMSO) and $2 \mathrm{~mL}$ of deionized water were combined. Then, the solution was excited at $320 \mathrm{~nm}$, and the fluorescence emission spectra were recorded. Repeat measurements were recorded for four separate trials.

The fluorescence emission spectra were integrated vs. wavenumber on the $\mathrm{X}$ axis, and fluorescence modulation was measured by the ratio of integrated emission of the fluorophore in the presence of the analyte to integrated emission of the fluorophore in the absence of the analyte, as shown in Equation 1:

Fluorescence Modulation $=F l_{\text {analyte }} F l_{\text {blank }}$ 
Where $F l_{\text {analyte }}$ is the integrated fluorescence emission of the fluorophore in the presence of $10 \mu \mathrm{L}$ of analyte $(1 \mathrm{mg} / \mathrm{mL}$ in $\mathrm{THF})$, and $F l_{\text {blank }}$ is the integrated fluorescence emission of the fluorophore in the absence of the analyte.

\section{DETAILED PROCEDURES FOR ARRAY GENERATION EXPERIMENTS}

Array analysis was performed using SYSTAT 13 statistical computing software with the following settings:

(a) Classical Discriminant Analysis

(b) Grouping variable: Analytes

(c) Predictors: S1, S2, and S3

(d) Long-range statistics: Mahal

\section{DETAILED PROCEDURES FOR LIMIT OF DETECTION EXPERIMENTS}

The limit of detection (LOD) is defined as the lowest concentration of analyte at which a signal can be detected. To determine this value, the following steps were performed for each cyclodextrin-analyte combination. In a quartz cuvette, $0.5 \mathrm{~mL}$ of S1, S2, or S3 solutions (5 $\mu \mathrm{M}$ in DMSO) and $2 \mathrm{~mL}$ of deionized (DI) water were combined. Then, the solution was excited at $320 \mathrm{~nm}$, and the fluorescence emission spectra were recorded starting at $330 \mathrm{~nm}$. Six repeat measurements were taken.

Next, $2 \mu \mathrm{L}$ of analyte $(1 \mathrm{mg} / \mathrm{mL}$ in $\mathrm{THF})$ was added, and again the solution was excited at the fluorophore's excitation wavelength, and the fluorescence emission spectra were recorded. Six repeat measurements were taken. This step was repeated

for $4 \mu \mathrm{L}$ of analyte, $6 \mu \mathrm{L}$ of analyte, $8 \mu \mathrm{L}$ of analyte, $10 \mu \mathrm{L}$ of analyte, $12 \mu \mathrm{L}$ of analyte, $14 \mu \mathrm{L}$ of analyte, $16 \mu \mathrm{L}$ of analyte, $18 \mu \mathrm{L}$ of analyte, $20 \mu \mathrm{L}$ of analyte. 
All of the fluorescence emission spectra were integrated vs. wavenumber on the X-axis, and calibration curves were generated. The curves plotted the analyte concentration in $\mu \mathrm{M}$ on the $\mathrm{X}$-axis, and the fluorescence modulation ratio on the $\mathrm{Y}$ axis. The curve was fitted to a straight line and the equation of the line was determined.

The limit of detection is defined according to Equation 2:

$\mathrm{LOD}=3\left(\mathrm{SD}_{\text {blank }}\right) / m$

Where $\mathrm{SD}_{\text {blank }}$ is the standard deviation of the blank sample and $m$ is the slope of the calibration curve. In cases where the slope of the trendline was negative, the absolute value of the slope was used to calculate the LOD. In all cases, the LOD was calculated in $\mu \mathrm{M}$.

SUMMARY TABLES

FLUORESCENCE MODULATION SUMMARY TABLES

\begin{tabular}{|c|c|c|c|}
\hline Analyte & S1 & S2 & S3 \\
\hline benzyl alcohol & $1.00 \pm 0.00$ & $1.04 \pm 001$ & $0.98 \pm 0.01$ \\
\hline$o$-cresol & $1.01 \pm 0.00$ & $0.82 \pm 0.01$ & $0.88 \pm 0.01$ \\
\hline$m$-cresol & $0.99 \pm 0.00$ & $0.90 \pm 0.00$ & $1.05 \pm 0.02$ \\
\hline$p$-cresol & $1.01 \pm 0.01$ & $0.87 \pm 0.01$ & $0.75 \pm 0.01$ \\
\hline
\end{tabular}

\begin{tabular}{|c|c|c|c|}
\hline Analyte & S1 & S2 & S3 \\
\hline 1-methylcyclohexanol & $1.01 \pm 0.00$ & $0.89 \pm 0.00$ & $1.07 \pm 0.05$ \\
\hline cis -2-methylcyclohexanol & $1.01 \pm 0.00$ & $0.90 \pm 0.00$ & $0.97 \pm 0.01$ \\
\hline cyclohexylmethanol & $1.01 \pm 0.00$ & $0.99 \pm 0.03$ & $0.77 \pm 0.06$ \\
\hline trans -2-methylcyclohexanol & $0.99 \pm 0.00$ & $0.89 \pm 0.00$ & $1.14 \pm 0.01$ \\
\hline
\end{tabular}




\begin{tabular}{|c|c|c|c|}
\hline Analyte & S1 & S2 & S3 \\
\hline DDD & $1.00 \pm 0.00$ & $0.93 \pm 0.01$ & $1.33 \pm 0.03$ \\
\hline DDE & $1.01 \pm 0.00$ & $0.95 \pm 0.01$ & $1.07 \pm 0.04$ \\
\hline$o, p-\mathrm{DDT}$ & $0.99 \pm 0.01$ & $1.08 \pm 0.01$ & $1.04 \pm 0.05$ \\
\hline$p, p-\mathrm{DDT}$ & $0.98 \pm 0.01$ & $1.17 \pm 0.01$ & $1.35 \pm 0.05$ \\
\hline
\end{tabular}

\begin{tabular}{|c|c|c|c|}
\hline Analyte & S1 & S2 & S3 \\
\hline$n$-hexanes & $1.00 \pm 0.00$ & $1.01 \pm 0.01$ & $0.94 \pm 0.02$ \\
\hline 2-methylpentane & $1.05 \pm 0.00$ & $1.06 \pm 0.00$ & $0.93 \pm 0.02$ \\
\hline 3-methylentane & $0.98 \pm 0.00$ & $1.09 \pm 0.01$ & $0.95 \pm 0.02$ \\
\hline 2,3-dimethylbutane & $1.00 \pm 0.00$ & $0.99 \pm 0.01$ & $1.01 \pm 0.01$ \\
\hline 1-methylcyclopentane & $1.03 \pm 0.01$ & $1.03 \pm 0.02$ & $0.89 \pm 0.01$ \\
\hline
\end{tabular}

\begin{tabular}{|c|c|c|c|}
\hline Analyte & S1 & S2 & S3 \\
\hline PCB3 & $1.03 \pm 0.00$ & $1.06 \pm 0.06$ & $0.85 \pm 0.01$ \\
\hline PCB29 & $1.01 \pm 0.01$ & $1.02 \pm 0.04$ & $0.98 \pm 0.03$ \\
\hline PCB52 & $1.01 \pm 0.00$ & $1.07 \pm 0.04$ & $0.89 \pm 0.02$ \\
\hline PCB77 & $1.05 \pm 0.00$ & $0.56 \pm 0.01$ & $0.98 \pm 0.01$ \\
\hline PCB209 & $1.00 \pm 0.01$ & $0.92 \pm 0.03$ & $1.14 \pm 0.02$ \\
\hline
\end{tabular}




\section{LIMIT OF DETECTION SUMMARY TABLE}

\begin{tabular}{|c|c|c|c|c|}
\hline Analyte & Host & Equation & $\mathbf{R}^{\mathbf{2}}$ & $\mathbf{L O D}(\boldsymbol{\mu M})$ \\
\hline$p, p$-DDT & S1 & $\mathrm{y}=0.0094 \mathrm{x}+1.0385$ & 0.939 & 0.39 \\
\hline$p, p$-DDT & S2 & $\mathrm{y}=0.011 \mathrm{x}+0.971$ & 0.9406 & 0.51 \\
\hline$p, p$-DDT & S3 & $\mathrm{y}=0.0188 \mathrm{x}+0.9592$ & 0.9547 & 2.20 \\
\hline$o$-Cresol & S1 & $\mathrm{y}=0.0018 \mathrm{x}+1.0195$ & 0.9748 & 4.97 \\
\hline Benzyl alcohol & S2 & $\mathrm{y}=0.0032 \mathrm{x}+0.932$ & 0.8521 & 8.34 \\
\hline$o$-Cresol & S3 & $\mathrm{y}=-0.0026 \mathrm{x}+0.7242$ & 0.9893 & 11.79 \\
\hline Cyclohexylmethanol & S1 & $\mathrm{y}=0.01 \mathrm{x}+0.9866$ & 0.9708 & 1.17 \\
\hline Cyclohexylmethanol & $\mathbf{S 2}$ & $\mathrm{y}=-0.0031 \mathrm{x}+0.9648$ & 0.9405 & 1.85 \\
\hline 1-Methylcyclohexanol & $\mathbf{S 3}$ & $\mathrm{y}=0.0012 \mathrm{x}+0.942$ & 0.9236 & 26.30 \\
\hline 2-Methylpentane & $\mathbf{S 1}$ & $\mathrm{y}=0.0026 \mathrm{x}+0.9776$ & 0.9555 & 2.20 \\
\hline 3-Methylpentane & $\mathbf{S 2}$ & $\mathrm{y}=0.0017 \mathrm{x}+1.0775$ & 0.9864 & 15.74 \\
\hline 1-Methylcyclopentane & $\mathbf{S 3}$ & $\mathrm{y}=0.0038 \mathrm{x}+0.7209$ & 0.9421 & 19.82 \\
\hline PCB 77 & $\mathbf{S 1}$ & $\mathrm{y}=0.0116 \mathrm{x}+1.0153$ & 0.8832 & 0.29 \\
\hline PCB 209 & $\mathbf{S 2}$ & $\mathrm{y}=-0.0077 \mathrm{x}+0.8402$ & 0.9655 & 0.88 \\
\hline PCB 209 & $\mathbf{S 3}$ & $\mathrm{y}=0.0079 \mathrm{x}+1.0621$ & 0.8686 & 4.59 \\
\hline
\end{tabular}

\section{SUMMARY TABLES FOR ARRAYS}

All analytes

\begin{tabular}{|c|c|c|c|c|c|c|c|}
\hline & $\begin{array}{r}\text { 1-methylcyclohe- } \\
\text { xanol }\end{array}$ & $\begin{array}{r}\text { 1-methylcyclope- } \\
\text { ntane }\end{array}$ & $\begin{array}{r}2,3 \text {-dimethylbut- } \\
\text { ane }\end{array}$ & 2-methylpentane & 3-methylpentane & DDD & DDE \\
\hline 1-methylcyclohexanol & 4 & 0 & 0 & 0 & 0 & 0 & 0 \\
\hline 1-methylcyclopentane & 0 & 4 & 0 & 0 & 0 & 0 & 0 \\
\hline 2,3-dimethylbutane & 0 & 0 & 4 & 0 & 0 & 0 & 0 \\
\hline 2-methylpentane & 0 & 0 & 0 & 4 & 0 & 0 & 0 \\
\hline 3-methylpentane & 0 & 0 & 0 & 0 & 4 & 0 & 0 \\
\hline DDD & 0 & 0 & 0 & 0 & 0 & 4 & 0 \\
\hline DDE & 0 & 0 & 0 & 0 & 0 & 0 & 4 \\
\hline benzyl alcohol & 0 & 0 & 0 & 0 & 0 & 0 & 0 \\
\hline cis-2methylcyclohexanol & 0 & 0 & 0 & 0 & 0 & 0 & 0 \\
\hline cyclohexylmethanol & 0 & 0 & 0 & 0 & 0 & 0 & 0 \\
\hline m-cresol & 0 & 0 & 0 & 0 & 0 & 0 & 0 \\
\hline n-hexanes & 0 & 0 & 0 & 0 & 0 & 0 & 0 \\
\hline o-cresol & 0 & 0 & 0 & 0 & 0 & 0 & 0 \\
\hline opDDT & 0 & 0 & 0 & 0 & 0 & 0 & 0 \\
\hline p-cresol & 0 & 0 & 0 & 0 & 0 & 0 & 0 \\
\hline pcb209 & 0 & 0 & 0 & 0 & 0 & 0 & 0 \\
\hline pcb29 & 0 & 0 & 0 & 0 & 0 & 0 & 0 \\
\hline pcb3 & 0 & 0 & 0 & 0 & 0 & 0 & 0 \\
\hline pcb52 & 0 & 0 & 0 & 0 & 0 & 0 & 0 \\
\hline pcb77 & 0 & 0 & 0 & 0 & 0 & 0 & 0 \\
\hline ppDDT & 0 & 0 & 0 & 0 & 0 & 0 & 0 \\
\hline trans-2methylcyclohexano & 0 & 0 & 0 & 0 & 0 & 0 & 0 \\
\hline Total & 4 & 4 & 4 & 4 & 4 & 4 & 4 \\
\hline
\end{tabular}




\begin{tabular}{|c|c|c|c|c|c|c|c|c|c|}
\hline & benzyl alcohol & $\begin{array}{r}\text { cis-2methylcycl- } \\
\text { ohexanol }\end{array}$ & $\begin{array}{r}\text { cyclohexylmetha- } \\
\text { nol }\end{array}$ & m-cresol & n-hexanes & o-cresol & opDDT & p-cresol & pcb209 \\
\hline 1-methylcyclohexanol & 0 & 0 & 0 & 0 & 0 & 0 & 0 & 0 & 0 \\
\hline 1-methylcyclopentane & 0 & 0 & 0 & 0 & 0 & 0 & 0 & 0 & 0 \\
\hline 2,3-dimethylbutane & 0 & 0 & 0 & 0 & 0 & 0 & 0 & 0 & 0 \\
\hline 2-methylpentane & 0 & 0 & 0 & 0 & 0 & 0 & 0 & 0 & 0 \\
\hline 3-methylpentane & 0 & 0 & 0 & 0 & 0 & 0 & 0 & 0 & 0 \\
\hline DDD & 0 & 0 & 0 & 0 & 0 & 0 & 0 & 0 & 0 \\
\hline DDE & 0 & 0 & 0 & 0 & 0 & 0 & 0 & 0 & 0 \\
\hline benzyl alcohol & 4 & 0 & 0 & 0 & 0 & 0 & 0 & 0 & 0 \\
\hline cis-2methylcyclohexanol & 0 & 4 & 0 & 0 & 0 & 0 & 0 & 0 & 0 \\
\hline cyclohexylmethanol & 0 & 0 & 4 & 0 & 0 & 0 & 0 & 0 & 0 \\
\hline m-cresol & 0 & 0 & 0 & 4 & 0 & 0 & 0 & 0 & 0 \\
\hline n-hexanes & 0 & 0 & 0 & 0 & 4 & 0 & 0 & 0 & 0 \\
\hline o-cresol & 0 & 0 & 0 & 0 & 0 & 4 & 0 & 0 & 0 \\
\hline opDDT & 0 & 0 & 0 & 0 & 0 & 0 & 4 & 0 & 0 \\
\hline p-cresol & 0 & 0 & 0 & 0 & 0 & 0 & 0 & 4 & 0 \\
\hline pcb209 & 0 & 0 & 0 & 0 & 0 & 0 & 0 & 0 & 4 \\
\hline pcb29 & 0 & 0 & 0 & 0 & 0 & 0 & 0 & 0 & 0 \\
\hline pcb3 & 0 & 0 & 0 & 0 & 0 & 0 & 0 & 0 & 0 \\
\hline pcb52 & 0 & 0 & 0 & 0 & 0 & 0 & 0 & 0 & 0 \\
\hline pcb77 & 0 & 0 & 0 & 0 & 0 & 0 & 0 & 0 & 0 \\
\hline ppDDT & 0 & 0 & 0 & 0 & 0 & 0 & 0 & 0 & 0 \\
\hline trans-2methylcyclohexano & 0 & 0 & 0 & 0 & 0 & 0 & 0 & 0 & 0 \\
\hline Total & 4 & 4 & 4 & 4 & 4 & 4 & 4 & 4 & 4 \\
\hline
\end{tabular}

Jackknifed Classification Matrix (Contd.)

\begin{tabular}{|l|r|r|r|r|r|r|r|}
\hline & pcb29 & pcb3 & pcb52 & pcb77 & ppDDT & trans-2methylcy- & \%correct \\
clohexano & & 0 & 100 \\
\hline 1-methylcyclohexanol & 0 & 0 & 0 & 0 & 0 & 0 & 100 \\
\hline 1-methylcyclopentane & 0 & 0 & 0 & 0 & 0 & 0 & 100 \\
\hline 2,3-dimethylbutane & 0 & 0 & 0 & 0 & 0 & 0 & 100 \\
\hline 2-methylpentane & 0 & 0 & 0 & 0 & 0 & 0 & 100 \\
\hline 3-methylpentane & 0 & 0 & 0 & 0 & 0 & 0 & 100 \\
\hline DDD & 0 & 0 & 0 & 0 & 0 & 0 & 100 \\
\hline DDE & 0 & 0 & 0 & 0 & 0 & 0 & 100 \\
\hline benzyl alcohol & 0 & 0 & 0 & 0 & 0 & 0 & 100 \\
\hline cis-2methylcyclohexanol & 0 & 0 & 0 & 0 & 0 & 0 & 100 \\
\hline cyclohexylmethanol & 0 & 0 & 0 & 0 & 0 & 0 & 100 \\
\hline m-cresol & 0 & 0 & 0 & 0 & 0 & 0 & 100 \\
\hline n-hexanes & 0 & 0 & 0 & 0 & 0 & 0 & 100 \\
\hline 0-cresol & 0 & 0 & 0 & 0 & 0 & 0 & 100 \\
\hline opDDT & 0 & 0 & 0 & 0 & 0 & 0 & 100 \\
\hline p-cresol & 0 & 0 & 0 & 0 & 0 & 0 & 100 \\
\hline pcb209 & 0 & 0 & 0 & 0 & 0 & 0 & 100 \\
\hline pcb29 & 4 & 0 & 0 & 0 & 0 & 0 & 100 \\
\hline pcb3 & 0 & 4 & 0 & 0 & 0 & 0 & 100 \\
\hline pcb52 & 0 & 0 & 4 & 0 & 0 & 0 & 100 \\
\hline pcb77 & 0 & 0 & 0 & 4 & 0 & 0 & 100 \\
\hline ppDDT & 0 & 0 & 0 & 0 & 4 & 4 & 100 \\
\hline trans-2methylcyclohexano & 0 & 0 & 0 & 0 & 0 & 100 \\
\hline Total & 4 & 4 & 4 & 4 & 4 & 0 & 0 \\
\hline
\end{tabular}

Cumulative Proportion of Total Dispersion

\begin{tabular}{|l|l|l|}
\hline 0.908 & 0.994 & 1.000 \\
\hline
\end{tabular}

Aromatic alcohols 
Jackknifed Classification Matrix

\begin{tabular}{|l|r|r|r|r|r|}
\hline & benzyl alcohol & m-cresol & 0-cresol & p-cresol & \%correct \\
\hline benzyl alcohol & 4 & 0 & 0 & 0 & 100 \\
\hline m-cresol & 0 & 4 & 0 & 0 & 100 \\
\hline o-cresol & 0 & 0 & 4 & 0 & 100 \\
\hline p-cresol & 0 & 0 & 0 & 4 & 100 \\
\hline Total & 4 & 4 & 4 & 4 & 100 \\
\hline
\end{tabular}

Cumulative Proportion of Total Dispersion

\begin{tabular}{|l|l|l|}
\hline 0.859 & 0.950 & 1.000 \\
\hline
\end{tabular}

Pesticides

Jackknifed Classification Matrix

\begin{tabular}{|l|r|r|r|r|r|}
\hline & DDD & DDE & opDDT & ppDDT & \%correct \\
\hline DDD & 4 & 0 & 0 & 0 & 100 \\
\hline DDE & 0 & 4 & 0 & 0 & 100 \\
\hline opDDT & 0 & 0 & 4 & 0 & 100 \\
\hline ppDDT & 0 & 0 & 0 & 4 & 100 \\
\hline Total & 4 & 4 & 4 & 4 & 100 \\
\hline
\end{tabular}

Cumulative Proportion of Total Dispersion

\begin{tabular}{|l|l|l|}
\hline 0.995 & 1.000 & 1.000 \\
\hline
\end{tabular}

Alkanes

Jackknifed Classification Matrix

\begin{tabular}{|c|c|c|c|c|c|c|}
\hline & $\begin{array}{r}\text { 1-methylcyclope- } \\
\text { ntane }\end{array}$ & $\begin{array}{r}2,3 \text {-dimethylbut- } \\
\text { ane }\end{array}$ & 2-methylpentane & 3-methylpentane & n-hexanes & \%correct \\
\hline 1-methylcyclopentane & 4 & 0 & 0 & 0 & 0 & 100 \\
\hline 2,3-dimethylbutane & 0 & 4 & 0 & 0 & 0 & 100 \\
\hline 2-methylpentane & 0 & 0 & 4 & 0 & 0 & 100 \\
\hline 3-methylpentane & 0 & 0 & 0 & 4 & 0 & 100 \\
\hline n-hexanes & 0 & 0 & 0 & 0 & 4 & 100 \\
\hline Total & 4 & 4 & 4 & 4 & 4 & 100 \\
\hline
\end{tabular}

Cumulative Proportion of Total Dispersion

\begin{tabular}{|l|l|l|}
\hline 0.767 & 0.930 & 1.000 \\
\hline
\end{tabular}

Aliphatic alcohols 
Jackknifed Classification Matrix

\begin{tabular}{|l|r|r|r|r|r|}
\hline & $\begin{array}{r}\text { 1-methylcyclohe- } \\
\text { xanol }\end{array}$ & $\begin{array}{r}\text { cis-2methylcycl- } \\
\text { ohexanol }\end{array}$ & $\begin{array}{r}\text { cyclohexylmetha- } \\
\text { nol }\end{array}$ & $\begin{array}{r}\text { trans-2methylcy- } \\
\text { clohexano }\end{array}$ & \%correct \\
\hline 1-methylcyclohexanol & 4 & 0 & 0 & 0 & 100 \\
\hline cis-2methylcyclohexanol & 0 & 4 & 0 & 0 & 100 \\
\hline cyclohexylmethanol & 0 & 0 & 4 & 0 & 100 \\
\hline trans-2methylcyclohexano & 0 & 0 & 0 & 4 & 100 \\
\hline Total & 4 & 4 & 4 & 4 & 100 \\
\hline
\end{tabular}

Cumulative Proportion of Total Dispersion

\begin{tabular}{l|l|l|}
0.775 & 0.990 & 1.000 \\
\hline
\end{tabular}

\section{PCBs}

Jackknifed Classification Matrix

\begin{tabular}{|l|r|r|r|r|r|r|}
\hline & pcb209 & pcb29 & pcb3 & pcb52 & pcb77 & \%correct \\
\hline pcb209 & 4 & 0 & 0 & 0 & 0 & 100 \\
\hline pcb29 & 0 & 4 & 0 & 0 & 0 & 100 \\
\hline pcb3 & 0 & 0 & 4 & 0 & 0 & 100 \\
\hline pcb52 & 0 & 0 & 0 & 4 & 0 & 100 \\
\hline pcb77 & 0 & 0 & 0 & 0 & 4 & 100 \\
\hline Total & 4 & 4 & 4 & 4 & 4 & 100 \\
\hline
\end{tabular}

Cumulative Proportion of Total Dispersion

0.806

0.996

1.000

\section{1:1 binary mixtures of analytes $\mathbf{5 - 8}$}

Jackknifed Classification Matrix

\begin{tabular}{|l|r|r|r|r|r|r|r|}
\hline & BA-M & BA-O & BA-P & M-P & O-M & O-P & \%correct \\
\hline BA-M & 2 & 0 & 0 & 0 & 0 & 2 & 50 \\
\hline BA-O & 0 & 4 & 0 & 0 & 0 & 0 & 100 \\
\hline BA-P & 1 & 0 & 3 & 0 & 0 & 0 & 75 \\
\hline M-P & 0 & 0 & 0 & 4 & 0 & 0 & 100 \\
\hline O-M & 0 & 0 & 0 & 0 & 4 & 0 & 100 \\
\hline O-P & 1 & 0 & 0 & 0 & 0 & 3 & 75 \\
\hline Total & 4 & 4 & 3 & 4 & 4 & 5 & 83 \\
\hline
\end{tabular}

Cumulative Proportion of Total Dispersion

0.889

0.981

1.000

\section{SUMMARY FIGURES}




\section{SUMMARY FIGURES FOR FLUORESCENCE MODULATION}

$o$-Cresol

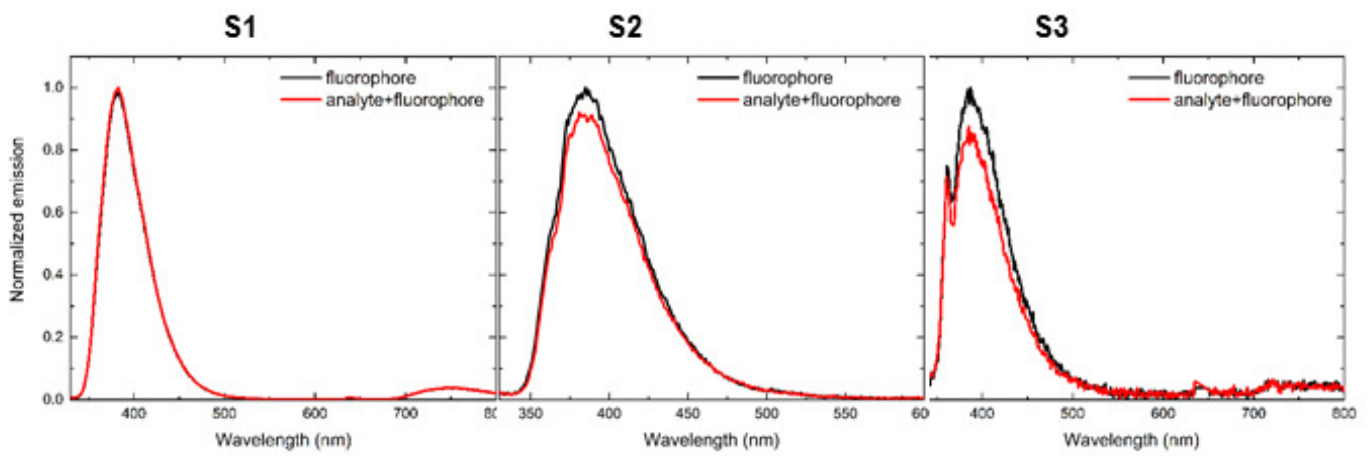

$m$-Cresol

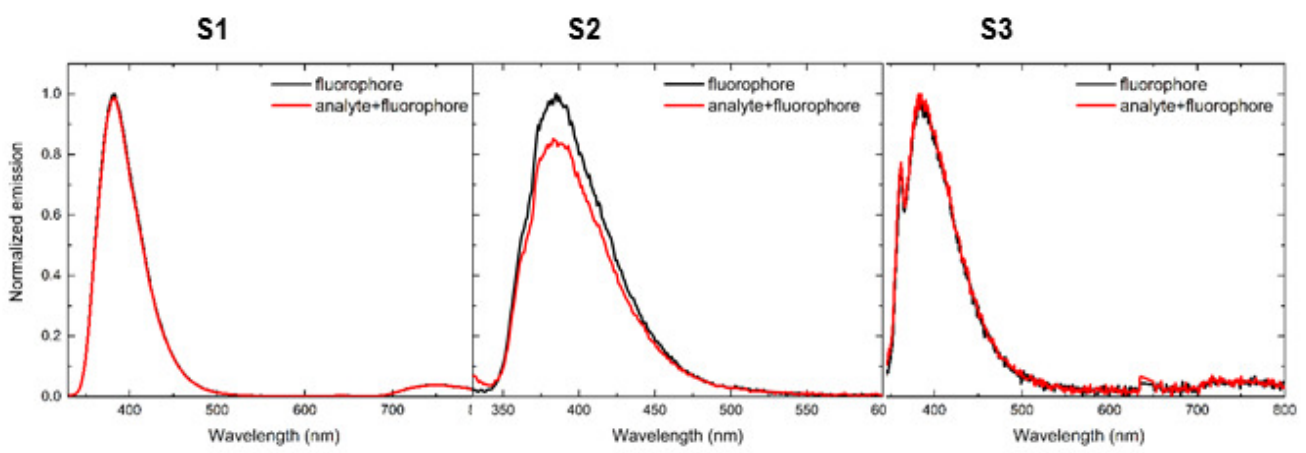

p-Cresol

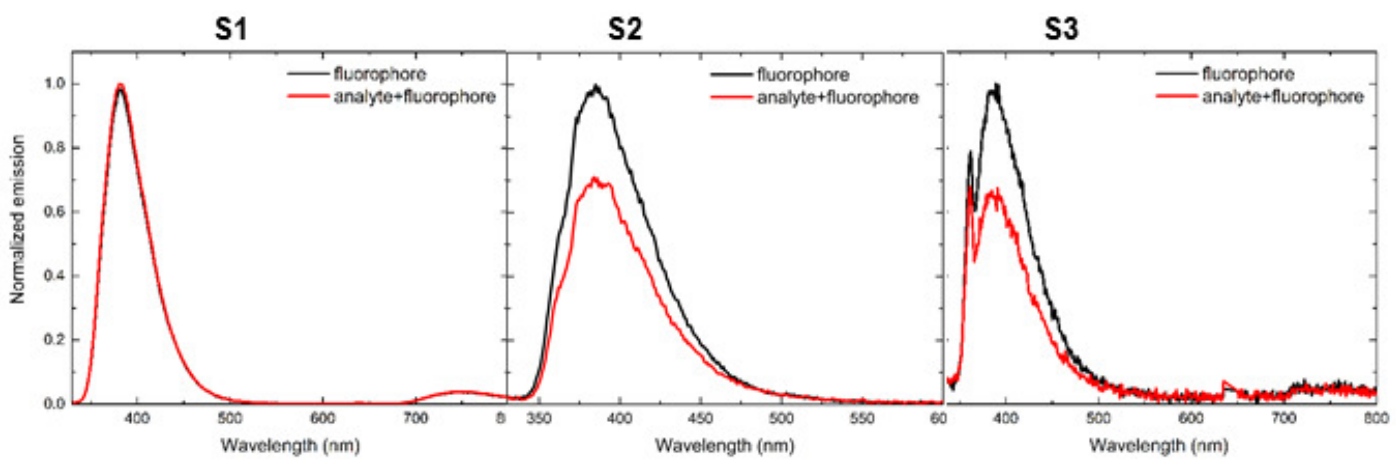


DDD

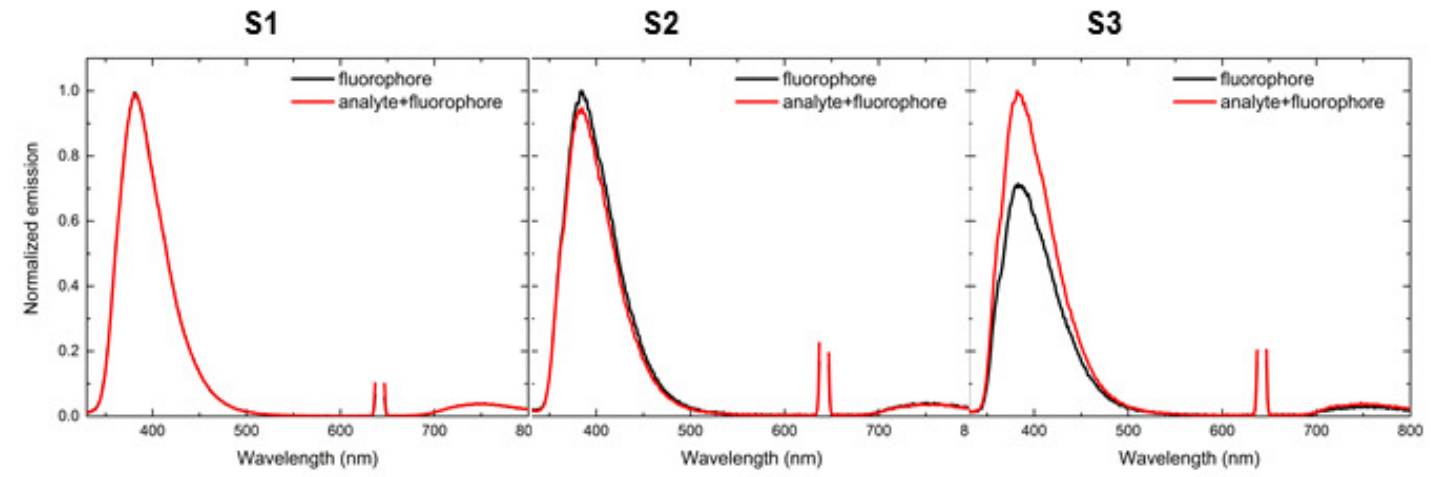

DDE

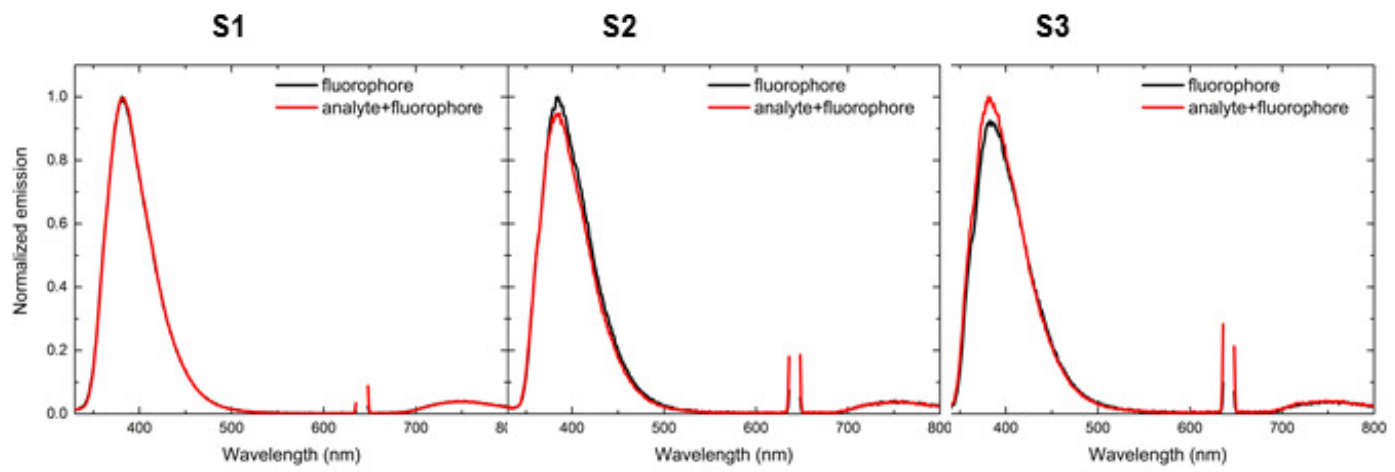

$o, p$-DDT

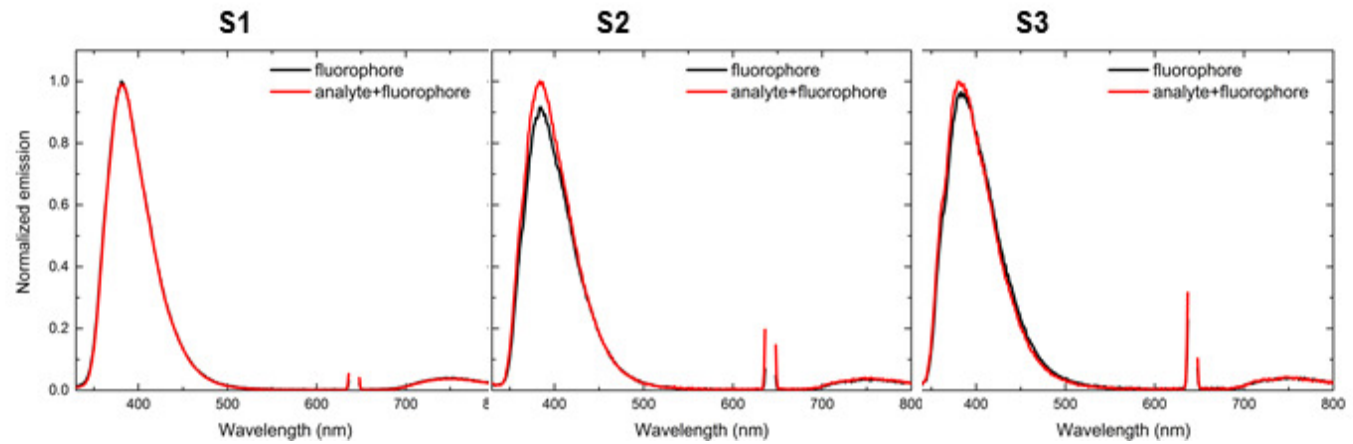

$p, p$-DDT 


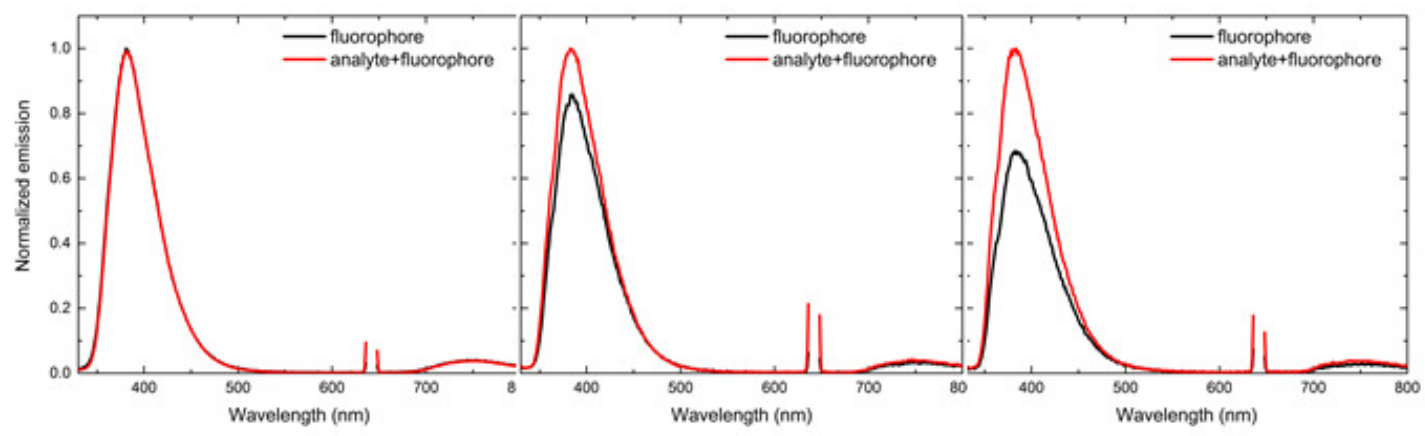

n-Hexanes

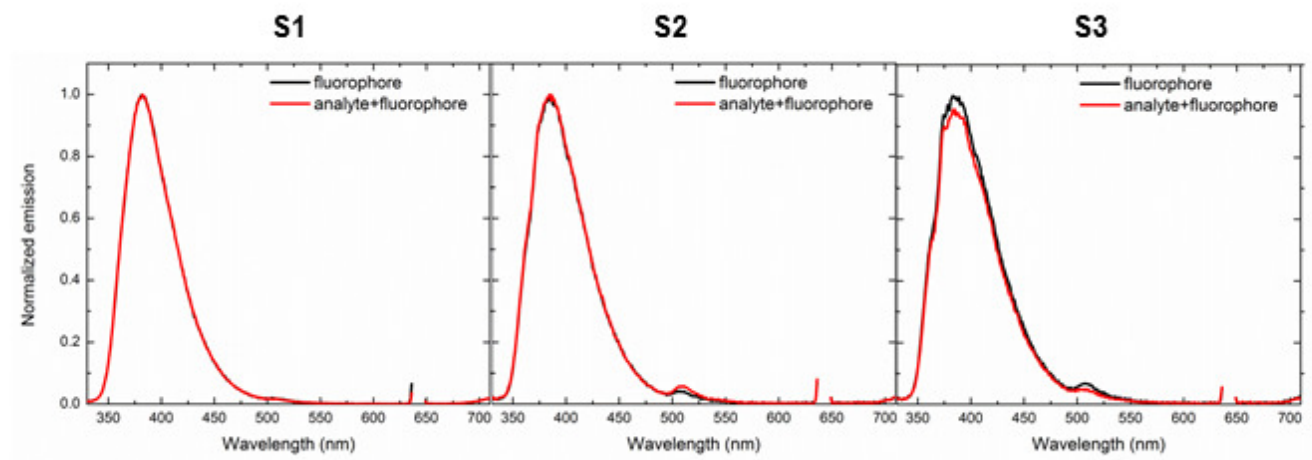

2-Methylpentane

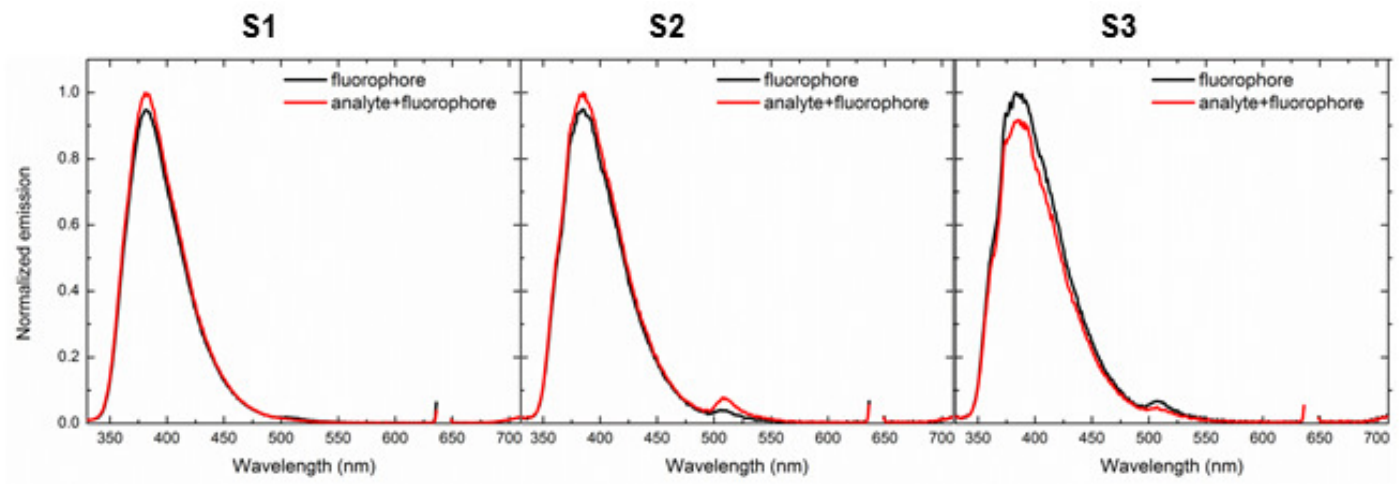

\section{3-Methylpentane}




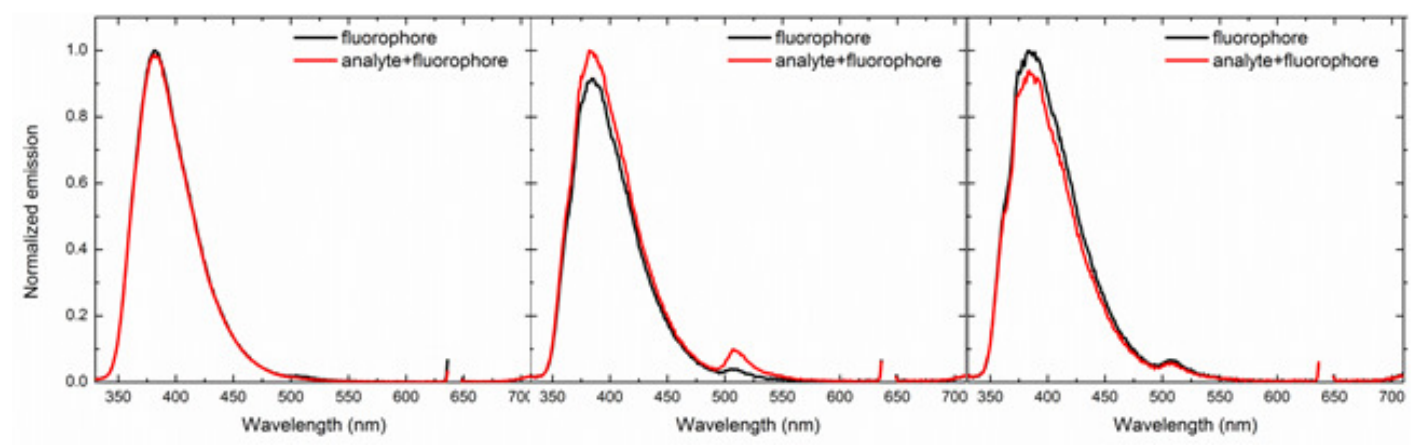

\section{2,3-Dimethylbutane}

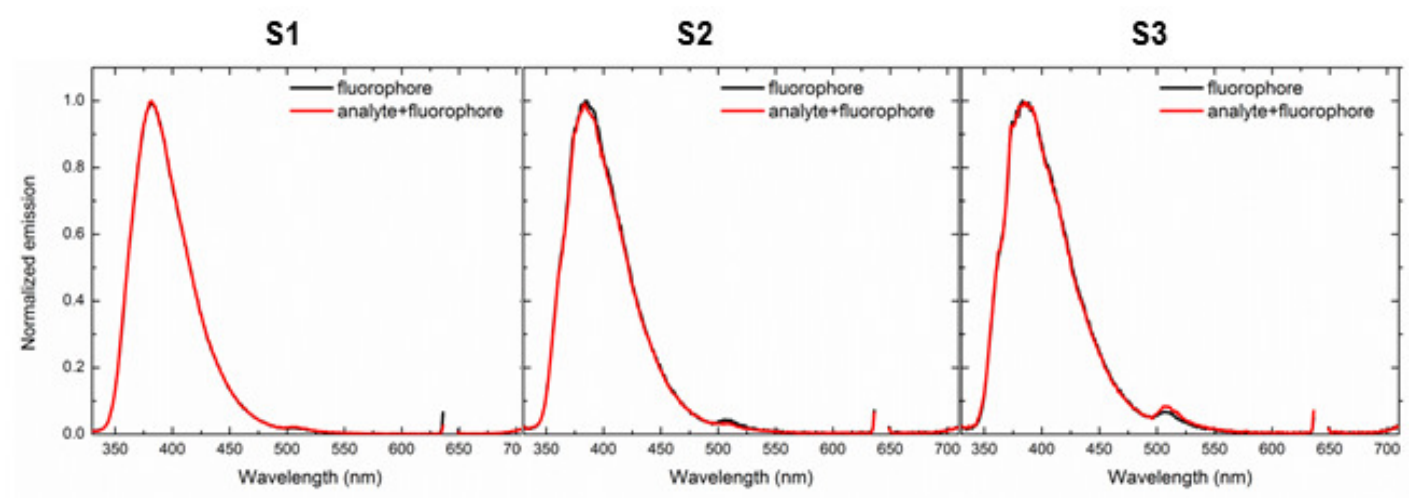

1-Methylcyclopentane

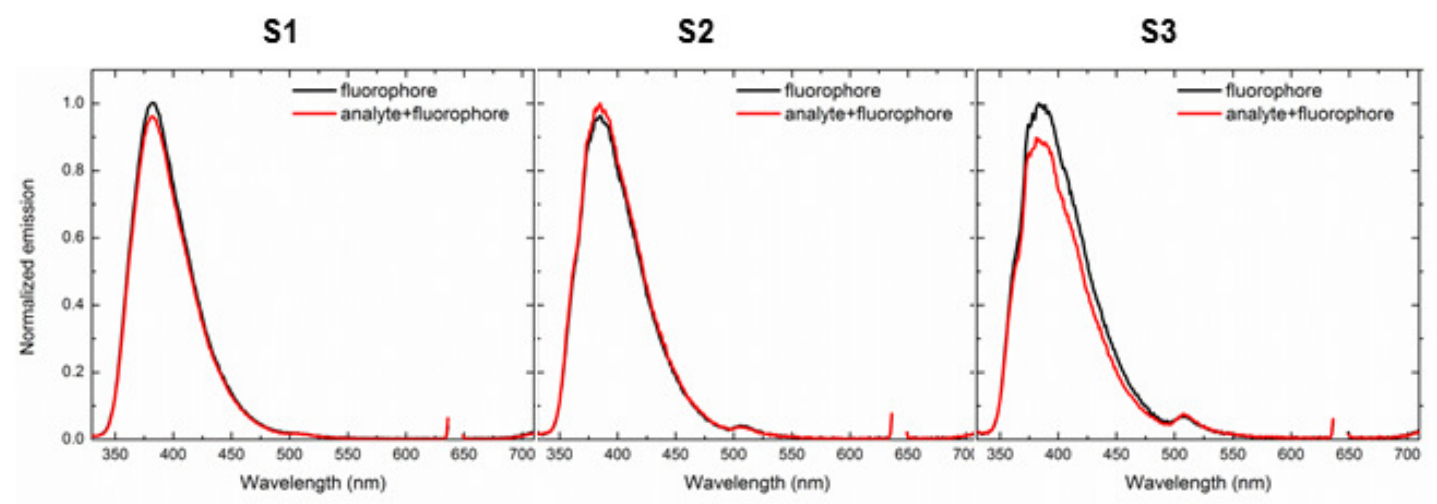

1-Methylcyclohexanol 


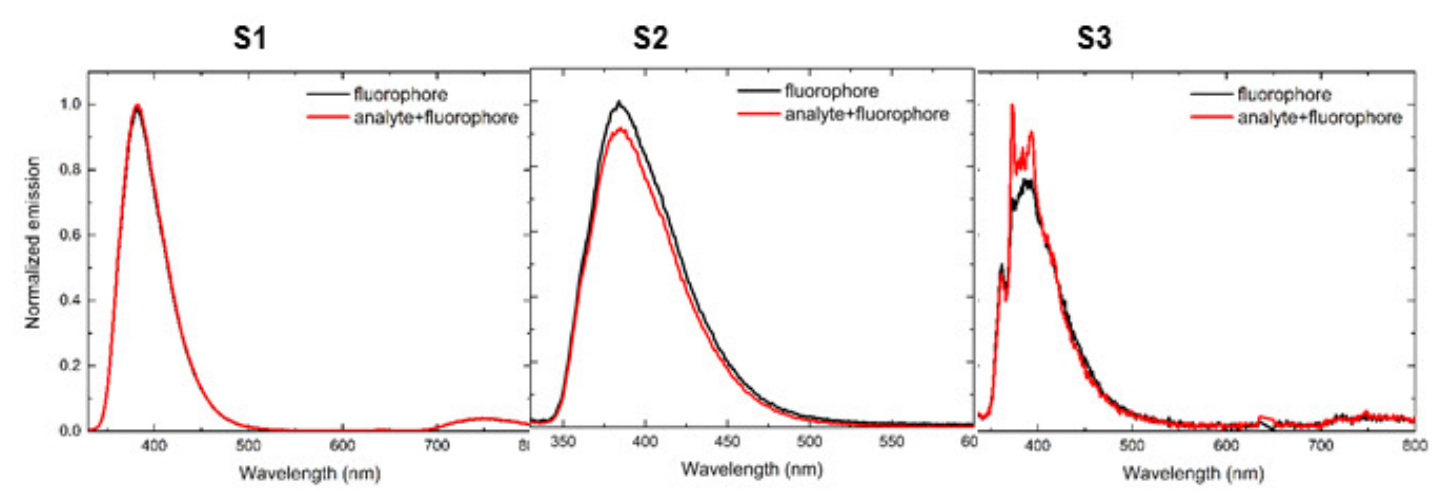

cis-2-Methylcyclohexanol

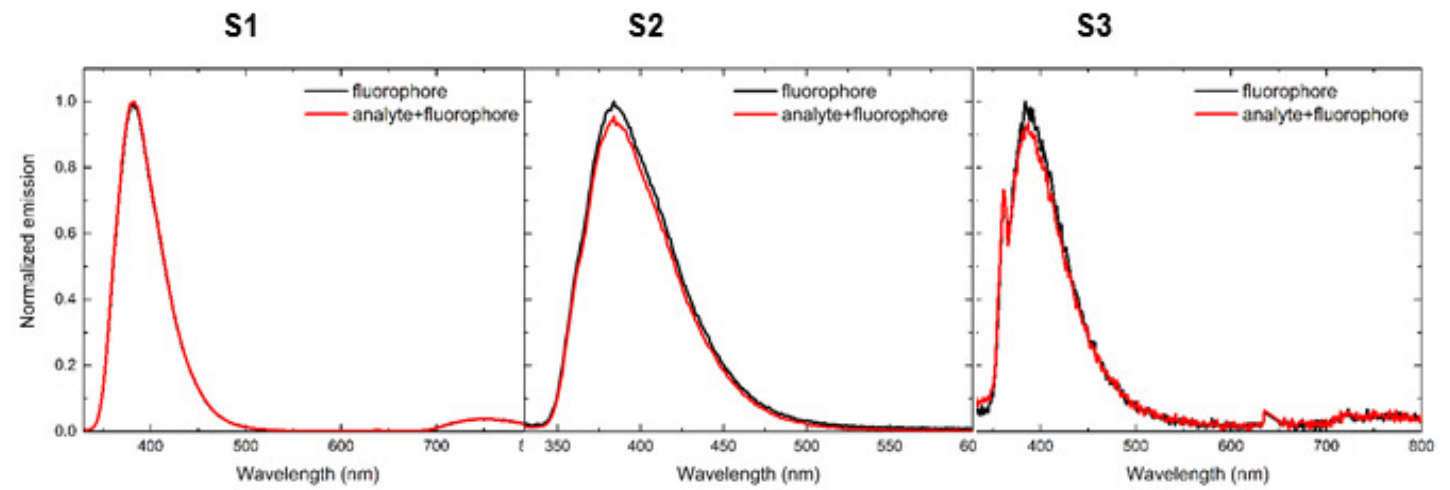

trans-2-Methylcyclohexanol

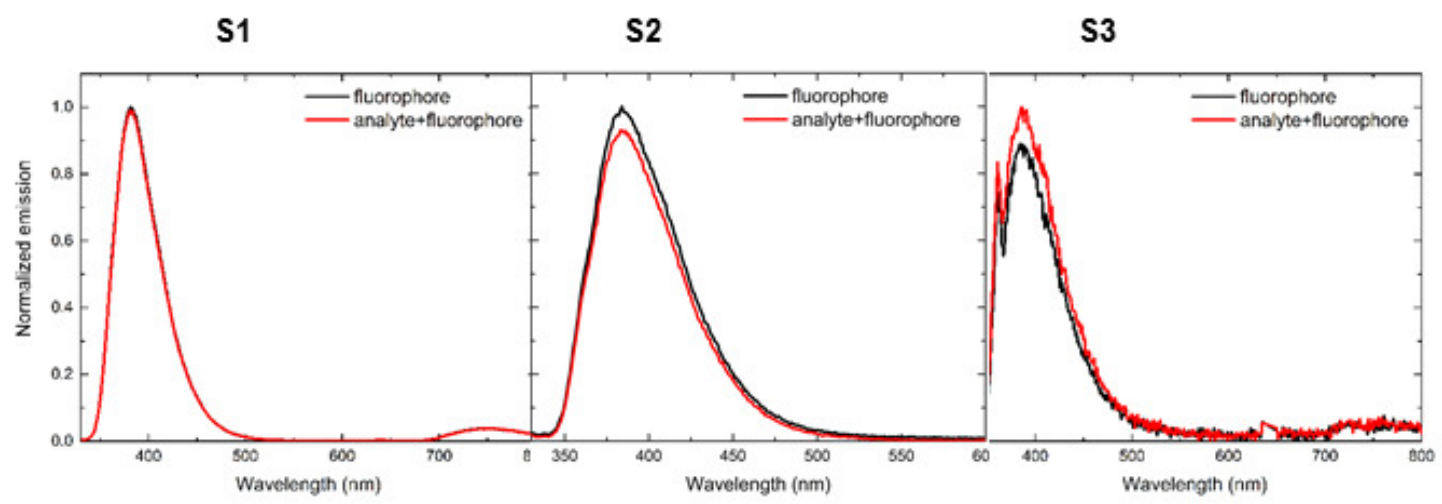

PCB3 


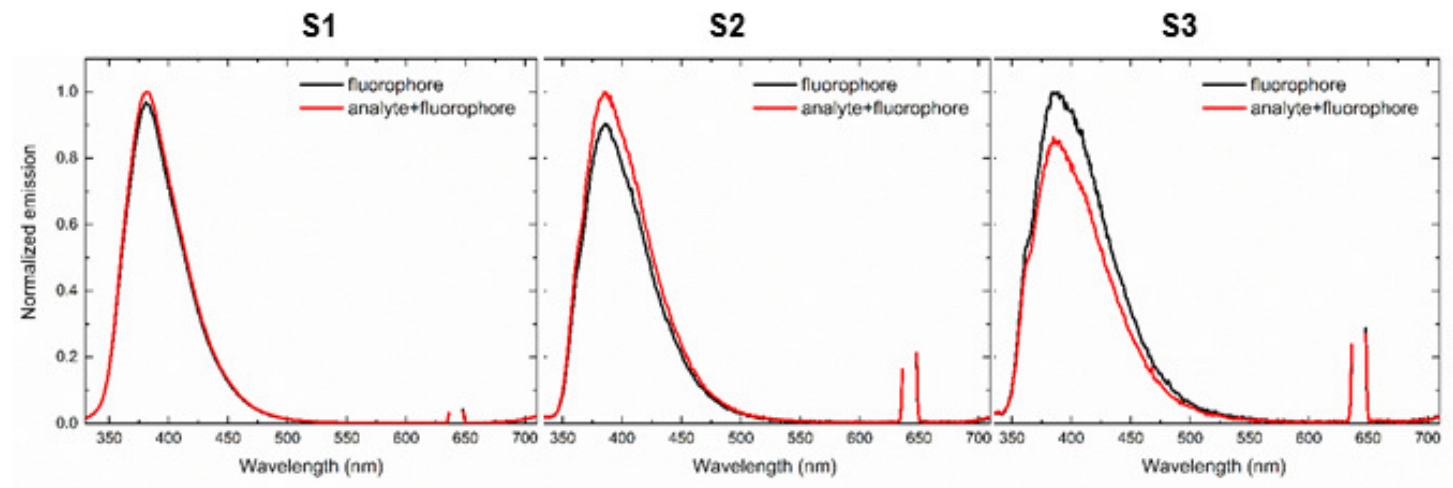

PCB29

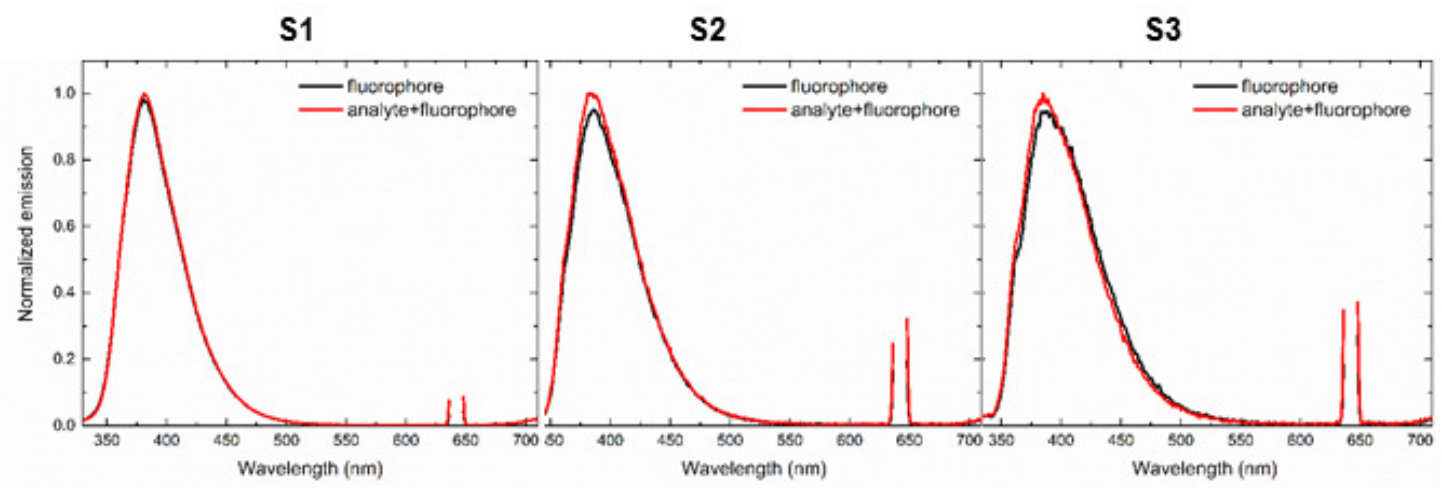

\section{PCB52}

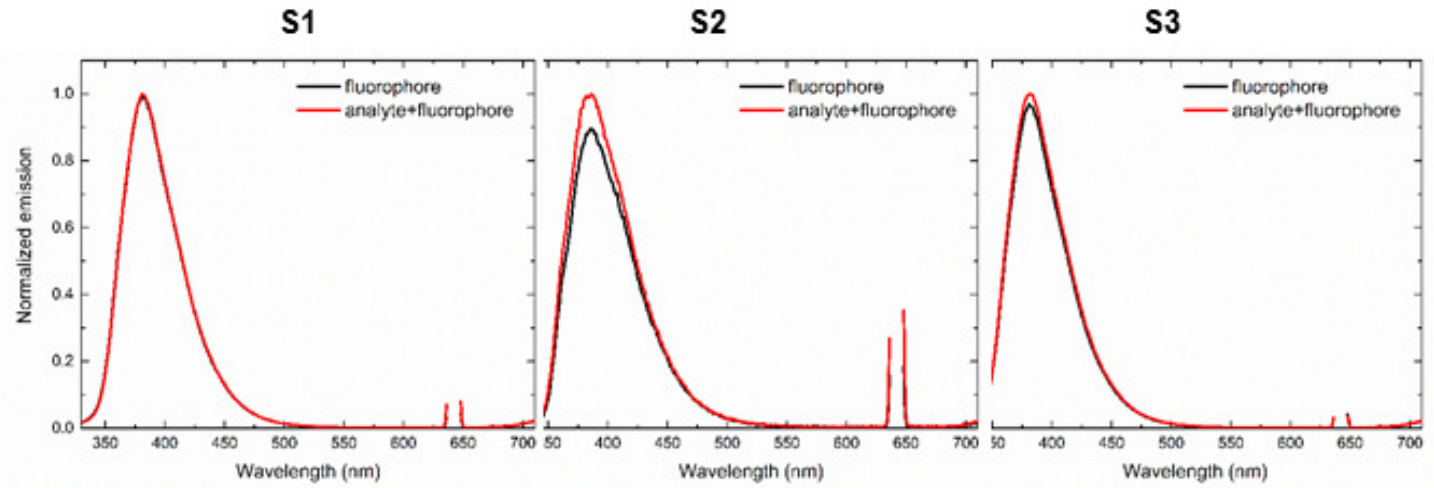




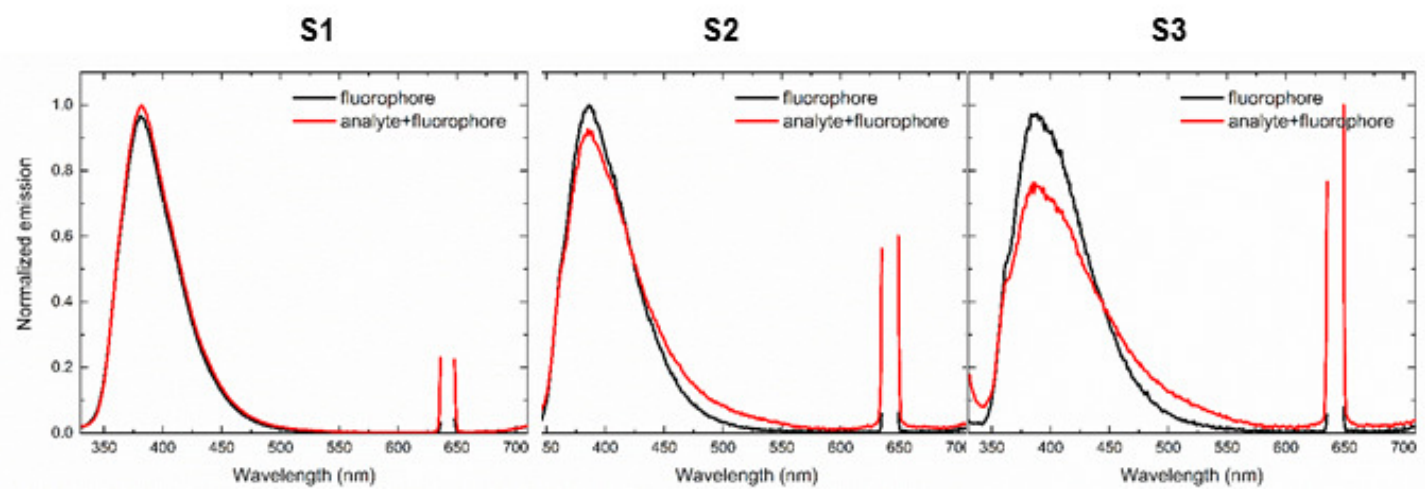

PCB209

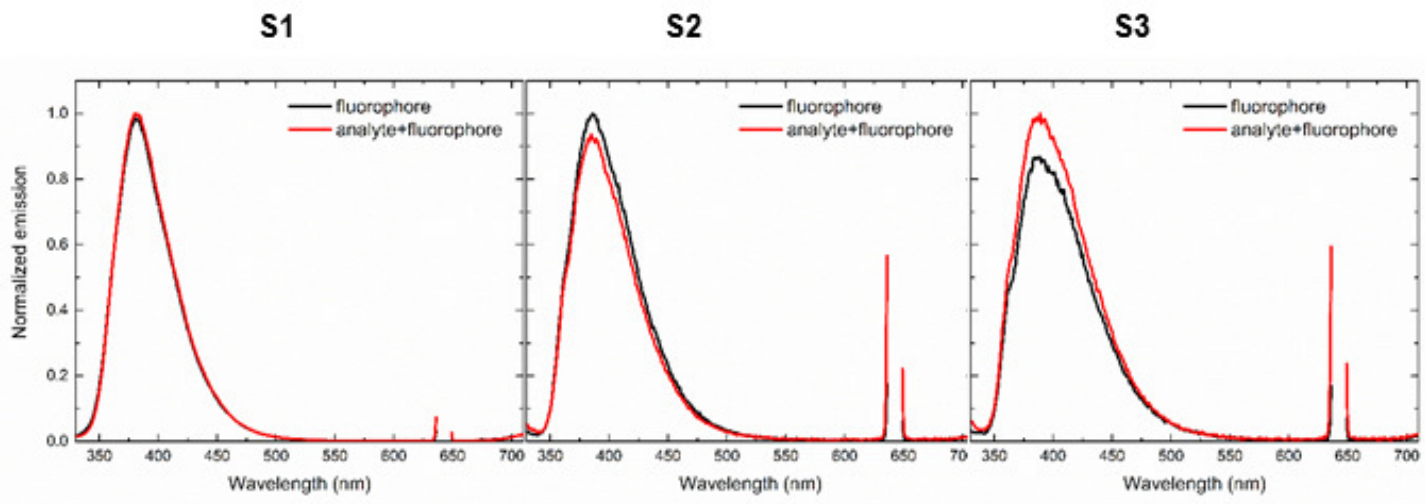




\section{SUMMARY FIGURES LIMIT OF DETECTION}

$p, p-\mathrm{DDT}-\mathbf{S 1}$

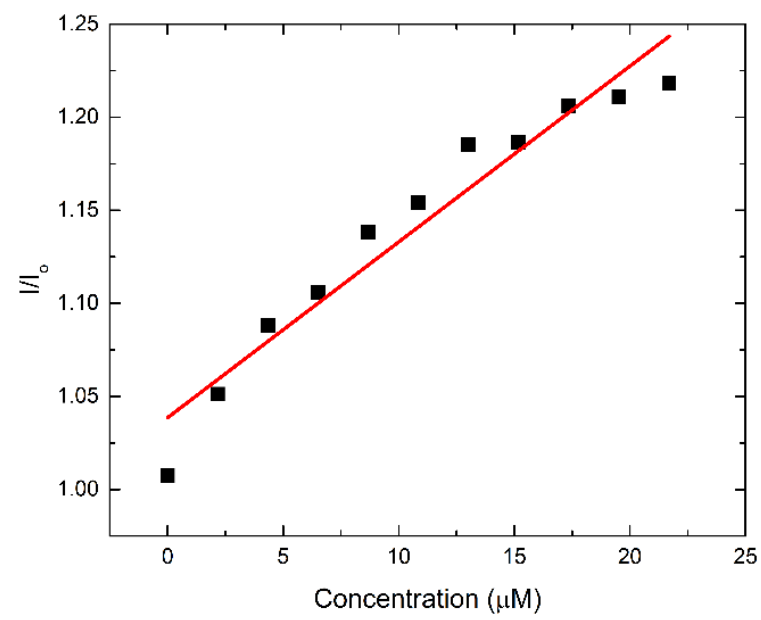

$p, p-\mathrm{DDT}-\mathbf{S} 2$

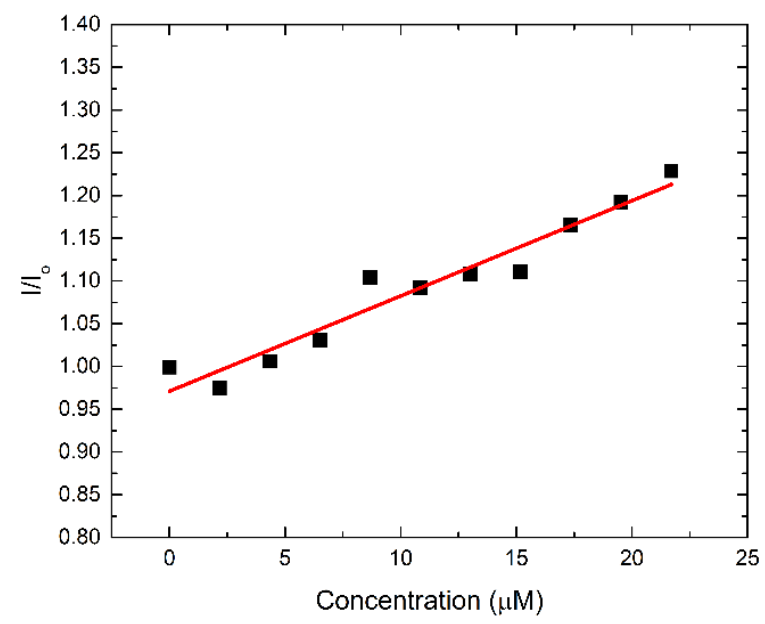

$p, p$-DDT - S3 


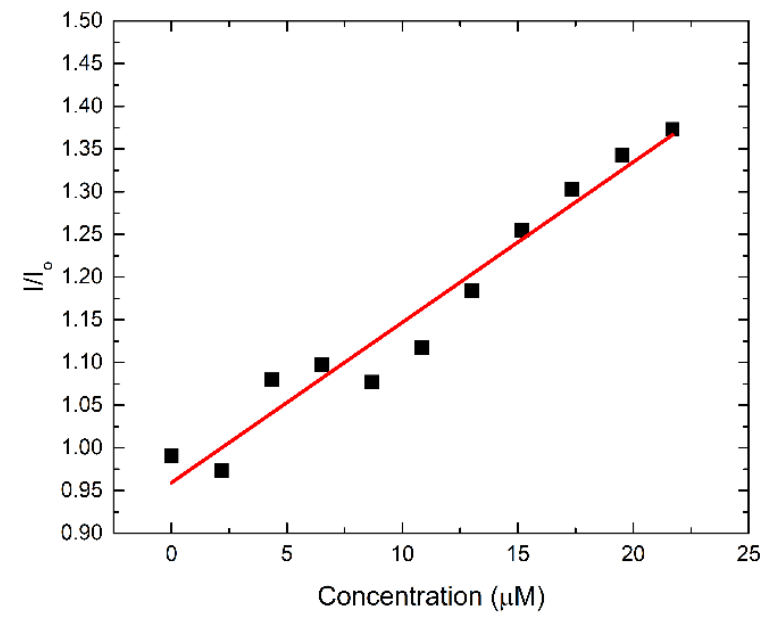

$o$-Cresol - S1

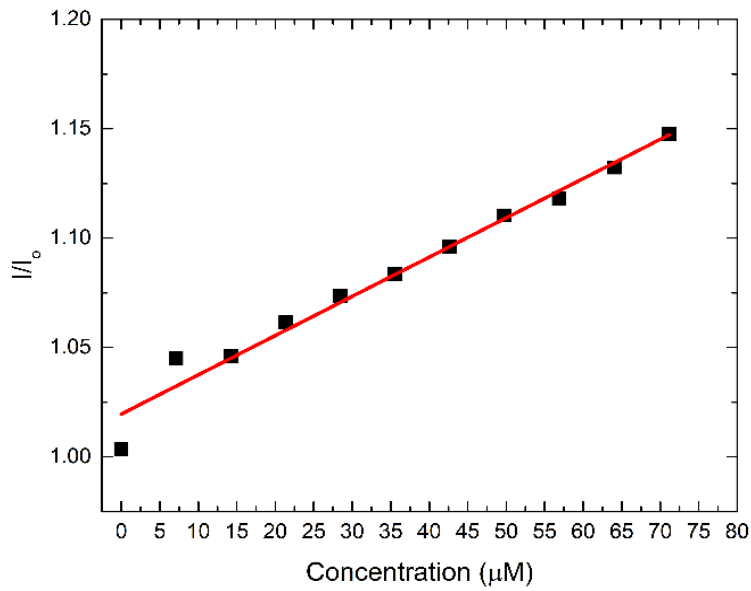

Benzyl alcohol - S2

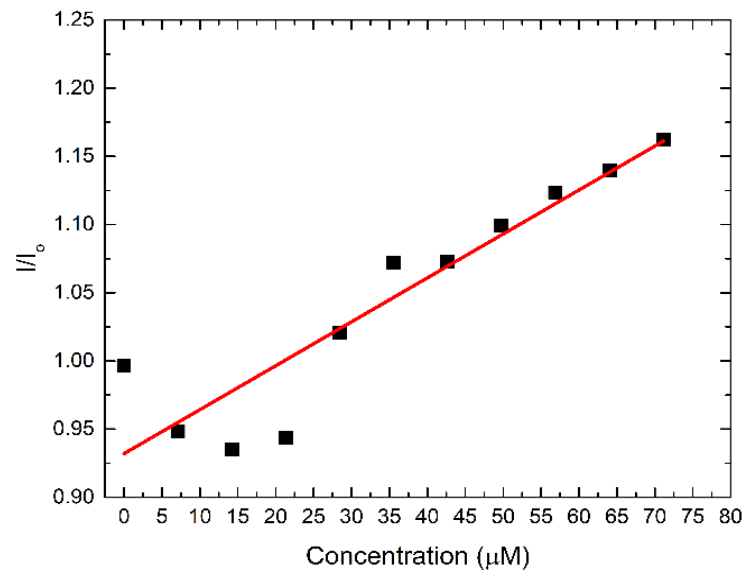


$o$-Cresol - S3

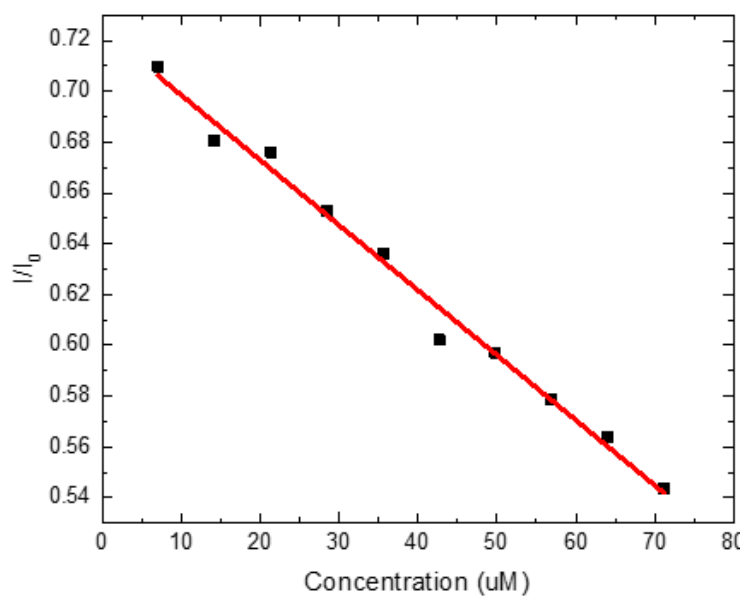

Cyclohexylmethanol - S1

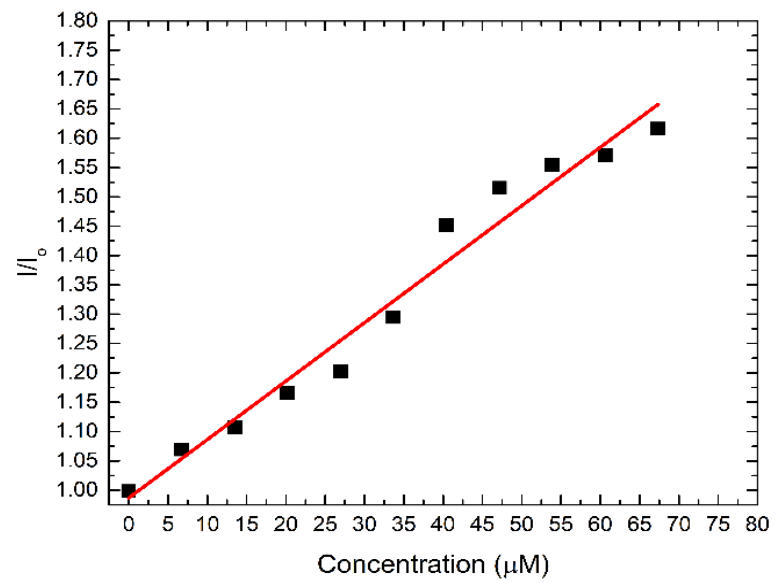

Cyclohexylmethanol - S2 


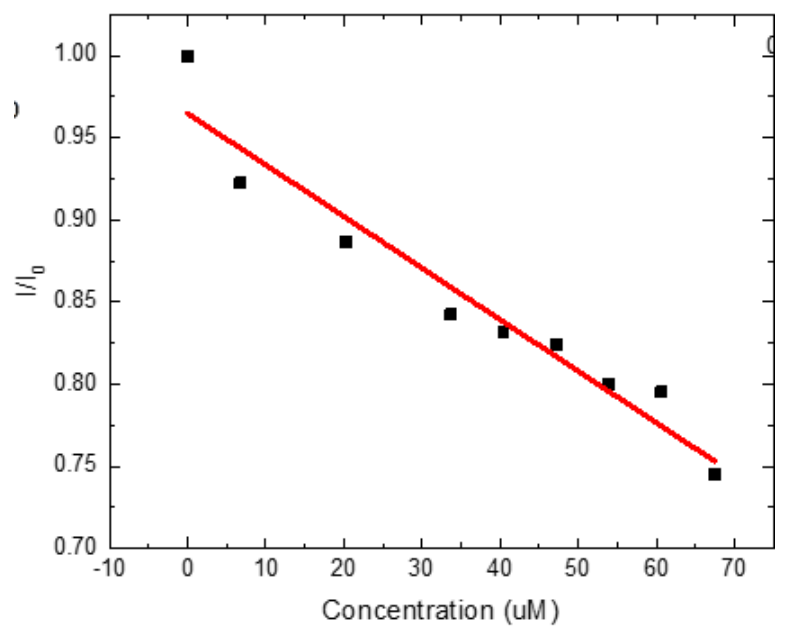

1-Methylcyclohexanol - S3

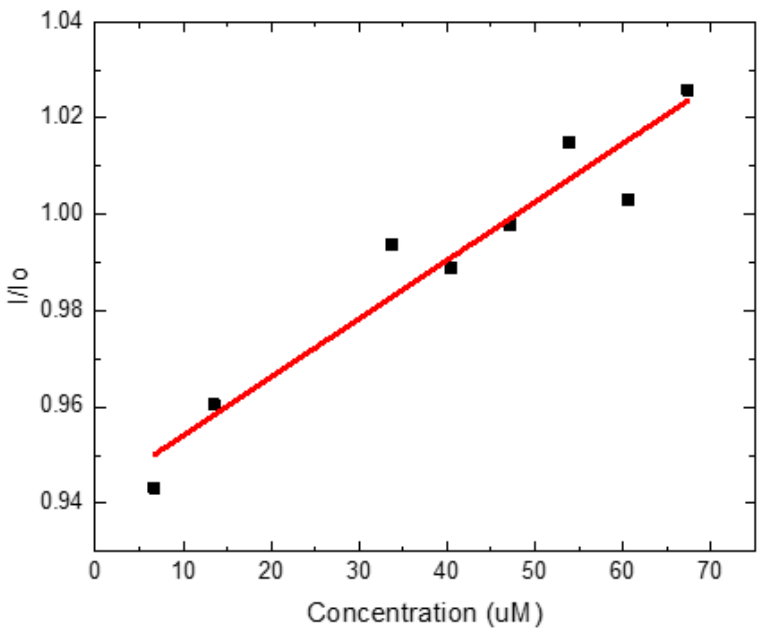

PCB77 - S1 


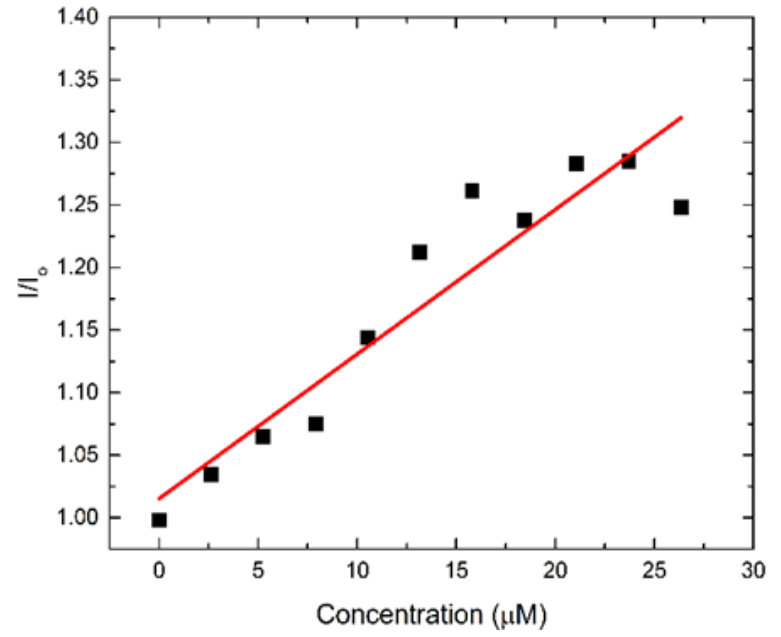

PCB209 - S2

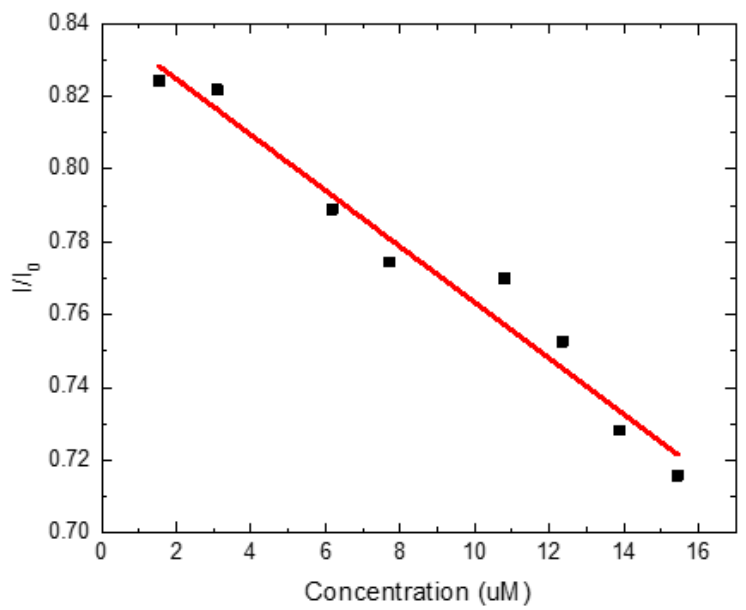

PCB209 - S3 


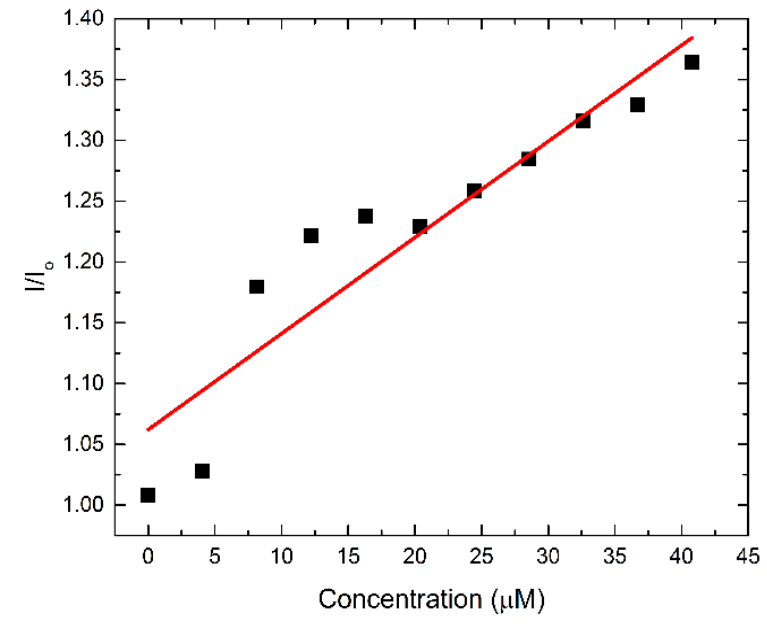

2-Methylpentane - S1

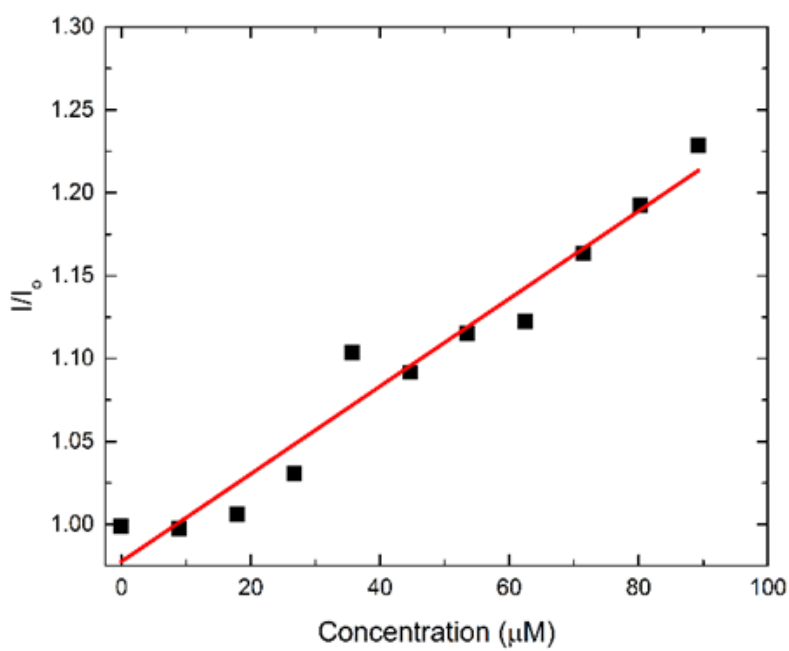

3-Methylpentane - S2 


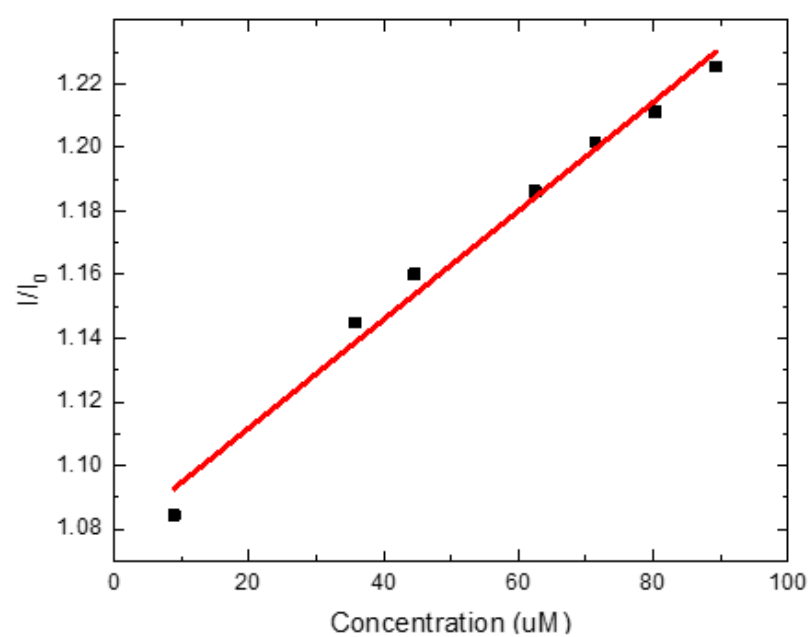

1-Methylcyclopentane - S3

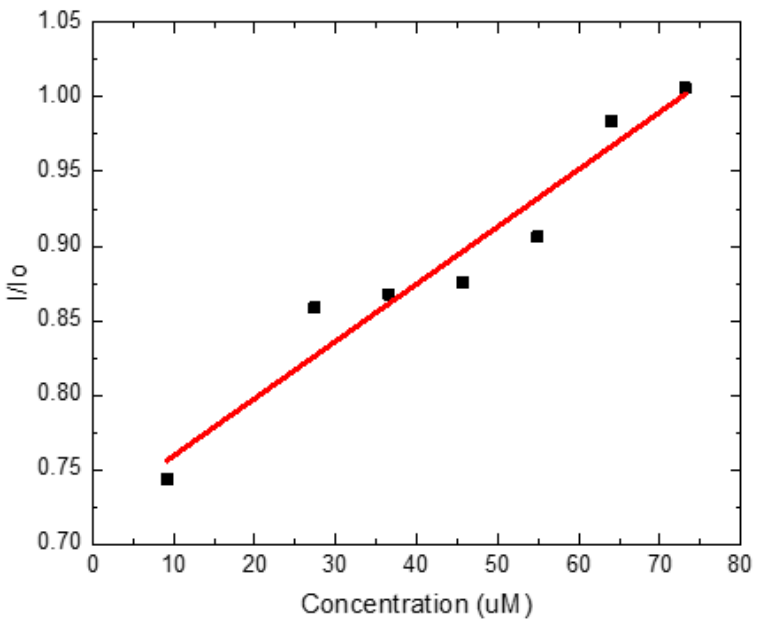




\section{SUMMARY FIGURES ARRAYS}

\section{All Analytes}

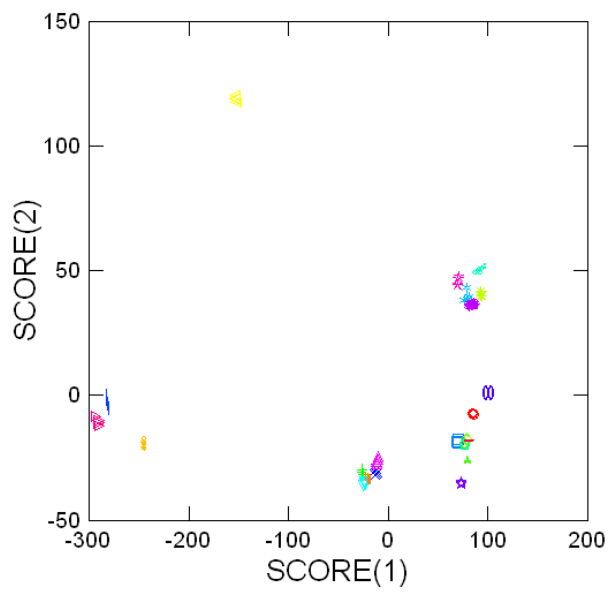

ANALYTE \$

n-hexanes 1-methylcyclohexanol

- o-cresol $\times 1$-methylcyclopentane

I opDDT + 2,3-dimethylbutane

p-cresol $\triangle 2$-methylpentane

* pcb209 $\quad \nabla$ 3-methylpentane

* pcb29

pcb3

* pcb52

pcb77

ppDDT

DDD

$\triangleright \mathrm{DDE}$

$\square$ benzyl alcohol cis-2methylcyclohexanol

\& cyclohexylmethanol

0 trans-2methylcyclohexano m-cresol

Aromatic alcohols

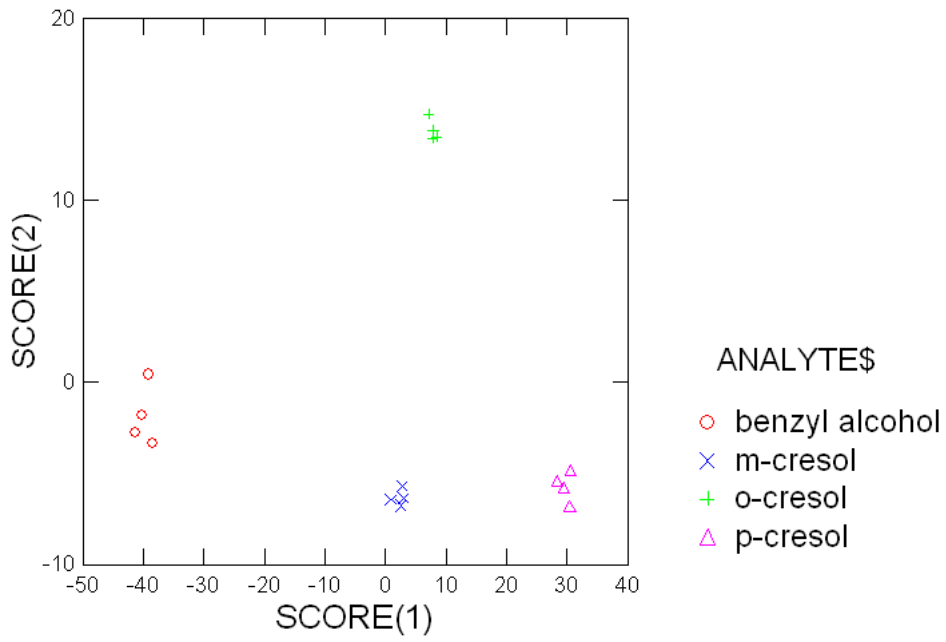

\section{Pesticides}




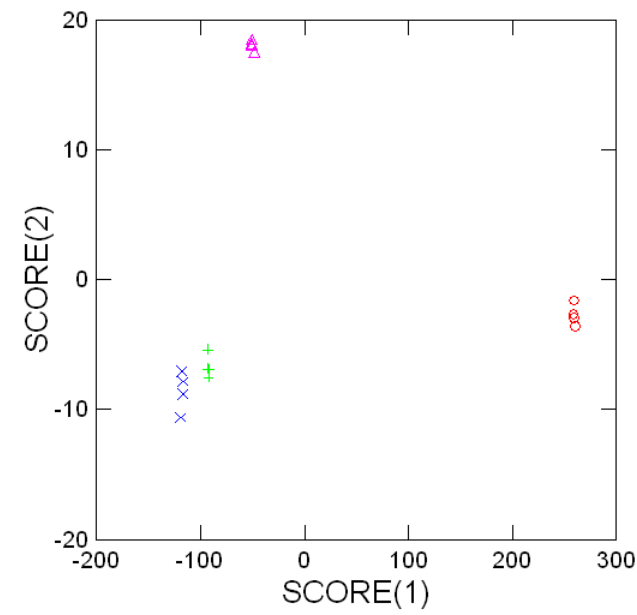

ANALYTE $\$$

DDD

$\times$ DDE

+ opDDT

$\triangle$ ppDDT

Alkanes

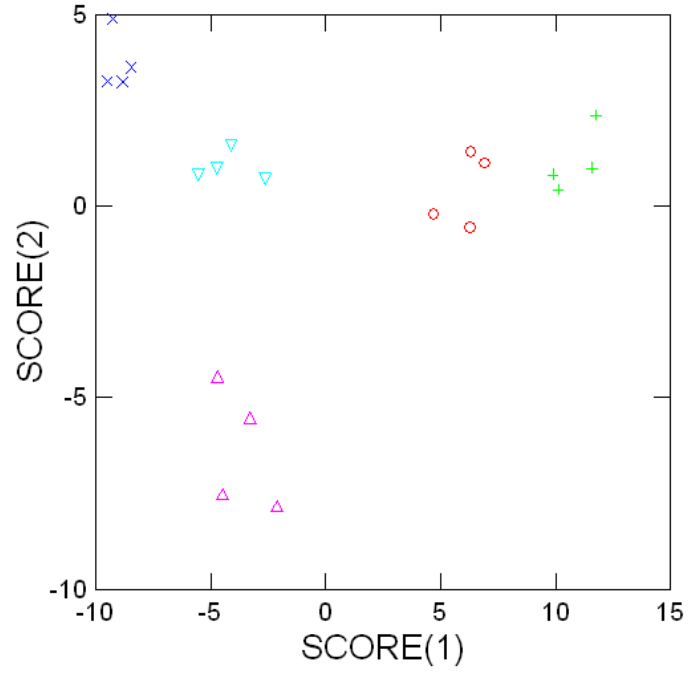

\section{ANALYTE\$}

- 1-methylcyclopentane

$\times$ 2,3-dimethylbutane

+ 2-methylpentane

$\triangle$ 3-methylpentane

n-hexanes

Alcohols 


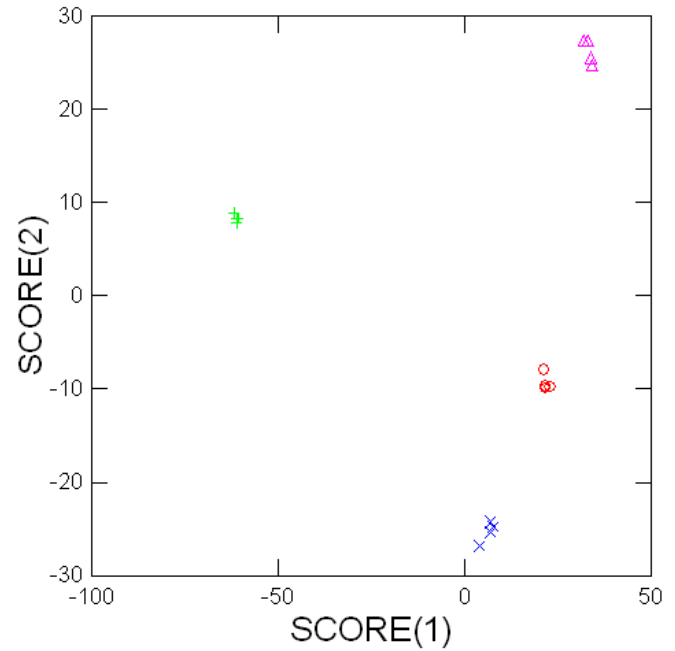

\section{PCBs}

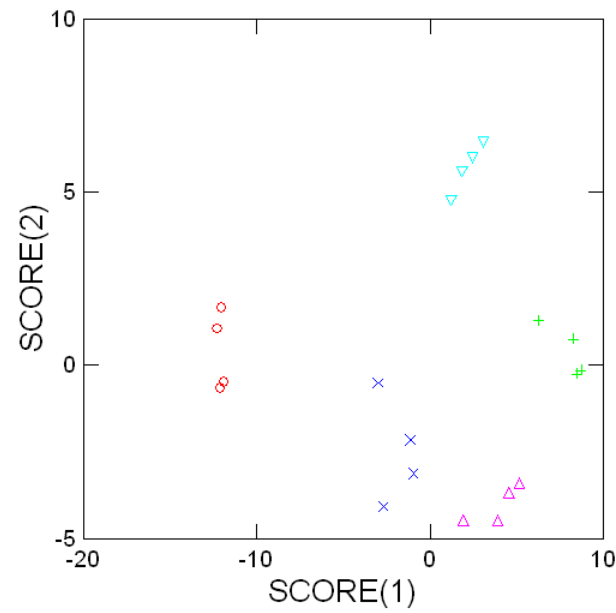

ANALYTE\$

pcb209

$\times$ pcb29

pcb3

$\triangle$ pcb52

pcb77

\section{1:1 binary mixtures of analytes $\mathbf{5 - 8}$}




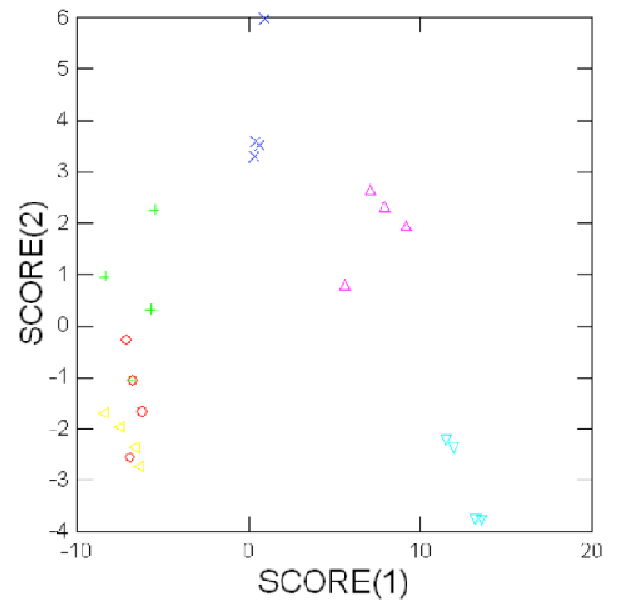

ANALYTE\$

- BA-M

$\times$ BA-O

+ BA-P

$\triangle \mathrm{M}-\mathrm{P}$

O-M

$\mathrm{O}-\mathrm{P}$

\section{NMR SPECTRA OF ALL NEW COMPOUNDS}

\section{Compound 2}

\section{${ }^{1} \mathrm{H}$ NMR}

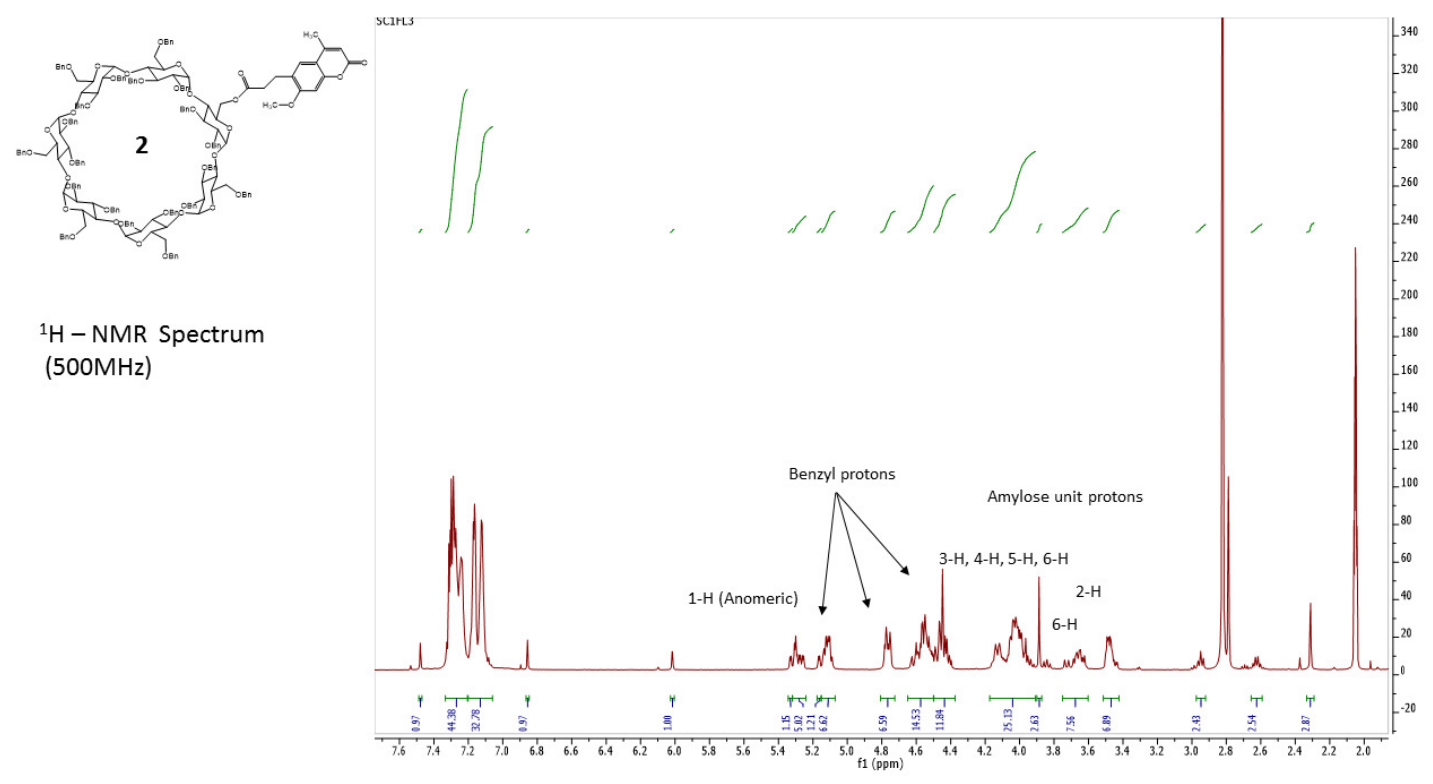

${ }^{13} \mathrm{C}$ NMR 


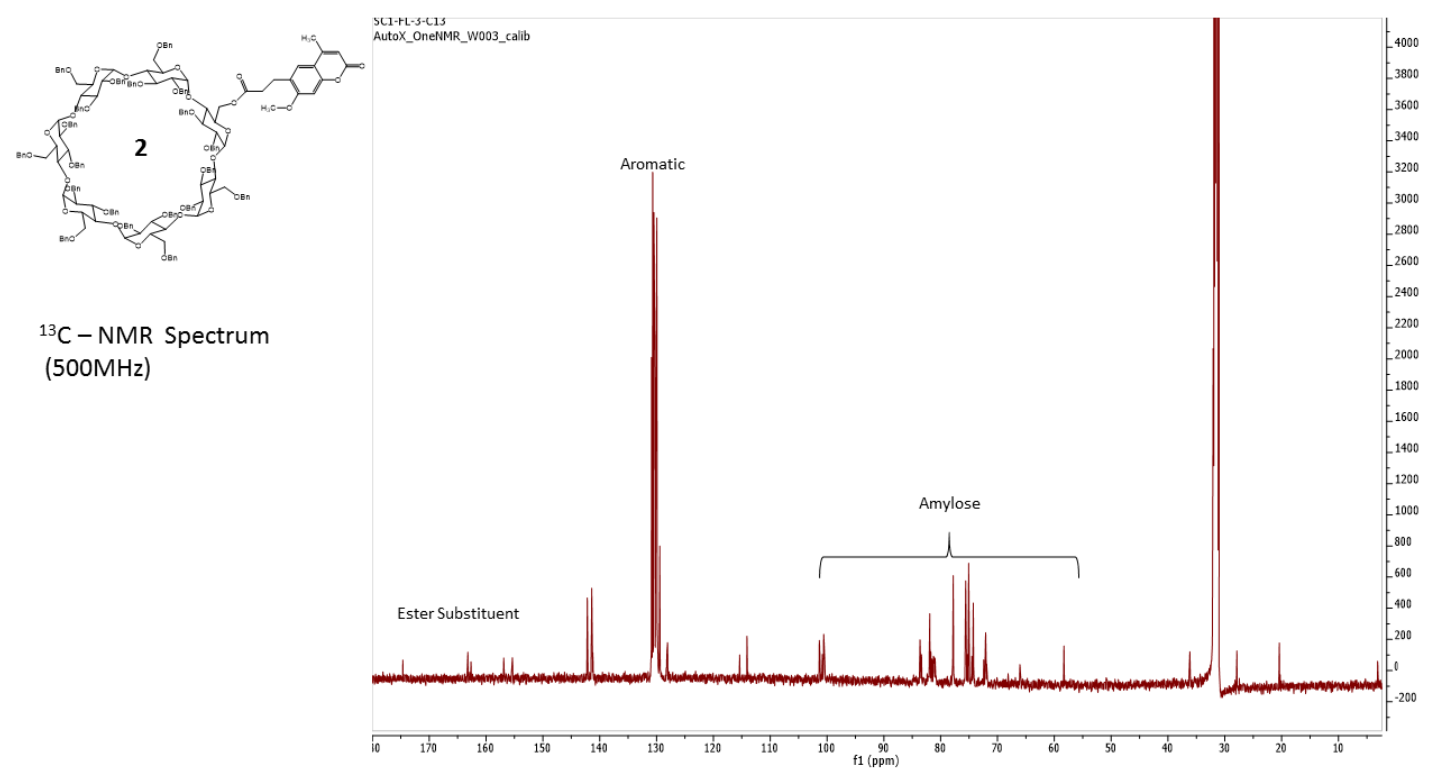

COSY NMR

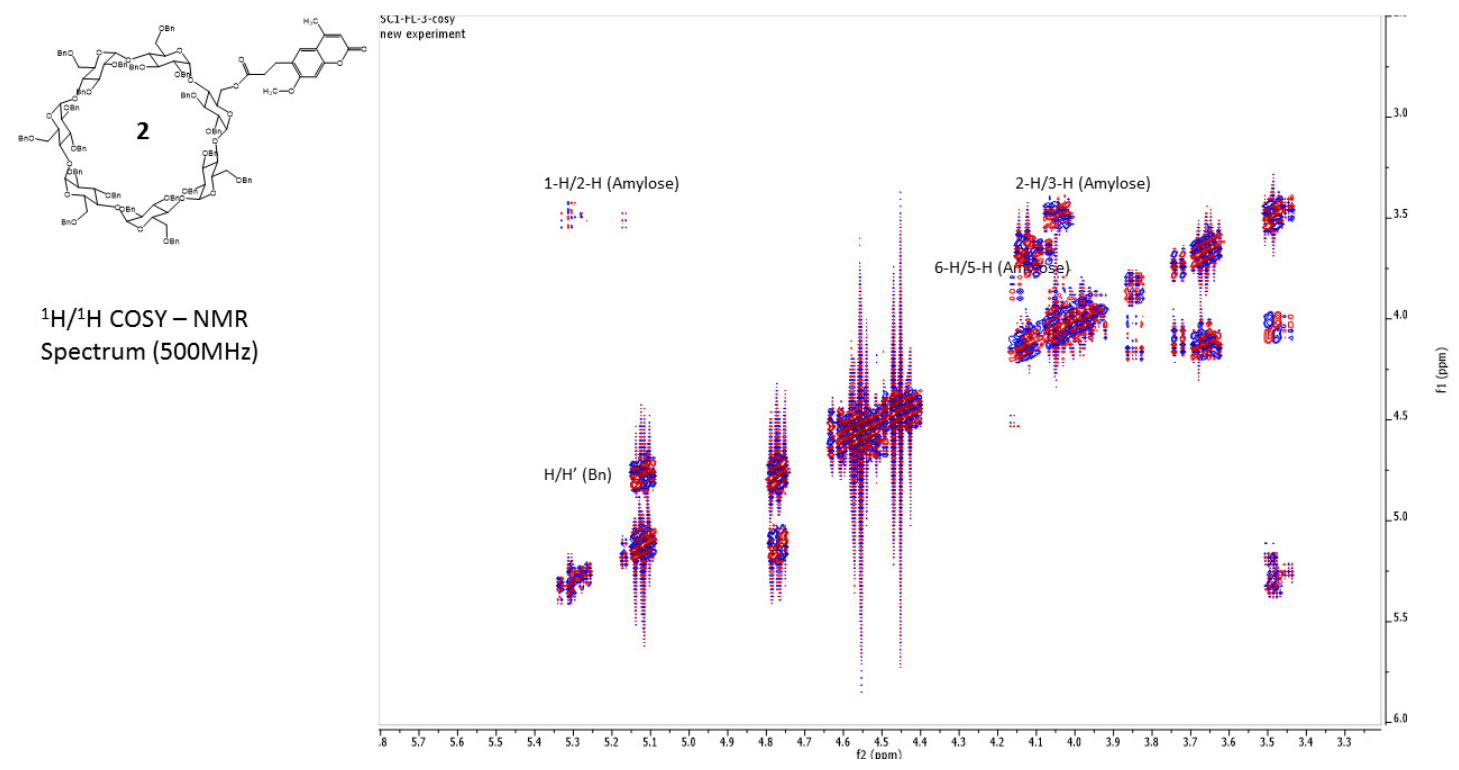

Compound 3

${ }^{1} \mathrm{H}$ NMR 


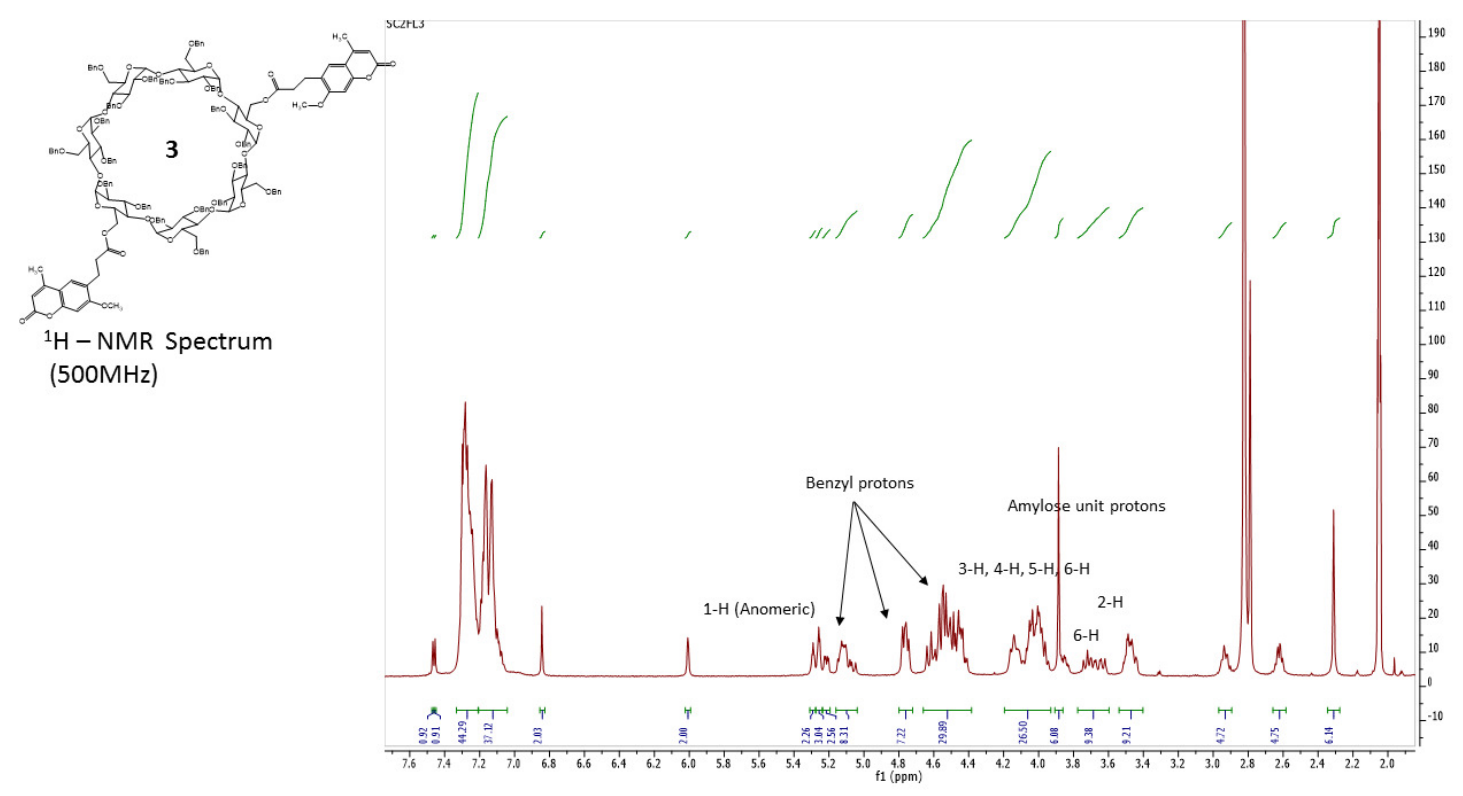

\section{${ }^{13} \mathrm{C}$ NMR}

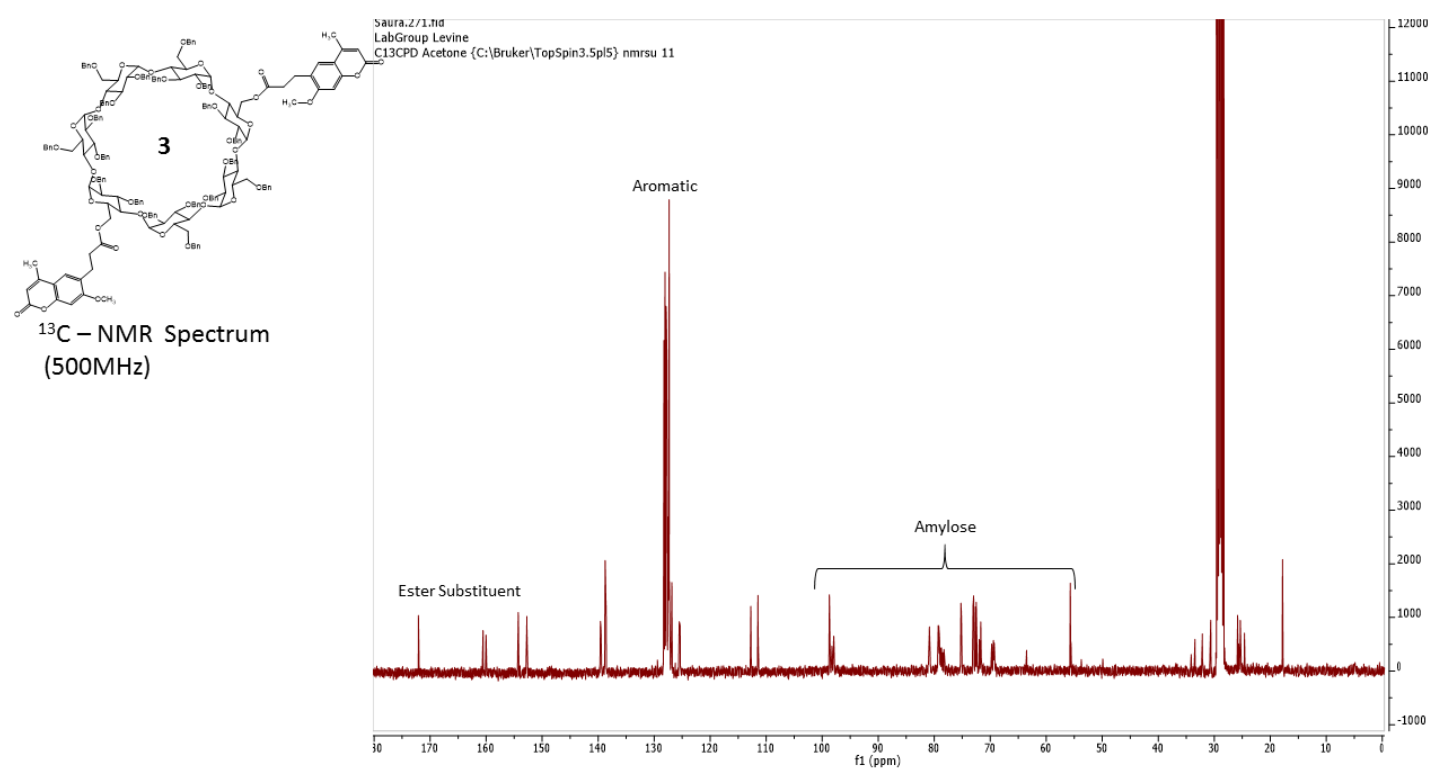

COSY NMR 


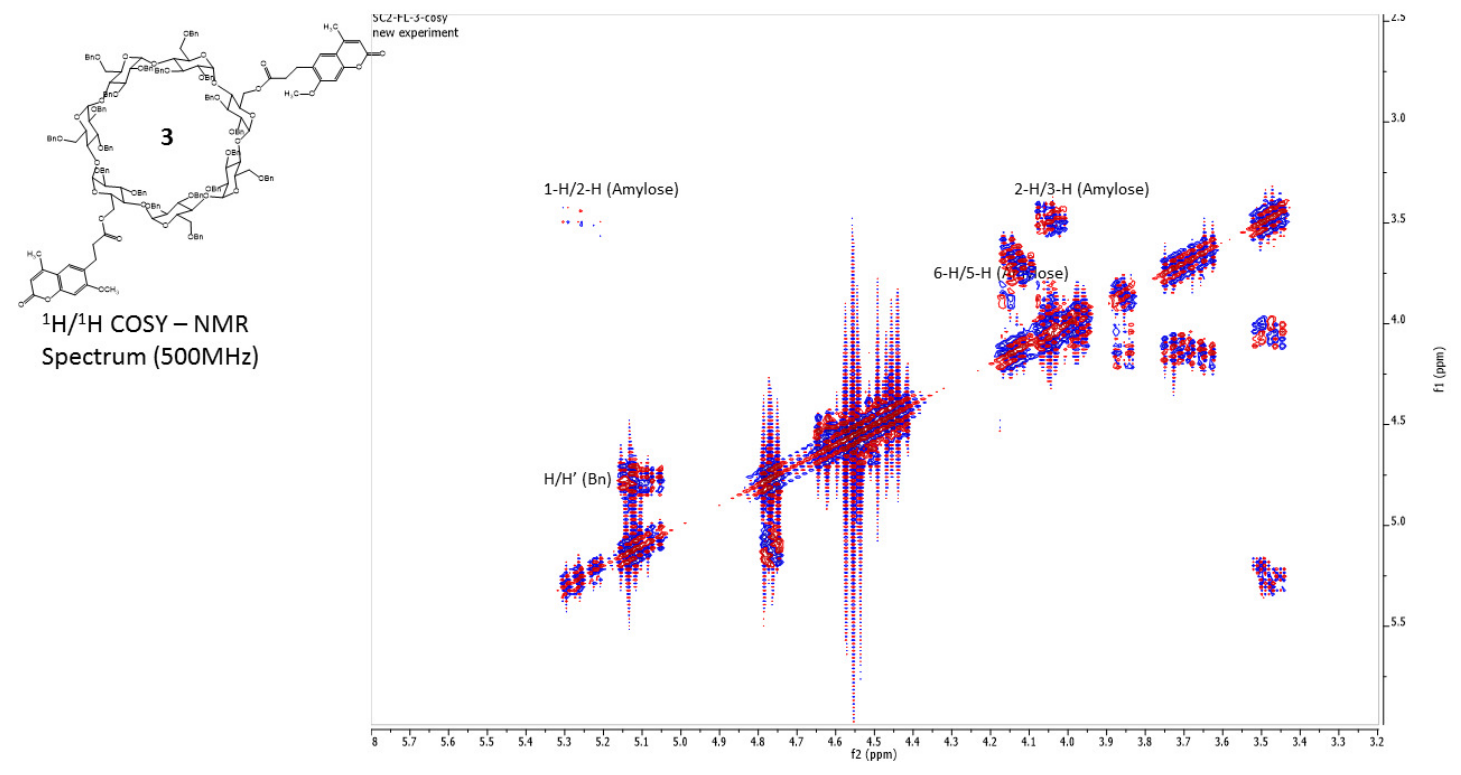

SPECTROSCOPIC INVESTIGATIONS OF SENSORS S1-S3

ABSORPTION SPECTRA

UV-Visible Absorption Spectra of S2 and S3 $(1 \mu \mathrm{M})$ in DMSO measured at room temperature:

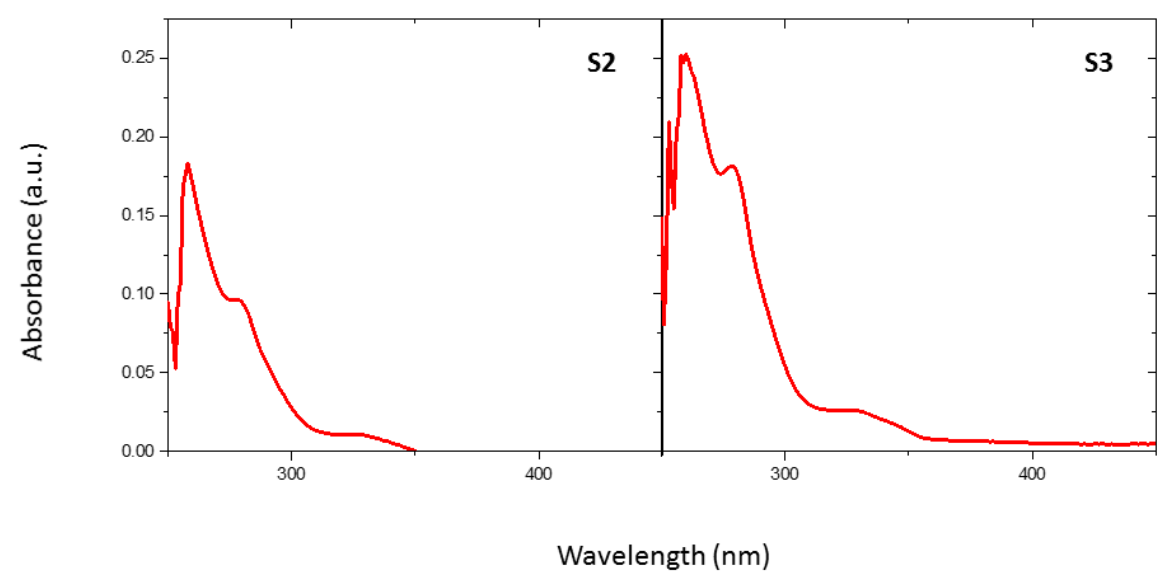

VARIATION OF FLUORESCENCE EMISSION OF SENSORS IN $\mathrm{H}_{2} \mathrm{O}$ /DMSO MIXTURES 
Fluorescence emission spectra of S1, S2 and S3 (at $1 \mu \mathrm{M}$ concentration) in 80:20 ( $\mathrm{H}_{2} \mathrm{O}:$ DMSO) (black trace), 60:40 $\left(\mathrm{H}_{2} \mathrm{O}:\right.$ DMSO) (red trace), 40:60 $\left(\mathrm{H}_{2} \mathrm{O}:\right.$ DMSO) (blue trace), 20:80 $\left(\mathrm{H}_{2} \mathrm{O}:\right.$ DMSO) (purple trace), 0:100 $\left(\mathrm{H}_{2} \mathrm{O}: \mathrm{DMSO}\right)$ (green trace). $\left(\lambda_{\mathrm{ex}}=320 \mathrm{~nm}\right)$. All spectra were recorded at room temperature.

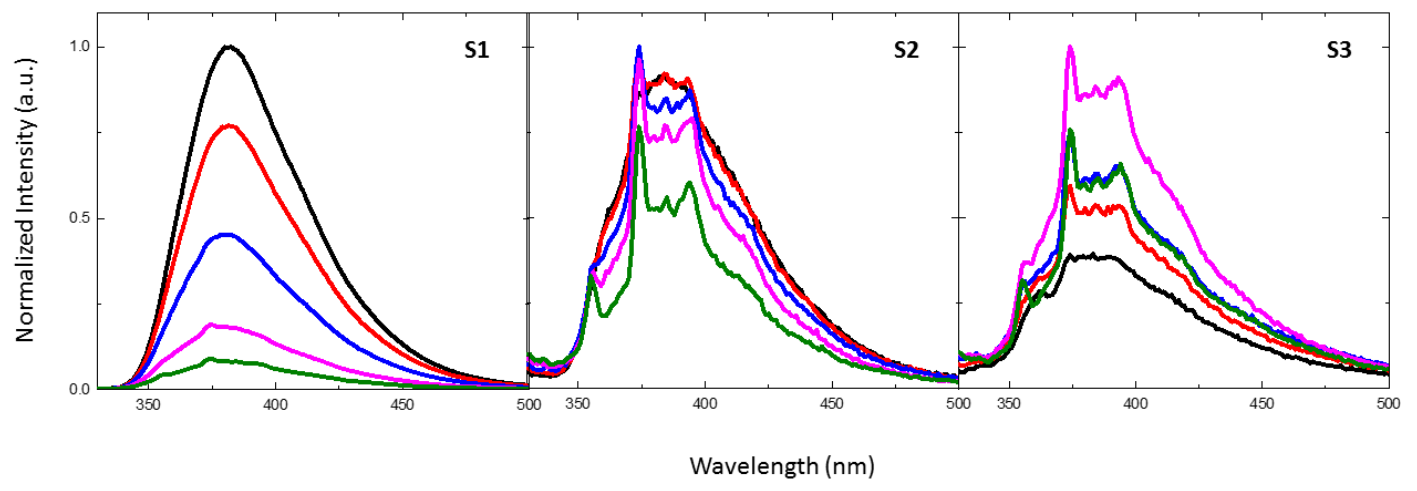

BENESI-HILDEBRAND PLOTS FOR NMR TITRATION

Analyte $5\left(0.2 \mathrm{M}\right.$ in $\left.0.8 \mathrm{~mL} \mathrm{D}_{2} \mathrm{O}\right)$ was titrated against $0 \mu \mathrm{L}, 10 \mu \mathrm{L}, 20 \mu \mathrm{L}, 25 \mu \mathrm{L}, 30$ $\mu \mathrm{L}, 35 \mu \mathrm{L}, 40 \mu \mathrm{L}, 50 \mu \mathrm{L}, 60 \mu \mathrm{L}, 80 \mathrm{Ml}$ and $100 \mu \mathrm{L}$ of the host $(1 \mathrm{mg} / \mathrm{mL}$ dissolved in $\mathrm{d}_{6}$-DMSO) in a clean dry NMR tube. The volume was adjusted to $1.0 \mathrm{~mL}$ final volume with the addition of $\mathrm{d}_{6}$-DMSO. The ${ }^{1} \mathrm{H}$-NMR spectra of the samples were recorded in $300 \mathrm{MHz}$ Bruker AVANCE NMR Spectrometer at room temperature. The chemical shift of benzylic protons (highlighted in red in the figure below) were tracked, and the data was used to solve the Benesi-Hildebrand equation, below. 

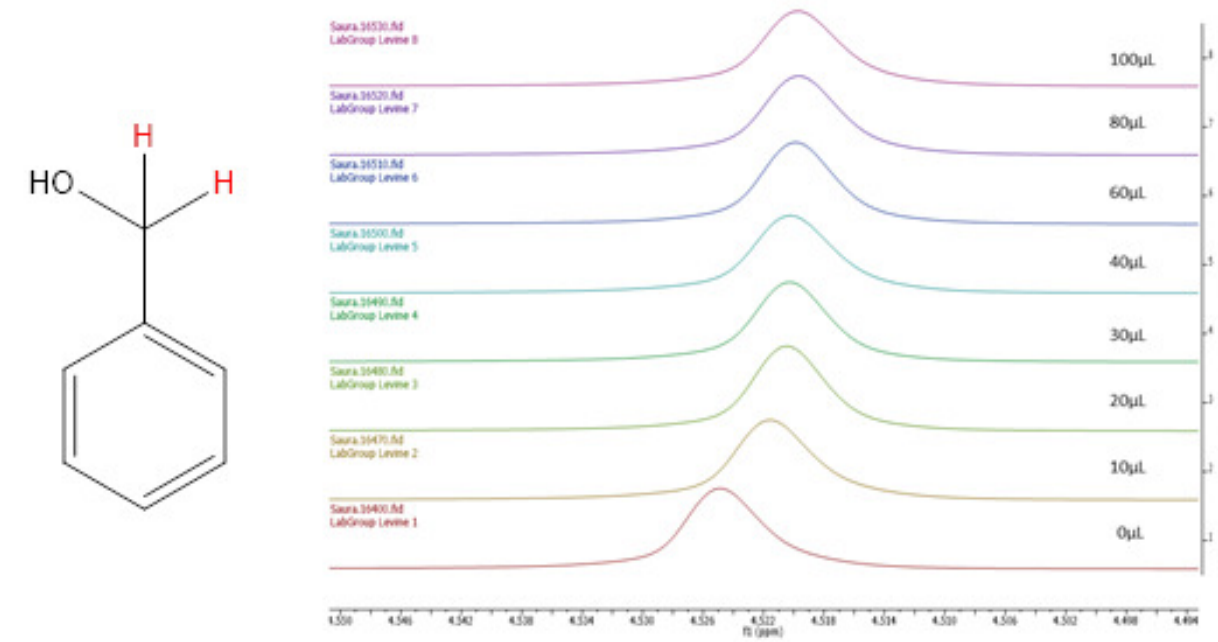

Benesi-Hildebrand Equation:

$1 / \Delta \delta=\left(1 / \mathrm{K}_{\mathrm{a}} \Delta \delta_{\max }\right) 1 /[\mathrm{H}]+\left(1 / \Delta \delta_{\max }\right)$

(Eq. S3)

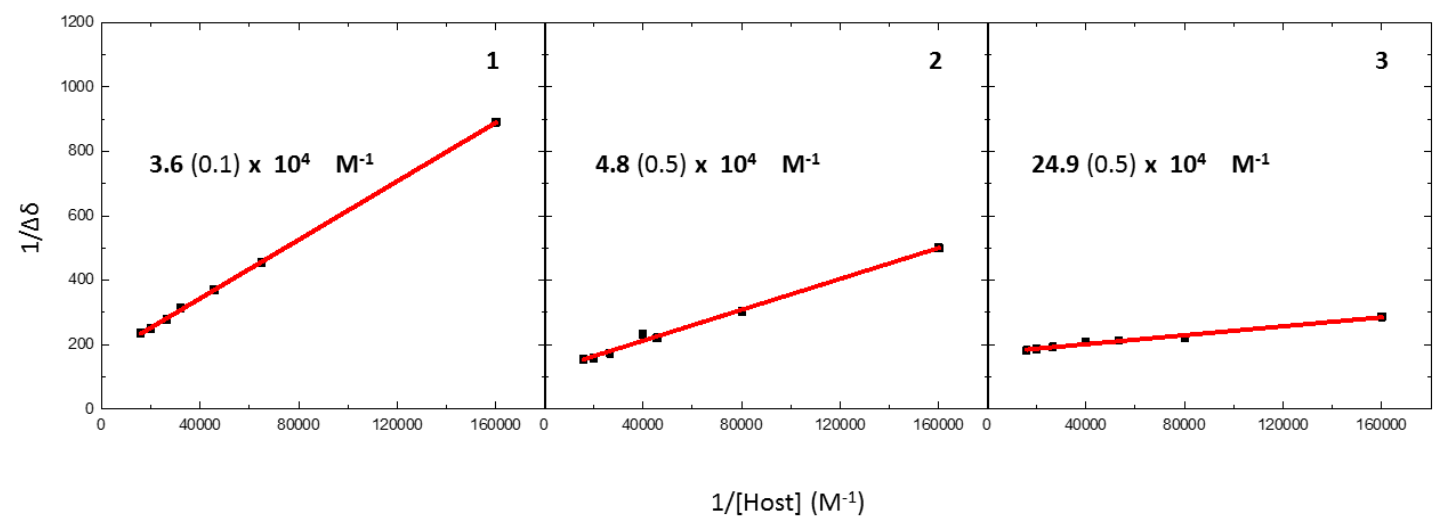

\begin{tabular}{|c|c|c|c|}
\hline Host & Equation & $\mathrm{K}_{\mathrm{a}}\left(\mathrm{M}^{-1}\right)$ & $\Delta \delta_{\max }$ \\
& & & \\
& & $3.6(0.1) \times 10^{4}$ & 0.0061 \\
\hline $\mathbf{1}$ & $\mathrm{y}=0.0045 \mathrm{x}+162.97$ & & \\
\hline $\mathbf{2}$ & $\mathrm{y}=0.0024 \mathrm{x}+116.62$ & $4.8(0.5) \times 10^{4}$ & 0.0085 \\
\hline $\mathbf{3}$ & $\mathrm{y}=0.0007 \mathrm{x}+173.27$ & $24.9(0.5) \times 10^{4}$ & 0.0057 \\
\hline
\end{tabular}


Benesi-Hildebrand plots for association constant calculations of analyte $\mathbf{5}$ with compounds $\mathbf{1}, \mathbf{2}$ and $\mathbf{3}$ in 80:20 water-DMSO at room temperature. (H is the host; $\mathrm{K}_{\mathrm{a}}$ is association constant; $\Delta \delta_{\max }$ is maximum peak shift at infinite host concentration $[\mathrm{H}]=$ $\infty ; \Delta \delta$ is the peak shift at a given host concentration) 


\section{CHAPTER 2}

\section{Enhanced binding complex characterization of fluorophores by fluorescence spectral variation in cyclodextrin mixtures}

\section{ABSTRACT}

Extensive literature has reported the properties of pyrene in $\beta$-cyclodextrin and $\gamma$-cyclodextrin, but little has been published on $\beta$-cyclodextrin derivatives (methyl- $\beta$ cyclodextrin and 2-hydroxypropyl- $\beta$-cyclodextrin) or mixtures of different cyclodextrins. This experiment focused on characterizing pyrene's interactions, as well as those pyrene-d10 and benzo[a]pyrene, within different cyclodextrin solutions using fluorescence spectroscopy. Vibronic bands within the fluorescence emission spectrum of pyrene reflected the polarity of the microenvironment around pyrene (as measured by Py values). Little change in the Py values was observed when pyrene was introduced to different concentrations of methyl- $\beta$-cyclodextrin and 2hydroxypropyl- $\beta$-cyclodextrin. Benzo $[a]$ pyrene had a large excimer peak when doped into $\gamma$ - or $\beta: \gamma$ solutions, which suggested that benzo[a]pyrene may be forming $2: 1$ complexes with the cyclodextrins. Deuterated pyrene (pyrene-d10) had a lower binding constant in $\beta$-cyclodextrin (compared to pyrene-h10), but a higher binding constant in $\gamma$-cyclodextrin (compared to pyrene-h10). Further studies should be conducted to determine why deuterium incorporation would produce a higher binding constant in the $\gamma$-cyclodextrin solutions.

\section{INTRODUCTION}

The hydrophobic cavity of cyclodextrin can be used as a binding site for a variety of environmentally important applications, such as molecular transportation ${ }^{1-3}$, 
extraction $^{4-6}$, or the fluorescence enhancement of environmental toxicants ${ }^{7,8}$. Guest binding to cyclodextrin can be driven by several different factors, including the displacement of water from the cyclodextrin cavity and an increase in the hydrophobic interactions between guest and host, as well as the low steric hindrance of the guest within the cyclodextrin cavity. ${ }^{9}$ Cyclodextrin cavity sizes vary and combining different cyclodextrins either through physically attaching them or through noncovalent mixing could increase the net energetic driving force, which in turn is likely to increase the guest binding affinity. ${ }^{10}$

Extensive research has been done on the binding of pyrene, ${ }^{11}$ which is a polycyclic aromatic hydrocarbon (PAH), to cyclodextrin, but far less has been studied on other PAHs binding to cyclodextrin. Pyrene's fluorescence characteristics, such as its fluorescence lifetime and fluorescence emission spectrum, ${ }^{12-14}$ depend strongly on solvent polarity. In fact, within the emission spectrum of pyrene, band I (at $~ 373 \mathrm{~nm}$ ) and band III (at $\sim 383 \mathrm{~nm}$ ), which are associated with different vibrational states of pyrene, change intensity depending on solvent interactions. ${ }^{12-15}$ The solvent polarity can be quantified in the pyrene fluorescence emission spectrum by dividing band I by band III (also referred to as the Py value or I/III value). ${ }^{12}$ 


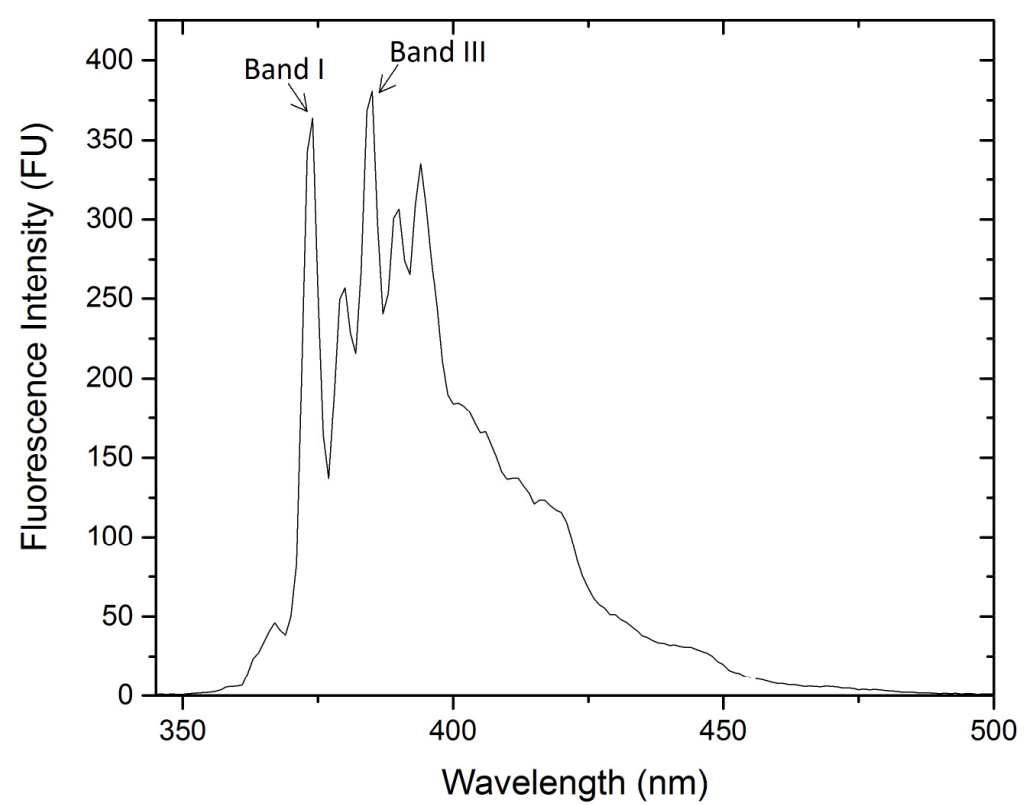

Figure 1. Pyrene doped into $10 \mathrm{mM} \beta$-cyclodextrin in water. Band I and Band III represent fluorescence emissions from different relaxation pathways.

As the polarity of the solvent increases, the Py value is typically greater than 1 . Accordingly ${ }^{15}$ Py values can be used for the determination of solvent polarity due to the strong $\mathrm{S}_{0} \rightarrow \mathrm{S}_{2}$ absorption between electronic states and the relaxation between $S_{1}$ $\rightarrow \mathrm{S}_{0}$. Band I corresponds to the fluorescence relaxation between $\mathrm{S}_{1}{ }^{\mathrm{v}=0} \rightarrow \mathrm{S}_{0}^{\mathrm{v}=0}$ and band III corresponds to the fluorescence relaxation between $\mathrm{S}_{1}{ }^{\mathrm{v}=0} \rightarrow \mathrm{S}_{0}^{\mathrm{v}=1}$. The Py value has been found to be independent of the presence of oxygen. ${ }^{15}$ Py values have been used to calculate the binding constant of pyrene to a host as described in Equation 1. ${ }^{11}$

$$
\text { Equation 1. } \frac{[\mathrm{PCD}]}{[\mathrm{P}]_{0}}=\frac{\mathrm{Py}_{0}-\mathrm{P}_{\mathrm{CD}}}{\mathrm{P}_{\mathrm{y}_{0}}-\mathrm{P}_{\mathrm{X}}}
$$

Pyrene is found to have a 2:1 CD:pyrene stoichiometry rather than a 1:1 complex when mixed with high concentrations of beta-cyclodextrin ( $\beta$-CD). ${ }^{11}$ A 1:1 complex is more favorable than 2:1 CD:pyrene complex for pyrene in gamma-cyclodextrin $(\gamma-$ 
CD) solutions, although at high concentrations of $\gamma$-CD, 2:2 complexation may be a more favorable state. ${ }^{11,16}$ The 2:1 complex may be favored due to the limited space in the $\beta$-CD cavity, ${ }^{11,9}$ which would decrease the polarity around pyrene (giving a Py value less than 1). Limited research has been conducted on PAH binding with $\beta$-CD derivatives, such as methyl- $\beta$-cyclodextrin (M $\beta-\mathrm{CD})$ and 2-hydroxypropyl- $\beta$ cyclodextrin (2HPCD), as well as on mixtures of cyclodextrins. This study's goal is to explore the binding characteristics of pyrene and other PAHs to cyclodextrin and cyclodextrin mixtures.

\section{METHOD}

$20 \mathrm{mM}$ stock solutions of $\gamma-\mathrm{CD}, \mathrm{M} \beta-\mathrm{CD}$, and $2 \mathrm{HPCD}$ were prepared as well as a $15 \mathrm{mM}$ stock solution of $\beta-\mathrm{CD}$ (due to the low solubility of $\beta$-CD). These stock solutions were used to prepare the $10 \mathrm{mM}$ solutions of the single component cyclodextrin mixtures ( $\beta-\mathrm{CD}, \gamma-\mathrm{CD}, \mathrm{M} \beta-\mathrm{CD}$, and $2 \mathrm{HPCD})$ and the mixed cyclodextrin solutions ( $\beta: \gamma-\mathrm{CD}, \beta: \mathrm{M} \beta-\mathrm{CD}, \beta: 2 \mathrm{HPCD}, \gamma: \mathrm{M} \beta-\mathrm{CD}, \gamma: 2 \mathrm{HPCD}, \mathrm{M} \beta: 2 \mathrm{HPCD}) . \quad \mathrm{PAH}$ stock solutions (pyrene and benzo[ $[a]$ pyrene) were prepared at a concentration of 1 $\mathrm{mg} / \mathrm{mL}$ in tetrahydrofuran (THF). $2.5 \mathrm{~mL}$ of the $10 \mathrm{mM}$ cyclodextrin solutions was added to a cuvette and the fluorescence of the solution run (in quadruplicate) at the PAH excitation wavelength $\lambda_{\mathrm{p}}$ (335 $\mathrm{nm}$ for pyrene and $360 \mathrm{~nm}$ for benzo $[a]$ pyrene) and collected from $\lambda_{\mathrm{p}}+10 \mathrm{~nm}$ to $710 \mathrm{~nm}$. The absorption spectra of the solutions were also measured, from $180 \mathrm{~nm}$ to $900 \mathrm{~nm}$. An aliquot of the selected PAH solution was doped into the cuvette at $0.5 \mu \mathrm{L}$ and the fluorescence and absorption spectra were run again. PAH solution was continually added until a total of $2 \mu \mathrm{L}$ of solution had been reached. The data was then extracted from the fluorescence and absorption 
instruments and compiled into a worksheet. Each fluorescence spectrum was integrated with wavenumber as the $\mathrm{X}$-axis, and the fluorescence spectra with pyrene as the analyte at the location of band I and band III were recorded as well as the fluorescence intensity at the bands. The Py value of each spectrum was determined by dividing band I by band III. The average Py value for each solution (from the quadruplicate data collection) was used for the polarity comparison. The spectra were also analyzed for the presence of excimer peaks and the excimer peak intensities were recorded and then integrated. Binding constants were calculated based on the Py values received and fitted with linear and nonlinear regression lines then compared to the binding constant calculated by using integrated fluorescence emissions.

Binding constants for 1:1 guest:cyclodextrin were calculated by using the BenesiHildebrand method. ${ }^{17}$ After integrating each spectra, the inverse integration was plotted against the inverse concentration of cyclodextrin in molarity. A best fitted line with an $\mathrm{R}^{2}$ value of 0.95 or greater represents a $1: 1$ guest:cyclodextrin complex. The binding constant was calculated using the slope of the line and the integrated fluorescence emission of pyrene in pure water.

\section{RESULTS}

The fluorescence intensity of pyrene increased as the amount of pyrene added to the solutions increased; however, the Py value was consistent with small concentrations of pyrene (Table 1). Py values only changed significantly when the solvent polarity changed. At concentrations of $\beta$-cyclodextrin greater than $1 \mathrm{mM}$, the

Py value was below 1 , similar to what was found in the non-polar solutions ( $n$-octane). Pure $\gamma$-cyclodextrin solutions showed Py values greater than 1 at all concentrations. 
Table 1. Pyrene $(1 \mathrm{mg} / \mathrm{mL}$ in THF) doped into different solvents. I/III ratios calculated from each fluorescence spectrum.

\begin{tabular}{|l|l|l|}
\hline $2.5 \mathrm{~mL}$ of solvent & Conc. $(\mu \mathrm{L})$ & Py value \\
\hline DI water & 0.5 & $1.94 \pm 0.04$ \\
\hline DI water & 1 & $1.96 \pm 0.05$ \\
\hline$\beta$-CD $10 \mathrm{mM}$ & 0.5 & $0.96 \pm 0.01$ \\
\hline$\beta$-CD $10 \mathrm{mM}$ & 1 & $0.95 \pm 0.01$ \\
\hline$\beta: \gamma$ CD $(5: 5)$ & 0.5 & $0.98 \pm 0.01$ \\
\hline$\beta: \gamma$ CD $(5: 5)$ & 1 & $0.96 \pm 0.01$ \\
\hline$\gamma$-CD 10mM & 0.5 & $1.66 \pm 0.05$ \\
\hline$\gamma$-CD 10mM & 1 & $1.67 \pm 0.03$ \\
\hline$n$-octane & 1 & $0.74 \pm 0.04$ \\
\hline
\end{tabular}

Similar trends were seen between the monomer emission $(345-455 \mathrm{~nm})$ and excimer emission $(456-600 \mathrm{~nm})$ integration. High intensities of monomer were seen in high concentrations of $\beta$-cyclodextrin, but the monomer intensity drastically decreases when $\beta$-cyclodextrin concentrations drop below $1 \mathrm{mM}$. A general increase of the excimer emission is seen in pure $\gamma$-cyclodextrin, but excimer emission is higher in the $\beta: \gamma$ mixture (from cyclodextrin ratios above No significant excimer peaks were seen with pure $\beta$-cyclodextrin solutions.
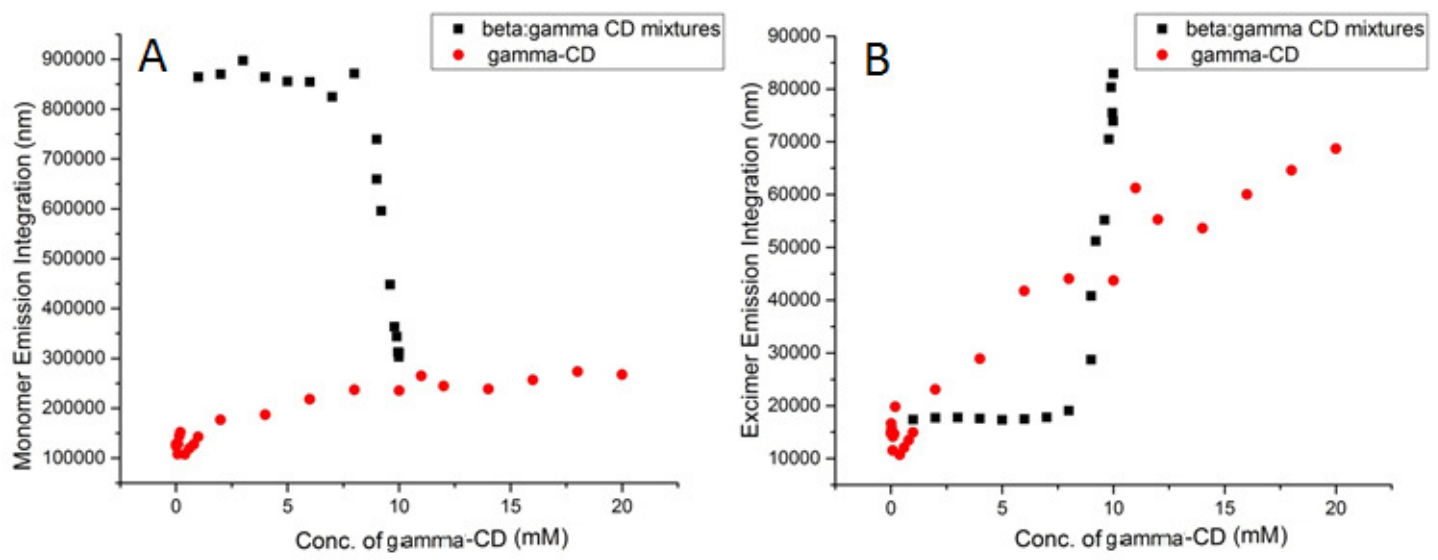
Figure 2. A. Monomer emission (345 - $455 \mathrm{~nm})$ and B. Excimer emission (456 - 600 $\mathrm{nm}$ ) intensity with increasing concentration of $\gamma$-cyclodextrin.

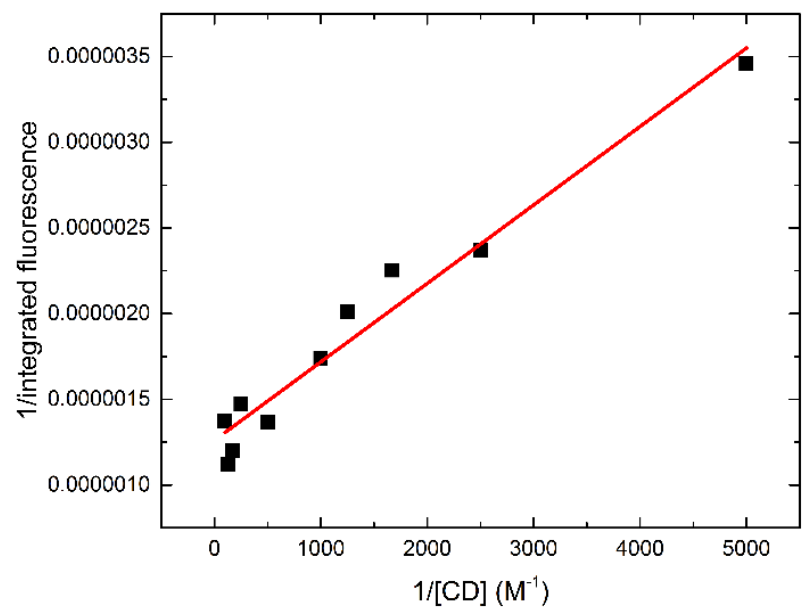

Figure 3. B-H plot for the binding of pyrene-h10 to $\beta$-cyclodextrin. The best fit line $y=5 E-10 X+1 E-6$ with an $R^{2}$ value of 0.9605 and calculated binding constant: Ka = $2000 \mathrm{M}^{-1}$

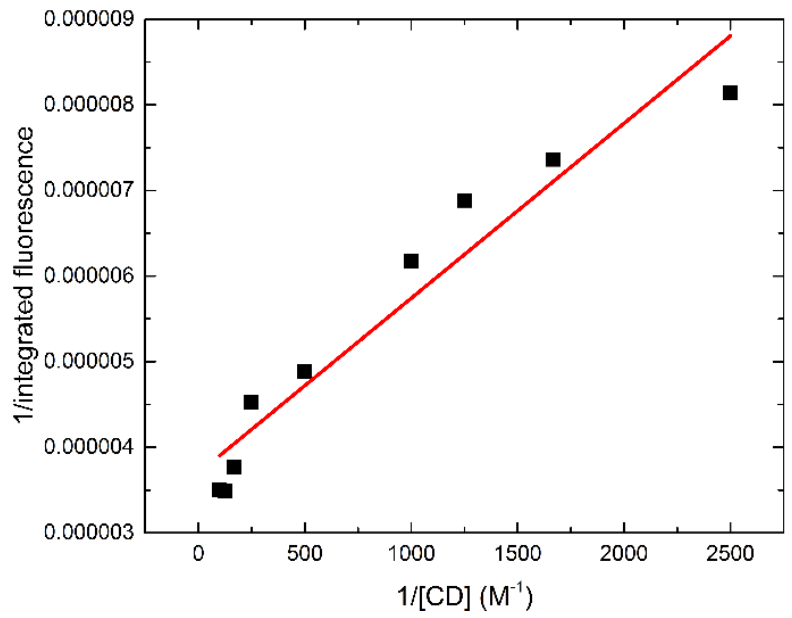

Figure 4. B-H plot for the binding of pyrene-h10 to $\gamma$-cyclodextrin. The best fit line $y$ $=2 \mathrm{E}-9 \mathrm{x}+4 \mathrm{E}-6$ with an $\mathrm{R}^{2}$ value of 0.9335 and calculated binding constant: $\mathrm{Ka}=$ $2000 \mathrm{M}^{-1}$ 


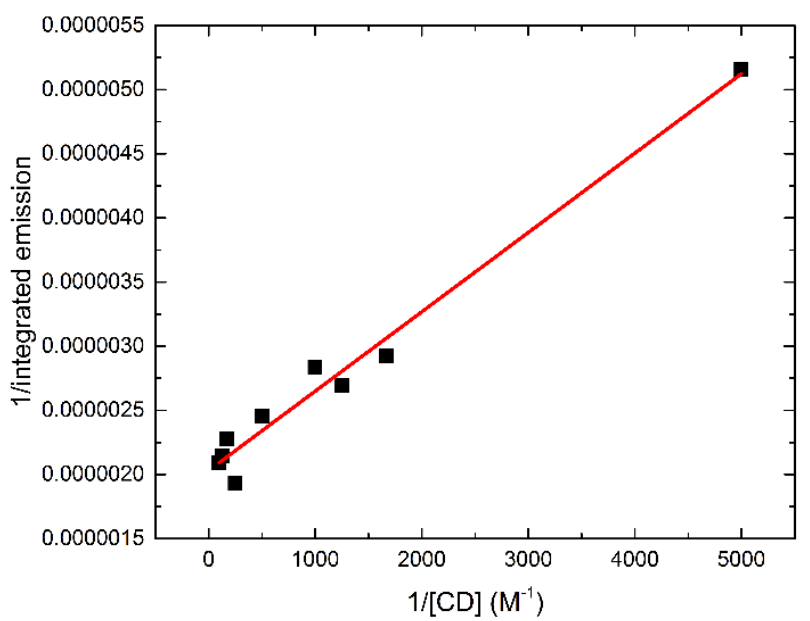

Figure 5. B-H plot for the binding of pyrene-d10 to $\beta$-cyclodextrin. The best fit line $y=(6 E-10) x+2 E-6$ with an $R^{2}$ value of 0.9784 and calculated binding constant: $\mathrm{Ka}=$ $3333 \mathrm{M}^{-1}$.

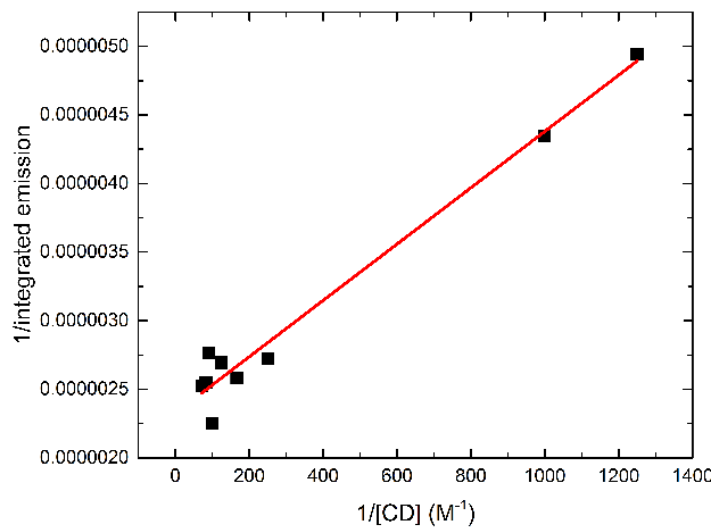

Figure 6. B-H plot for the binding of pyrene-d10 to $\gamma$-cyclodextrin. The best fit line $y$ $=(2 \mathrm{E}-9) \mathrm{x}+(2 \mathrm{E}-6)$ with an $\mathrm{R}^{2}$ value of 0.9735 and calculated binding constant: $\mathrm{Ka}=$ $1000 \mathrm{M}^{-1}$ 

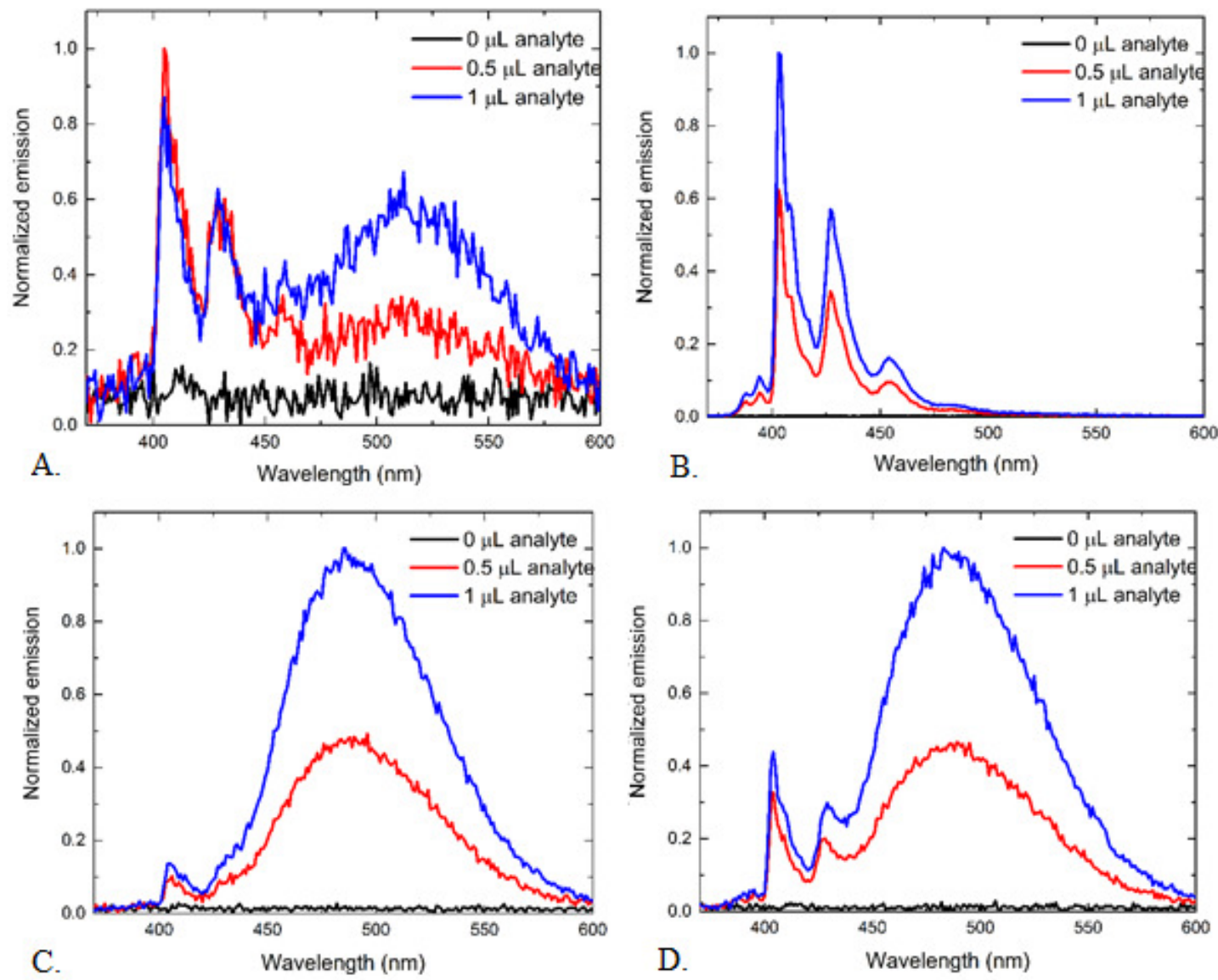

Figure 7. Benzo[a]pyrene $(1 \mathrm{mg} / \mathrm{mL})$ solution doped in $2.5 \mathrm{~mL}$ of A. water, B. 10 mM $\beta$-cyclodextrin, C. $10 \mathrm{mM} \gamma$-cyclodextrin, D. $5 \mathrm{mM}: 5 \mathrm{mM} \beta$-cyclodextrin: $\gamma$ cyclodextrin.

Table 2. Benzo[a]pyrene Fluorescence $(\mathrm{Fl})$ Ratio (integration of benzo[a]pyrene in host solution/integration of benzo[a]pyrene in water) and Excimer ratio (integration of excimer peak of benzo[a]pyrene/integration of the monomer peak of benzo[a]pyrene). 


\begin{tabular}{|c|c|c|}
\hline Host & Fl Ratio & Excimer Ratio \\
\hline n-octane & & $0.31 \pm 0.00$ \\
\hline DI water & & $2.08 \pm 0.11$ \\
\hline$\beta$-CD & $20.24 \pm 0.42$ & $0.23 \pm 0.00$ \\
\hline $1: 1 \beta$-CD: $\gamma$-CD & $9.23 \pm 0.04$ & $6.32 \pm 0.05$ \\
\hline$\gamma C D$ & $8.76 \pm 0.05$ & $15.11 \pm 0.11$ \\
\hline
\end{tabular}

\section{DISCUSSION}

Pyrene is sterically constrained as to how it can occupy the cavity of cyclodextrin. $\beta$-cyclodextrin has a cavity size of $7.8 \AA,{ }^{18}$ which doesn't allow pyrene to fit along its $\mathrm{z}$-axis (Figure 8 ) and restricts it to the $\mathrm{y}$-axis, ${ }^{19}$ and $\gamma$-cyclodextrin has a cavity size of $9.5 \AA{ }^{18}$ which is large enough to fit pyrene along the z- or y-axis. ${ }^{19}$ The steric limitations of pyrene fitting into $\beta$-cyclodextrin would leave pyrene partially exposed to the polar solvent. However, as the concentration of $\beta$-cyclodextrin increases, there is evidence that it moves from a 1:1 pyrene:cyclodextrin environment to a 1:2 pyrene:cyclodextrin environment, which would encapsulate pyrene and represent a more non-polar microenvironment (seen by the shift in the I/III ratio from $>1$ to $<1$ ). Since $\gamma$-cyclodextrin has a larger cavity size, our results suggest that water may also occupy the cavity along with the pyrene, maintaining a more polar microenvironment (I/III is still $>1$ at all concentrations of $\gamma$-cyclodextrin). As $\gamma$ cyclodextrin concentration increases above $1 \mathrm{mM}$, the excimer peak increased (470 $\mathrm{nm}$ ), which indicates the likelihood of a 2:2 pyrene:cyclodextrin complex. ${ }^{16}$ There is a continual increase in the excimer/monomer ratio as the $\gamma$-cyclodextrin concentration increases, however when mixed with $\beta$-cyclodextrin, there is a $\sim 30 \%$ increase in the excimer/monomer ratio (table excimer). This could be due to the formation of 1:1:1 pyrene: $\beta$-cyclodextrin: $\gamma$-cyclodextrin, but the different number of cyclodextrin 
monomers in between $\gamma$ and $\beta$-cyclodextrin $(\beta-7$ glucose units, $\gamma-8$ glucose units $)$ may sterically restrict this complexation.

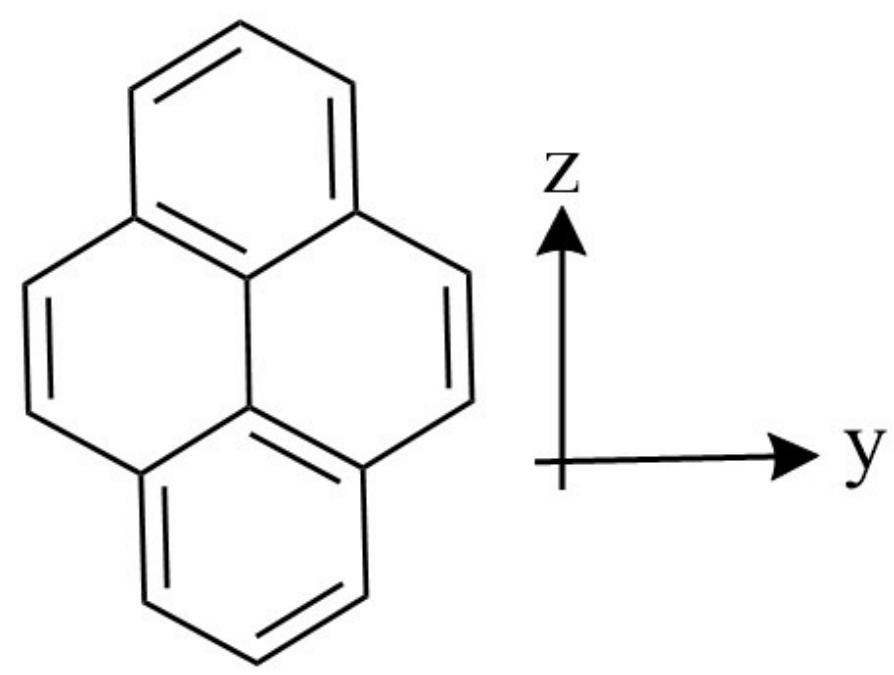

Figure 8. One of pyrene's 6 Kekulé structures with the vertical axis defined as the zaxis and the horizontal axis defined as the y-axis. ${ }^{20}$

The microenvironment around pyrene in the $\beta: \gamma$ mixed cyclodextrin solutions transitions from a polar environment at low concentrations of $\beta$-cyclodextrin to a nonpolar environment above 1-2 mM $\beta$-cyclodextrin. This suggests that there is no 1:2 pyrene: $\beta$-cyclodextrin below $1 \mathrm{mM}$ of $\beta$-cyclodextrin. The increase in $\mathrm{I} / \mathrm{I}_{0}$ ratio may be attributed to the addition of both pyrene: $\gamma$-cyclodextrin and pyrene: $\beta$-cyclodextrin fluorescence signals. Further investigation using life-time studies could determine whether there is a new conformation between two different cyclodextrins and the pyrene.

Methyl- $\beta$-cyclodextrin and 2-hydroxypropyl- $\beta$-cyclodextrin both I/III band ratios that were greater than 1 and the absence of any notable excimer peak (Figure 8). Even as the concentration of each $\beta$-cyclodextrin derivative increases, there is no change in the Py values. This suggests that pyrene maintains a polar 
microenvironment when occupying the cavity of methyl- $\beta$-cyclodextrin or 2hydroxypropyl- $\beta$-cyclodextrin. No significant change in the Py value was seen when either $\beta$-cyclodextrin derivative was mixed with $\beta$-cyclodextrin (Table S1).
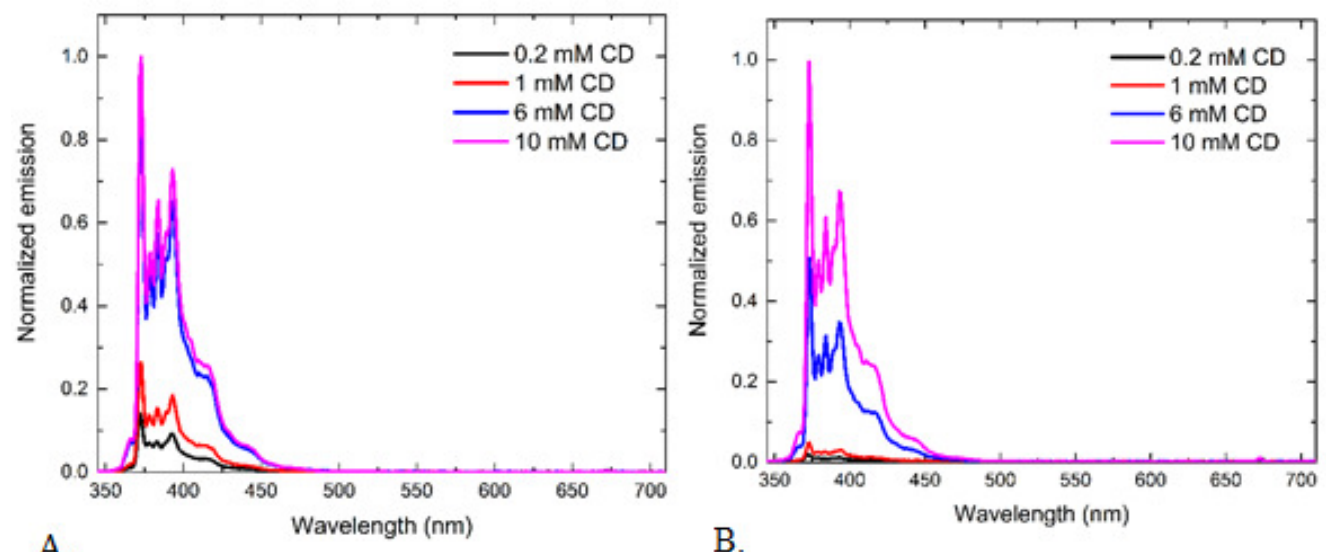

Figure 9. $1 \mu \mathrm{L}$ of pyrene $(1 \mathrm{mg} / \mathrm{mL})$ doped into $2.5 \mathrm{~mL}$ of A. methyl- $\beta$-cyclodextrin and B. 2-hydroxypropyl- $\beta$-cyclodextrin.

The binding constant of pyrene-d10 to $\beta$-cyclodextrin increased compared to pyrene-h10 with $\beta$-cyclodextrin, however, the opposite was seen with $\gamma$-cyclodextrin. Previous studies have reported that deuterated guest molecules decrease in binding with cyclodextrin host. ${ }^{21}$ Decrease in the binding constant of deuterated pyrene may be caused by the change in enthalpy with the addition of heavy hydrogen.

Preliminary results for benzo[a]pyrene and mixed cyclodextrins suggest that there is a significant increase in the fluorescence signal with the addition of cyclodextrin, but the excimer of benzo[a]pyrene is only present when $\gamma$-cyclodextrin is one of the host molecules or in the complete absence of a host molecule. At 1:1 $\beta$ cyclodextrin: $\gamma$-cyclodextrin mixture, the monomer signal increased significantly from benzo $[a]$ pyrene in a pure water solution or a pure $\gamma$-cyclodextrin solution, however, the excimer signal decrease in the mixture solution compared to the excimer signal 
from a pure $\gamma$-cyclodextrin solution. This suggests that benzo[a]pyrene may be occupying both $\beta$-cyclodextrin and $\gamma$-cyclodextrin. Further studies on whether the excimer is due to a $2: 1$ benzo[a]pyrene:cyclodextrin complex or a $2: 2$ benzo[a]pyrene:cyclodextrin complex would involve increase the range of concentrations of the cyclodextrin solutions to see if the excimer peak is eliminated at lower concentrations (similar to the pyrene and cyclodextrin complexation).

\section{CONCLUSION}

Due to steric hindrance, pyrene's microenvironment varies greatly between cyclodextrins cavities. When the concentration of cyclodextrin increase above $1 \mathrm{mM}$ of $\beta$-cyclodextrin or $\gamma$-cyclodextrin, the pyrene:cyclodextrin complexation changes from 1:1 to either a $2: 1$ or a 2:2 complexation. Our results were not able to determine whether there is a 1:1:1 pyrene: $\beta$-cyclodextrin: $\gamma$-cyclodextrin complex forming, further fluorescence life-time studies could help determine if a 1:1:1 complex is forming. Deuterated pyrene showed an increase in binding to $\beta$-cyclodextrin, which does not support the literature reported on the binding of deuterated analytes. Although benzo[ $[a]$ pyrene does not have a change in its band ratios with a change in solvent polarity, the change in the excimer peak ratios is evidence that benzo $[a]$ pyrene has a higher affinity for $\gamma$-cyclodextrin compared to $\beta$-cyclodextrin, which is the opposite that we see with pyrene.

\section{ACKNOWLEDEMENTS}

The authors would like to thank fellow group members Nicole Serio, Dana DiScenza, Missy Smith, and Sauradip Chaudhuri for their suggestions and support with this project. 


\section{REFERENCES}

(1) Loftsson, T.; Brewster, M. E. J. Pharm. Sci. 1996, 85 (10), 1017-1025.

(2) Loftsson, T.; Vogensen, S. B.; Brewster, M. E.; Konrádsdóttir, F.; Mensitieri, G.; Miro, A.; Quaglia, F.; Russo, R.; Sánchez, G.; Garrigues, T. M.; Merino, V. J. Pharm. Sci. 2007, 96 (10), 2532-2546.

(3) Gu, L.-Q.; Cheley, S.; Bayley, H. J. Gen. Physiol 2001, 118, 481-493.

(4) Stokes, J. D.; Wilkinson, A.; Reid, B. J.; Jones, K. C.; Semple, K. T. Environ. Toxicol. Chem. 2005, 24 (6), 1325-1330.

(5) Papadopoulos, A.; Paton, G. I.; Reid, B. J.; Semple, K. T. J. Environ. Monit. 2007, 9, 516-522.

(6) Milles, S.; Meyer, T.; Scheidt, H. A.; Schwarzer, R.; Thomas, L.; Marek, M.; Szente, L.; Bittman, R.; Herrmann, A.; Pomorski, T. G.; Huster, D.; Müller, P. BBA - Biomembr. 2013, 1828, 1822-1828.

(7) Ueno, A. Supramol. Sci. 1996, 3 (396), 36-968.

(8) Serio, N.; Miller, K.; Levine, M. Chem. Commun. (Camb). 2013, 49 (42), $4821-4823$.

(9) Del Valle, E. M. M. Process Biochem. 2004, 39 (9), 1033-1046.

(10) Malaekeh-Nikouei, B.; Tabassi, S. A. S.; Gerayeli, G.; Salmani, M. A.; Gholamzadeh, A. J. Incl. Phenom. Macrocycl. Chem. 2012, 72 (3-4), 383-387.

(11) Munoz de la Pena, A.; Ndou, T.; Zung, J. B.; Warner, I. M. J. Phys. Chem. 1991, 95, 3330-3334.

(12) Street, K. W.; Acree, W. E. Analyst 1986, 111, 1197-1201.

(13) Nelson, G.; Patonay, G.; Warner, I. M. Anal. Chem. 1988, 279 (6), 274-279. 
(14) Fletcher, K. A.; Storey, I. A.; Hendricks, A. E.; Pandey, S. S.; Pandey, S. S. Green Chem. 2001, 3 (5), 210-215.

(15) Karpovich, D.; Blanchard, G. J. Phys. Chem. 1995, 99 (12), 3951-3958.

(16) Dyck, A. S. M.; Kisiel, U.; Bohne, C. J. Phys. Chem. B 2003, 107 (42), 1165211659.

(17) Kuntz, I. D.; Gasparro, F. P.; Johnston, M. D.; Taylor, R. P. J. Am. Chem. Soc. 1968, $90,4778-4781$.

(18) Das, S. K.; Rajabalaya, R.; David, S.; Gani, N.; Khanam, J.; Nanda, A. Res. J. Pharm. Biol. Chem. Sci. 2013, 4 (2), 1694-1720.

(19) Robertson, J. M.; White, J. G. J. Chem. Soc. 1947, 72, 358-368.

(20) Cyvin, S. J. Match 1982, 13, 167-171.

(21) Rekharsky, M. V; Inoue, Y. JACS 2002, 124, 12361-12371. 
Supporting Information

Enhanced binding complex characterization of fluorophores by fluorescence spectral variation in cyclodextrin mixtures

Table S1. Py values for mixed cyclodextrins containing $1 \mathrm{mM} \beta$-cyclodextrin and 9 $\mathrm{mM}$ of 2-hydroxypropyl- $\beta$-cyclodextrin, methyl- $\beta$-cyclodextrin, or $\gamma$-cyclodextrin.

\begin{tabular}{|l|l|l|}
\hline & CD ratio & Py (I/III) \\
\hline$\beta C D: 2 H P \beta C D$ & $1: 9$ & 1.147 \\
\hline$\beta C D: M \beta C D$ & $1: 9$ & 1.171 \\
\hline$\beta C D: \gamma C D$ & $1: 9$ & 1.111 \\
\hline
\end{tabular}

Table S2. Excimer/monomer ratio calculations based on the integrated values found for the monomer and the excimer emissions.

\begin{tabular}{|c|c|c|c|c|c|c|c|}
\hline $\begin{array}{l}\beta-\gamma \\
(\mathrm{mM}: \mathrm{mM})\end{array}$ & $\begin{array}{l}\text { Monomer } \\
(345-455 \\
\mathrm{nm})\end{array}$ & $\begin{array}{l}\text { Excimer } \\
(456-600 \\
\mathrm{nm})\end{array}$ & $\mathrm{E} / \mathrm{M}$ & $\begin{array}{l}\gamma \mathrm{CD} \\
(\mathrm{mM})\end{array}$ & $\begin{array}{l}\text { Monomer } \\
(345-455 \\
\mathrm{nm})\end{array}$ & $\begin{array}{l}\text { Excimer } \\
(456-600 \\
\mathrm{nm})\end{array}$ & $\mathrm{E} / \mathrm{M}$ \\
\hline $9: 1$ & $8.64 \mathrm{E}+05$ & $1.74 \mathrm{E}+04$ & 0.020 & 0.1 & $1.28 \mathrm{E}+05$ & $1.41 \mathrm{E}+04$ & 0.111 \\
\hline $8: 2$ & $8.70 \mathrm{E}+05$ & $1.77 \mathrm{E}+04$ & 0.020 & 0.15 & $1.44 \mathrm{E}+05$ & $1.47 \mathrm{E}+04$ & 0.102 \\
\hline $7: 3$ & $8.97 \mathrm{E}+05$ & $1.78 \mathrm{E}+04$ & 0.020 & 0.2 & $1.52 \mathrm{E}+05$ & $1.98 \mathrm{E}+04$ & 0.131 \\
\hline $6: 4$ & $8.64 \mathrm{E}+05$ & $1.76 \mathrm{E}+04$ & 0.020 & 0.4 & $1.08 \mathrm{E}+05$ & $1.07 \mathrm{E}+04$ & 0.099 \\
\hline $5: 5$ & $8.56 \mathrm{E}+05$ & $1.74 \mathrm{E}+04$ & 0.020 & 0.6 & $1.19 \mathrm{E}+05$ & $1.20 \mathrm{E}+04$ & 0.101 \\
\hline $4: 6$ & $8.55 \mathrm{E}+05$ & $1.75 \mathrm{E}+04$ & 0.020 & 0.8 & $1.27 \mathrm{E}+05$ & $1.35 \mathrm{E}+04$ & 0.106 \\
\hline $3: 7$ & $8.25 \mathrm{E}+05$ & $1.78 \mathrm{E}+04$ & 0.022 & 1 & $1.42 \mathrm{E}+05$ & $1.49 \mathrm{E}+04$ & 0.105 \\
\hline $2: 8$ & $8.71 \mathrm{E}+05$ & $1.91 \mathrm{E}+04$ & 0.022 & 2 & $1.77 \mathrm{E}+05$ & $2.31 \mathrm{E}+04$ & 0.131 \\
\hline $1: 9$ & $7.39 \mathrm{E}+05$ & $2.88 \mathrm{E}+04$ & 0.039 & 4 & $1.87 \mathrm{E}+05$ & $2.89 \mathrm{E}+04$ & 0.155 \\
\hline $0.8: 9.2$ & $5.96 \mathrm{E}+05$ & $5.12 \mathrm{E}+04$ & 0.086 & 6 & $2.18 \mathrm{E}+05$ & $4.18 \mathrm{E}+04$ & 0.191 \\
\hline $0.4: 9.6$ & $4.48 \mathrm{E}+05$ & $5.52 \mathrm{E}+04$ & 0.123 & 8 & $2.37 \mathrm{E}+05$ & $4.40 \mathrm{E}+04$ & 0.186 \\
\hline $0.2: 9.8$ & $3.64 \mathrm{E}+05$ & $7.05 \mathrm{E}+04$ & 0.194 & 10 & $2.35 \mathrm{E}+05$ & $4.37 \mathrm{E}+04$ & 0.186 \\
\hline $0.1: 9.9$ & $3.44 \mathrm{E}+05$ & $8.03 \mathrm{E}+04$ & 0.234 & 11 & $2.65 \mathrm{E}+05$ & $6.12 \mathrm{E}+04$ & 0.231 \\
\hline 0.05:9.95 & $3.13 \mathrm{E}+05$ & $7.55 \mathrm{E}+04$ & 0.242 & 12 & $2.45 \mathrm{E}+05$ & $5.53 \mathrm{E}+04$ & 0.226 \\
\hline $0.01: 9.99$ & $3.03 E+05$ & $7.39 \mathrm{E}+04$ & 0.244 & 14 & $2.39 \mathrm{E}+05$ & $5.36 \mathrm{E}+04$ & 0.225 \\
\hline \multirow[t]{3}{*}{$0.005: 9.995$} & $3.12 \mathrm{E}+05$ & $8.29 \mathrm{E}+04$ & 0.266 & 16 & $2.57 \mathrm{E}+05$ & $6.00 \mathrm{E}+04$ & 0.234 \\
\hline & & & & 18 & $2.74 \mathrm{E}+05$ & $6.46 \mathrm{E}+04$ & 0.236 \\
\hline & & & & 20 & $2.68 \mathrm{E}+05$ & $6.87 \mathrm{E}+04$ & 0.257 \\
\hline
\end{tabular}


Table S3. Py values calculated for $\gamma-, \beta-$, and $\beta: \gamma$ cyclodextrin concentration used during the course of this experiment.

\begin{tabular}{|l|l|l|l|l|l|}
\hline$\beta-\gamma$ & $\beta-\gamma$ & & & $\gamma \mathrm{CD}$ & $\beta \mathrm{CD}$ \\
\hline $\mathrm{mM}: \mathrm{mM}$ & $\mathrm{I} / \mathrm{III}$ & & $\mathrm{mM}$ & $\mathrm{I} / \mathrm{III}$ & $\mathrm{I} / \mathrm{III}$ \\
\hline $0.005: 9.995$ & 1.60 & & 0.005 & 1.89 & 1.93 \\
\hline $0.01: 9.99$ & 1.59 & & 0.01 & 1.92 & 1.89 \\
\hline $0.05: 9.95$ & 1.59 & & 0.02 & 1.91 & 1.87 \\
\hline $0.1: 9.9$ & 1.55 & & 0.04 & 1.87 & 1.79 \\
\hline $0.2: 9.8$ & 1.48 & & 0.08 & 1.86 & 1.63 \\
\hline $0.4: 9.6$ & 1.31 & & 0.1 & 1.86 & 1.50 \\
\hline $0.8: 9.2$ & 1.17 & & 0.15 & 1.89 & 1.36 \\
\hline $1: 9$ & 1.06 & & 0.2 & 1.86 & 1.30 \\
\hline $2: 8$ & 1.11 & & 0.4 & 1.83 & 1.11 \\
\hline $3: 7$ & 0.97 & & 0.6 & 1.79 & 1.07 \\
\hline $4: 6$ & 0.97 & & 0.8 & 1.77 & 1.04 \\
\hline $5: 5$ & 0.98 & & 1 & 1.75 & 1.00 \\
\hline $6: 4$ & 0.98 & & 2 & 1.73 & 0.99 \\
\hline $7: 3$ & 0.98 & & 4 & 1.70 & 0.98 \\
\hline $8: 2$ & 0.97 & & 6 & 1.66 & 0.96 \\
\hline $9: 1$ & 0.95 & & 8 & 1.64 & 0.97 \\
\hline & & & 10 & 1.60 & 0.95 \\
\hline & & & 11 & 1.55 & \\
\hline & & & 12 & 1.43 & \\
\hline & & & 14 & 1.55 & \\
\hline & & & 16 & 1.52 & \\
\hline & & & 18 & 1.55 & \\
\hline & & & 20 & 1.56 & \\
\hline & & & & \\
\hline
\end{tabular}




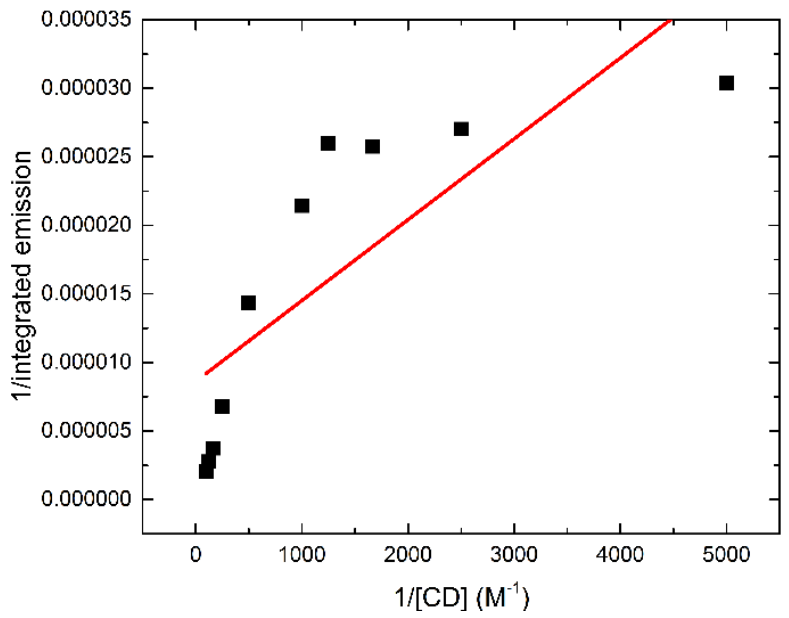

Figure S1. High concentrations of $2 \mathrm{HP} \beta C D 1 \mathrm{mM}-10 \mathrm{mM}$. Equation: $\mathrm{y}=2 \mathrm{E}-8 \mathrm{x}+$ 7E-7 and R2: 0.9652

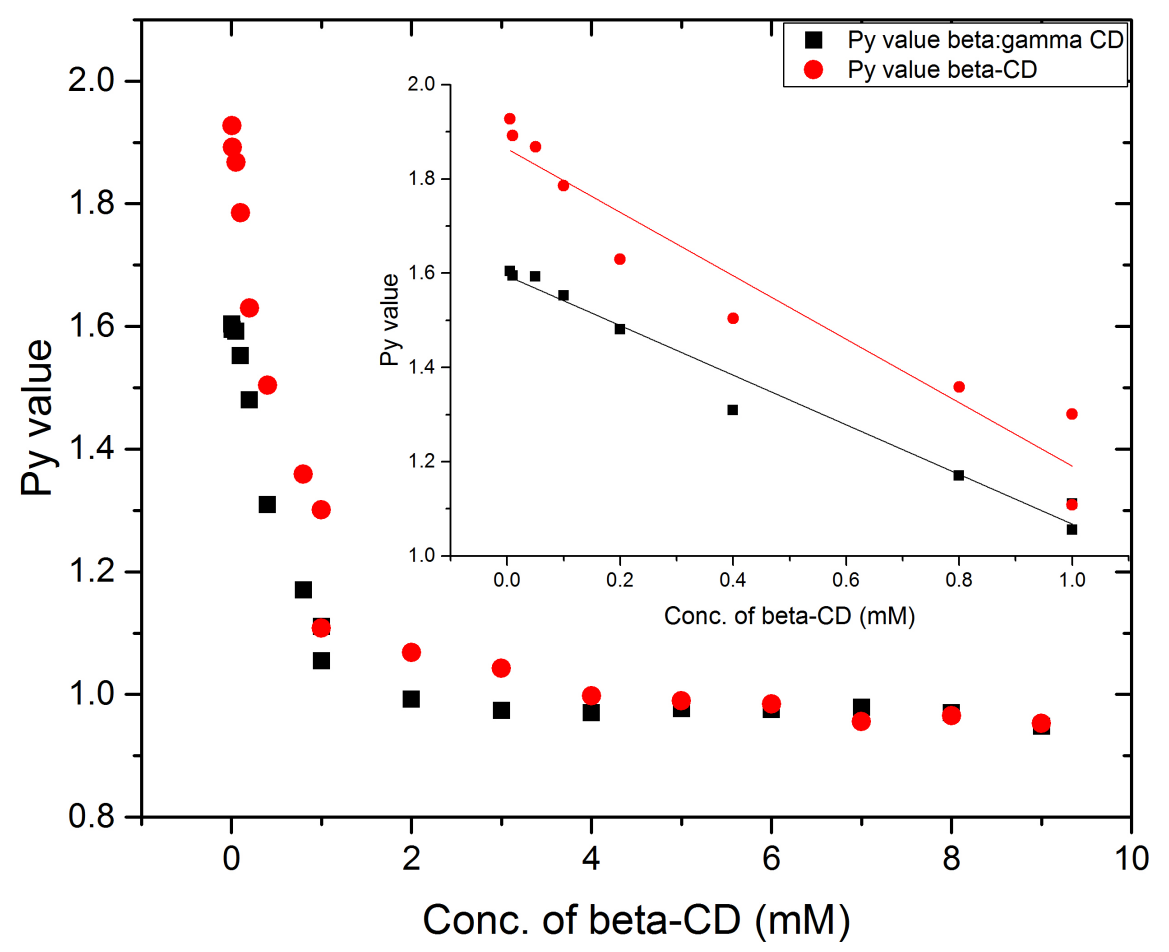

Figure S2. Py values for low concentrations of $\beta$-cyclodextrin and low concentrations of $\beta$-cyclodextrin in mixed cyclodextrin solution. 
Table S4. Integration ratios between the integration of the fluorescence emissions with the host $\left(\mathrm{I}_{\mathrm{w} / \mathrm{Host}}\right) /$ the integration of the fluorescence emissions of pyrene in water $\left(\mathrm{I}_{\mathrm{water}}\right), \mathrm{I}_{\mathrm{w} / \text { Host }} / \mathrm{I}_{\mathrm{water}}$

\begin{tabular}{|l|l|l|l|l|l|}
\hline & $\beta: \gamma$ & & & $\gamma \mathrm{CD}$ & $\beta \mathrm{CD}$ \\
\hline $\mathrm{mM}: \mathrm{mM}$ & $\mathrm{I} / \mathrm{I} 0$ & & $\mathrm{mM}$ & $\mathrm{I} / \mathrm{I} 0$ & $\mathrm{I} / \mathrm{I} 0$ \\
\hline $0.005: 9.995$ & 3.08 & & 0.005 & 1.10 & 1.08 \\
\hline $0.01: 9.99$ & 2.94 & & 0.01 & 1.13 & 1.13 \\
\hline $0.05: 9.95$ & 3.03 & & 0.02 & 1.09 & 1.13 \\
\hline $0.1: 9.9$ & 3.31 & & 0.04 & 1.12 & 1.24 \\
\hline $0.2: 9.8$ & 3.39 & & 0.08 & 0.93 & 1.52 \\
\hline $0.4: 9.6$ & 3.94 & & 0.1 & 1.11 & 1.87 \\
\hline $0.8: 9.2$ & 5.06 & & 0.15 & 1.24 & 2.54 \\
\hline $1: 9$ & 5.74 & & 0.2 & 1.34 & 2.23 \\
\hline $2: 8$ & 6.96 & & 0.4 & 0.92 & 3.27 \\
\hline $3: 7$ & 6.59 & & 0.6 & 1.03 & 3.44 \\
\hline $4: 6$ & 6.82 & & 0.8 & 1.10 & 3.85 \\
\hline $5: 5$ & 6.82 & & 1 & 1.23 & 4.46 \\
\hline $6: 4$ & 6.89 & & 2 & 1.56 & 5.69 \\
\hline $7: 3$ & 7.15 & & 4 & 1.69 & 5.28 \\
\hline $8: 2$ & 6.94 & & 6 & 2.03 & 6.48 \\
\hline $9: 1$ & 6.89 & & 8 & 2.19 & 6.94 \\
\hline & & & 10 & 2.18 & 5.65 \\
\hline & & & 11 & 2.55 & \\
\hline & & & 12 & 2.34 & \\
\hline & & & 14 & 2.28 & \\
\hline & & & 16 & 2.48 & \\
\hline & & & 18 & 2.65 & \\
\hline & & & 20 & 2.63 & \\
\hline
\end{tabular}

